$5.78-14$
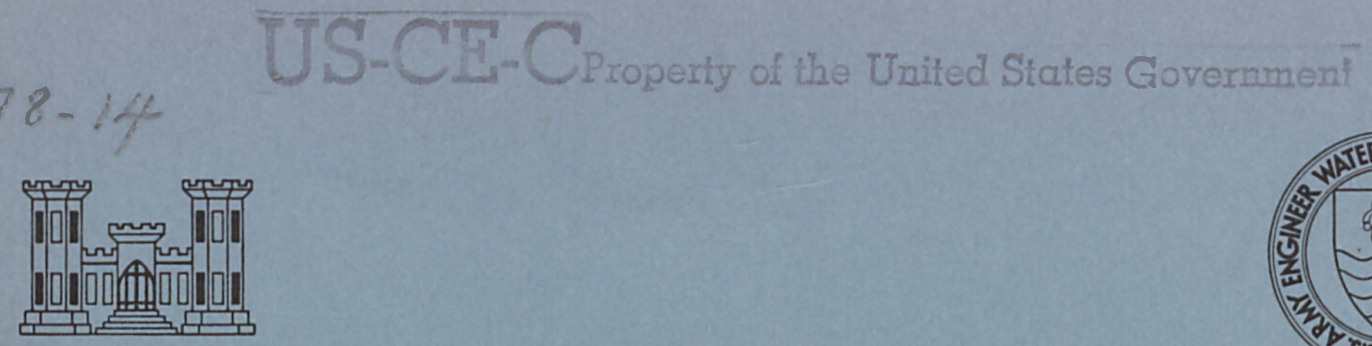

TECHNICAL REPORT S-78-14

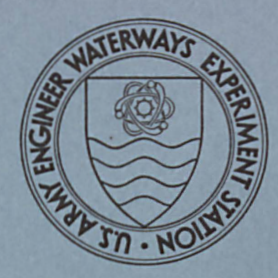

\title{
NON-NORMAL IMPACT AND PENETRATION: ANALYSIS FOR HARD TARGETS AND SMALL ANGLES OF ATTACK
}

by

Robert S. Bernard, Daniel C. Creighton

Soils and Pavements Laboratory

U. S. Army Engineer Waterways Experiment Station

P. O. Box 631, Vicksburg, Miss. 39180

September 1978

Final Report

Approved For Public Release; Distribution Unlimited

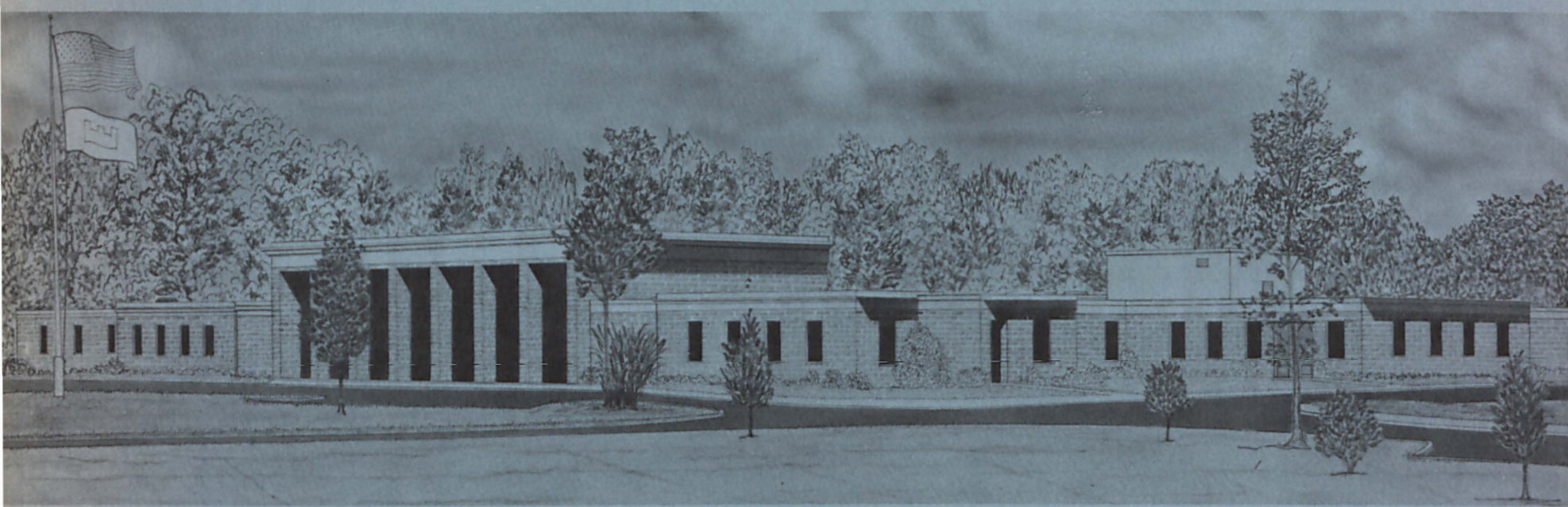

Prepared for Defense Nuclear Agency

Washington, D. C. 20305

Under Subtask Y99QAXSB21I, Work Unit 18 


\begin{tabular}{|c|c|}
\hline REPORT DOCUMENTATION PAGE & $\begin{array}{l}\text { READ INSTRUCTIONS } \\
\text { BEFORE COMPLETING FORM }\end{array}$ \\
\hline $\begin{array}{l}\text { 1. REPORT NUMBER } \\
\text { Technical Report S-78-14 }\end{array}$ & 3. RECIPIENT'S CATALOG NUMBER \\
\hline \multirow{2}{*}{$\begin{array}{l}\text { 4. TITLE (and Sublitı) } \\
\text { NON-NORMAL IMPACT AND PENETRATION: ANALYSIS FOR } \\
\text { HARD TARGETS AND SMALL ANGLES OF ATTACK }\end{array}$} & $\begin{array}{l}\text { 5. TYPE OF REPORT a PERIOD COVERED } \\
\text { Final report }\end{array}$ \\
\hline & 6. PERFORMING ORG. REPORT NUMBER \\
\hline $\begin{array}{l}\text { 7. AUTHOR(a) } \\
\text { Robert S. Bernard } \\
\text { Daniel C. Creighton }\end{array}$ & 8. CONTRACT OR GRANT NUMBER(0) \\
\hline $\begin{array}{l}\text { 9. PERFORMING ORGANIZATION NAME AND ADDRESS } \\
\text { U. S. Army Engineer Waterways Experiment Station } \\
\text { Soils and Pavements Laboratory } \\
\text { P. O. Box 631, Vicksburg. Miss. } 39180\end{array}$ & $\begin{array}{l}\text { 10. PROGRAM ELEMENT' PROJECT, TASK } \\
\text { AREA Q WORK UNIT NUMBERS } \\
\text { See Block } 18\end{array}$ \\
\hline \multirow{2}{*}{$\begin{array}{l}\text { 11. CONTROLLING OfFICE NAME AND ADDRESS } \\
\text { Defense Nuclear Agency } \\
\text { Washington, D. C. } 20305\end{array}$} & $\begin{array}{l}\text { 12. REPORT DATE } \\
\text { September } 1978\end{array}$ \\
\hline & $\begin{array}{l}\text { 13. NUMBER OF PAGES } \\
77\end{array}$ \\
\hline \multirow[t]{2}{*}{ 14. MONITORING AGENCY NAME \& ADDRESS(Il dlflorent from Controlline OIflco) } & $\begin{array}{l}\text { 15. SECURITY CLASS. (ol thle soport) } \\
\text { Unclassified }\end{array}$ \\
\hline & $\begin{array}{l}\text { 15a. DECLASSIFICATION/DOWNGRADING } \\
\text { SCHEDULE }\end{array}$ \\
\hline
\end{tabular}

16. DISTRIBUTION STATEMENT (OI thio ROpOSt)

Approved for public release; distribution unlimited.

17. DISTRIBUTION STATEMENT (ol the abatract enfored in Block 20, If diflorent from Roport)

18. SUPPLEMENTARY NOTES

This research was sponsored by the Defense Nuclear Agency under Subtask Y99QAXSB211, Work Unit 18, "Penetrator Summary."

19. KEY WORDS (Continue on reveree oide If neceecery end Identlly by block number)

Impact

Penetration

Projectile penetration
Target vulnerability

Targets

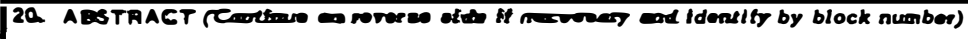

A rigid-projectile penetration analysis has been developed for non-normal impact, based on the Cavity Expansion Theory (CET). A modified version of the AVCO penetration code is used to implement the CET analysis, which is intended for hard targets (rock and concrete) and for small angles of attack (less than 10 degrees). Tentative verification has been obtained by comparison with 3-degree reverse ballistic data. More tests are needed for further

(Continued) 


\section{ABSTRACT (Continued).}

verification, but the initial results suggest that the CET analysis can be used by projectile designers to estimate internal and external forces and moments.

Appendix A describes the basic assumptions and results of the CET. Appendix $B$ presents the results of a dynamic structural analysis. Appendix $C$ compares lateral accelerations obtained using the CET and AVCO formulations of the force distribution. 
THE CONTENTS OF THIS REPORT ARE NOT TO BE USED FOR ADVERTISING, PUBLICATION, OR PROMOTIONAL PURPOSES. CITATION OF TRADE NAMES DOES NOT CONSTITUTE AN OFFICIAL ENDORSEMENT OR APPROVAL OF THE USE OF SUCH COMMERCIAL PRODUCTS. 
This investigation was sponsored by the Defense Nuclear Agency under Subtask Y99QAXSB211, "Penetration," Work Unit 18, "Penetrator Summary." This study was conducted by personnel of the Soils and Pavements Laboratory (S\&PL), U. S. Army Engineer Waterways Experiment Station (WES), during January through December 1977, under the general supervision of Messrs. J. P. Sale and R. G. Ahlvin, Chief and Assistant Chief, S\&PL, respectively. Mr. R. S. Bernard formulated the theory and $\mathrm{Mr}$. D. C. Creighton implemented the computer analysis, both under the direct supervision of Dr. J. G. Jackson, Chief of the Soil Dynamics Division (SDD), S\&PL. Drs. P. F. Hadala and B. Rohani, SDD, provided technical guidance. Mr. Bernard and Mr. Creighton prepared this report.

COL J. L. Cannon, CE, was Commander and Director of WES during the period of research and report preparation. Mr. F. R. Brown was Technical Director. 
PREFACE

CONVERSION FACTORS, U. S. CUSTOMARY TO METRIC (SI)

UNITS OF MEASUREMENT

CHAPTER 1 INTRODUCTION . . . . . . . . . . . . . . 7

1.1 Background . . . . . . . . . . . . . . . 7

1.2 Purpose and Scope .............. 7

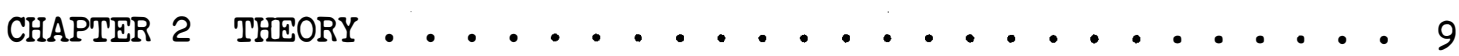

2.1 Projectile Motion in Two Dimensions . . . . . . . . 9

2.2 Force Distribution Due to Axial Motion .......... 10

2.3 Force Distribution Due to Lateral Motion ......... . Il

2.4 Force Distribution Due to Rotation ........... 12

2.5 Composite Force Distribution . . . . . . . . . . . 12

2.6 Wake Separation and Reattachment ........... 13

2.7 Internal Forces and Moments in a Rigid Projectile . . . . 15

2.8 Modified AVCO Computer Code . . . . . . . . . . 16

2.9 Restriction to Hard Targets and Small Angles of Attack . . . 17

CHAPTER 3 CALCULATIONS AND TEST DATA . . . . . . . . . 21

3.1 Availability of Non-Normal Test Data . . . . . . . . 21

3.2 Limitations and Simplifications in the CET Analysis . . . 21

3.3 Sandia Reverse Ballistic Tests . . . . . . . . . . . 22

3.3.1 Test Description . . . . . . . . . . . 22

3.3.2 Accelerometer Data . . . . . . . . . . . 23

3.3.3 Strain Gage Data . . . . ........... . 23

3.4 Parameter Study . . . . . . . . . . . . . 24

3.4.1 Calculated Effect of Attack Angle . . . . . . . . 24

3.4.2 Calculated Effect of Impact Velocity . . . . . . . . 25

3.4.3 Calculated Effect of Target Strength . . . . . . . . 25

3.4.4 Calculated Effect of Wake Separation ......... 25

3.5 AVCO Reverse Ballistic Tests . . . . . . . . . . . 26

3.5.1 Test Description . . . . . . . . . . . 26

3.5 .2 Accelerometer Data for 1050-ft/s Test . . . . . . . 27

3.5.3 Strain Gage Data for 1050-ft/s Test . . . . . . . . 27

3.5.4 Strain Gage Data for 1500-ft/s Tests . . . . . . . . 27

CHAPTER 4 CONCLUSIONS AND RECOMMENDATIONS . . . . . . . 55

REFERENCES ...................... 56

APPENDIX A CAVITY EXPANSION THEORY . . . . . . . . . 57

APPENDIX B NONRIGID PROJECTILE RESPONSE .......... 61

APPENDIX C COMPARISON OF CET AND AVCO CALCULATIONS . . . . . 67

APPENDIX D NOTATION .......................... 71 
2.1 Projectile motion in two dimensions . . . . . . . 18

2.2 Three-dimensional view of projectile ........ 19

2.3 Wake separation and reattachment for purely axial motion ............... . . 19

2.4 Idealized wake separation ............ 20

2.5 Block diagram for non-normal impact-and-penetration calculations using CET analysis and AVCO DAFL code . . 20

3.1 Projectile parameters, target properties, and impact conditions for Sandia RBT's . . . . . . . . 29

3.2 Axial location of strain gage and accelerometers for projectile used in Sandia RBT . . . . . . 30

3.3 Comparison of calculated and measured axial decelerations for Sandia RBT (forward accelerometer) . . . . 31

3.4 Comparison of calculated and measured lateral accelerations for Sandia RBT (forward accelerometer) . . . 32

3.5 Comparison of calculated and measured axial decelerations for Sandia RBT (rear accelerometer) . . . . 33

3.6 Comparison of calculated and measured lateral accelerations for Sandia RBT (rear accelerometer) . . ... 34

3.7 Comparison of calculated and measured axial strains for Sandia RBT, strain gage S . . . . . 35

3.8 Calculated CG lateral acceleration for different angles of attack, Sandia RBT ......... 36

3.9 Calculated bending moment for different angles of
attack, Sandia RBT, section S . . . . . 37

3.10 Calculated CG lateral acceleration for different

3.11 Calculated bending moment for different impact velocities, Sandia RBT, section S . . . . . 39

3.12 Calculated CG lateral acceleration for different values of target strength, Sandia RBT . . . . . . 40

3.13 Calculated bending moment for different values of target.strength, Sandia RBT, section S ...... 41

3.14 Calculated CG lateral acceleration for different amounts of wake separation, Sandia RBT . . . . . 42

3.15 Calculated bending. moment for different amounts of wake separation, Sandia RBT, section S . . . . . 43

3.16 Projectile parameters, target properties, and impact conditions for AVCO 1050-ft/s RBT . . . . . . . 44

3.17 Projectile parameters, target properties, and impact conditions for AVCO 1500-ft/s RBT ......... 45

3.18 Axial location of strain gage and accelerometers for projectile used in AVCO $1050-\mathrm{ft} / \mathrm{sec}$ RBT . . . . . 46

3.19 Axial location of strain gage for projectile used in AVCO 1500-ft/s RBT ................................. 47

3.20 Comparison of calculated and measured axial decelerations for AVCO 1050-ft/sec RBT, rear accelerometer 
3.21 Comparison of calculated and measured lateral accelerations for AVCO 1050-ft/s RBT, forward accelerometer . . 49

3.22 Comparison of calculated and measured strains for AVCO 1050-ft/s RBT, strain gage S . . . . . . . . 50

3.23 Comparison of calculated and measured strains for AVCO 2-degree RBT, strain gage S . . . . . . . 51

3.24 Comparison of calculated and measured strains for AVCO 5-degree RBT, strain gage S . . . . . . 52

3.25 Comparison of calculated and measured strains for AVCO 10-degree RBT, strain gage S . . . . . . . 53

3.26 Comparison of calculated and measured strain levels for AVCO 1500-ft/s RBT, strain gage S . . . . . . 54

A.1 Bilinear failure envelope . . . . . . . . . . 6 60

A.2 Slowly expanding spherical cavity in an infinite elastic-plastic medium ........... . 60

B.1 Comparison of rigid and nonrigid projectile-response calculations for forward accelerometers, Sandia RBT . . . 62

B.2 Comparison of rigid and nonrigid projectile-response calculations for rear accelerometer, Sandia RBT . . . 63

B.3 Comparison of measured lateral accelerations with dynamic structural-response calculation for forward accelerometer, Sandia RBT ........... 64

B. 4 Comparison of measured lateral accelerations with dynamic structural-response calculation for rear accelerometer, Sandia RBT . . . . . . . 65

B.5 Comparison of measured axial strains with dynamic structural-response calculation for strain gage S, Sandia RBT .............. 66

C.1 Baseline AVCO projectile parameters .........68

C.2 Comparison of AVCO and CET calculations of lateral acceleration ................. 69 
U. S. customary units of measurement used in this report can be converted to metric (SI) units as follows:

Multiply

feet per second

inches

pounds (force)

per square inch

inch-pounds

pounds (mass)

pounds (mass)

per cubic foot

pounds-square

inches

slugs per cubic

foot

square inches
By

0.3048

0.0254

6894.757

0.1130

0.4535924

16.01846

0.0002926

515.50336

0.00064516
To Obtain

metres per second

metres

pascals

newton-metres

kilograms

kilograms per cubic metre

kilograms-square nietres

kilograms per cubic metre

square metres 
CHAPTER 1

INTRODUCTION

\subsection{BACKGROUND}

There now exist several techniques that are useful for making penetration predictions, provided the projectile survives the impact and remains stable thereafter. The projectile orientation and motion are usually assumed normal to the target surface, but perfectly normal impact seldom occurs in practice. A small angle of attack is ordinarily to be expected.

The Defense Nuclear Agency (DNA) recently initiated an investigation of non-normal impact and penetration, with emphasis on small attack angles (less than 10 degrees $^{l}$ ). As a part of this effort, DNA asked the U. S. Army Engineer Waterways Experiment Station (WES) to develop a nonnormal penetration analysis based on the Cavity Expansion Theory (CET). ${ }^{2}$ AVCO Corporation (Reference l) had previously developed a computer code for analyzing projectile motion in three dimensions, using an empirical Differential-Area Force Law (DAFL) to specify the surface loads on the projectile. The AVCO version of the DAFL code input contains a set of user-selected empirical parameters describing the target, and it was felt that the CET analysis might offer a simpler, more rational target description.

\subsection{PURPOSE AND SCOPE}

The purpose of this study was to extend the WES CET-based penetration theory for normal impact (Reference 2) to include non-normal impact.

\footnotetext{
1 A table of factors for converting U. S. customary units of measurement 2 to metric (SI) units is presented on page 6.

The Cavity Expansion Theory is discussed in Appendix A.
} 
With the CET analysis in place of AVCO's force distribution, a modified version of the DAFL code was used to make calculations for comparison with test data. Sandia Laboratories and AVCO Corporation have each conducted a series of instrumented reverse ballistic tests (RBT's) for DNA at attack angles between 0 and 10 degrees. Comparison with these tests shows the CET analysis to be tentatively acceptable as a rigid-body prediction technique for hard targets and small angles of attack. 
CHAPTER 2

THEORY

\subsection{PROJECTILE MOTION IN TWO DIMENSIONS}

Previous CET-based penetration analyses (Reference 2) have addressed only the axial motion of the projectile, obtaining expressions for the total resisting force. The non-normal problem in two dimensions, however, involves three degrees of freedom: one rotational, and two translational (Figure 2.1).

Consider a rigid, deeply buried projectile (no free-surface effects), whose motion lies in the $X Z$-plane. ${ }^{l}$ The rotation is described by the angular velocity $\dot{\theta}$; the translation is described by $\dot{X}$ and $\dot{z}$, which are the $X-$ and $Z$-velocity components of the center of gravity (CG).2,3 For analysis, it is convenient to express the CG velocity in terms of its lateral and axial ( $\mathrm{x}$ - and $\mathrm{z}-$ ) $\operatorname{components} \mathrm{V}_{\mathrm{x}}$ and $\mathrm{V}_{\mathbf{z}}$, respectively: 4

$$
\begin{aligned}
& \mathrm{v}_{\mathrm{x}}=\dot{\mathrm{x}} \cos \theta-\dot{\mathrm{z}} \sin \theta \\
& \mathrm{v}_{\mathrm{z}}=\dot{\mathrm{x}} \sin \theta+\dot{\mathrm{z}} \cos \theta
\end{aligned}
$$

For purely axial motion $\left(v_{x}=0, \dot{\theta}=0\right)$, the force distribution on the projectile is symmetric, and the net force is in the z-direction. The introduction of rotation $(\dot{\theta} \neq 0)$ and lateral motion $\left(v_{x} \neq 0\right)$ destroys this symmetry, and simplifying assumptions are necessary in order to calculate the resulting (asymmetric) force distribution.

Whenever the lateral and rotational velocities are small

\footnotetext{
1 The XZ-coordinate system is fixed in the target (Figure 2.1). A dot above any quantity indicates differentiation with respect to 3 time.

3 For convenience, symbols and abbreviations used in this report are 4 listed and defined in the Notation, Appendix D. The xz-coordinate system is fixed on the projectile axis, with its origin at the CG (Figure 2.1).
} 
$\left(\mathrm{V}_{\mathrm{x}} \ll \mathrm{V}_{\mathbf{z}}, \mathrm{L} \dot{\theta} \ll \mathrm{V}_{\mathbf{z}}\right.$ where $\mathrm{L}$ is projectile length), their contributions to the force distribution are assumed to be independent of the axial motion. Thus, defining the angle of attack as

$$
\alpha=\tan ^{-1}\left(\frac{V_{x}}{V_{z}}\right)
$$

the force contributions due to axial, lateral, and rotational motion can be defined separately when $\tan \alpha \ll 1$ and $\dot{\theta} \ll \mathrm{V}_{\mathrm{z}} / \mathrm{L} .^{5}$

Initially it is assumed that the entire projectile is in contact with the target. This assumption will later be modified when the effect of wake separation is investigated. Whether or not there is contact at a given point, the following assumption will remain in effect throughout the analysis: When any point on the projectile surface moves away from the adjacent target material, the stress at that point is zero.

\subsection{FORCE DISTRIBUTION DUE TO AXIAL MOTION}

For purely axial motion, the axial resisting force can be calculated by assuming that only normal stresses act on the projectile surface. 6 Assuming further that the axial force is unchanged for small attack angles, the following equation is used to approximate the compressive normal istress due to axial motion only: ${ }^{7}$

$$
\sigma_{a}=\dot{\sigma}_{s}+V_{z} \sqrt{\rho \sigma_{s}(I+\sin \eta)}
$$

where

5 The $\dot{\theta}$ criterion will always be satisfied for stable projectiles

6 when $\tan \alpha<1$.

The analysis in Reference 2 contains both normal and tangential stresses. For hard targets such as rock and concrete, however, the 7 calculated tangential stresses are small enough to be ignored.

7 Equation 2.4 is an assumed stress distribution that produces an approximation for the net axial force when integrated over the projectile surface. 


$$
\begin{aligned}
\sigma_{\mathrm{S}}= & \text { radial compressive stress at the surface of a slowly ex- } \\
& \text { panding spherical cavity in the target material (Appendix A) } \\
\rho= & \text { target mass density } \\
\tan \eta= & \text { slope of projectile surface at a given point, with respect } \\
& \text { to axis of symmetry } 8 \text { (Figure } 2.1)
\end{aligned}
$$

The $x$ - and z-components of $\sigma_{a}$ are, respectively,

$$
\begin{gathered}
\sigma_{x}^{\prime}=\sigma_{a} \cos \eta \cos \psi \\
\sigma_{z}^{\prime}=\sigma_{a} \sin \eta
\end{gathered}
$$

where $\psi$ is the azimuthal angle (Figure 2.2). For purely axial motion, with complete contact between target and projectile, only Equation 2.6 contributes to the net resisting force (no net lateral force). Otherwise there is a net lateral contribution from Equation 2.5.

\subsection{FORCE DISTRIBUTION DUE TO}

LATERAL MOTION

For small attack angles, the resisting force due to lateral motion is presumed to be unaffected by the axial motion. In this sense, the lateral motion can be regarded as a "separate" penetration problem, and it is assumed that the lateral motion produces only lateral resistance. Dropping the nose shape factor $(I+\sin \eta)$ and replacing $V_{z}$ with $\mathrm{V}_{\mathrm{x}}$, the expressions for the $\mathrm{x}$ - and z-components of the compressive stress due to lateral motion are assumed to be ${ }^{9}$

$$
\sigma_{x}^{\prime \prime}=\left\{\begin{array}{l}
\left(\sigma_{s}+v_{x} \sqrt{\rho \sigma_{s}}\right) \cos n \cos \psi, v_{x}>0 \\
\left(\sigma_{s}-v_{x} \sqrt{\rho \sigma_{s}}\right) \cos n \cos \psi, v_{x}<0
\end{array}\right.
$$

8 The quantity $1+\sin n$, which appears in Equation 2.4, is an empirical "nose shape" factor, introduced to produce a gradual increase in

9 axial resistance with increasing nose bluntness ( $\sin n$ ).

Equations 2.7 and 2.8 are analogous to Equations 2.5 and 2.6 . The nose shape factor is eliminated in the lateral stress because all projectiles of interest have circular cross sections. 


$$
\sigma_{z}^{\prime \prime}=0
$$

Wherever $\mathrm{v}_{\mathrm{x}} \cos \psi<0$, the lateral translation of that point is away from the adjacent target material, and so $\sigma_{x}^{\prime \prime} \equiv 0$ for that point on the projectile.

2.4 FORCE DISTRIBUTION DUE TO ROTATION

Assuming that the lateral velocity due to pure rotation $\mathbf{z} \dot{\theta}$ merely adds an additional velocity term to Equation 2.7, the $\mathrm{x}$ - and $\mathrm{z}-$ components of the compressive stress due to rotation are

$$
\begin{gathered}
\sigma_{x}^{\prime \prime \prime}=z \dot{\theta} \sqrt{\rho \sigma_{S}} \cos \eta \cos \psi \\
\sigma_{z}^{\prime \prime \prime}=0
\end{gathered}
$$

Wherever $z \dot{\theta} \cos \psi<0$, the rotation is away from the adjacent target material, and so $\sigma_{\mathbf{X}}^{\prime \prime \prime} \equiv 0$ for that point on the projectile.

\subsection{COMPOSITE FORCE DISTRIBUTION}

Equations 2.5 through 2.10 can now be combined to obtain the composite axial and lateral force distributions on the projectile. The net axial stress is

$$
\sigma_{z}=\sigma_{z}^{\prime}+\sigma_{z}^{\prime \prime}+\sigma_{z}^{\prime \prime \prime}=\sigma_{z}^{\prime}
$$

The net lateral stress is

$$
\sigma_{x}=\sigma_{x}^{\prime}+\sigma_{x}^{\prime \prime}+\sigma_{x}^{\prime \prime \prime}
$$

The lateral and axial force components (Figure 2.2) acting on any surface element $d A$ are, respectively,

$$
d F_{x}=-\sigma_{x} d A
$$




$$
d F_{z}=-\sigma_{z} d A
$$

where $d A$ is the differential surface area. The lateral and axial force components acting on the entire projectile are then

$$
\begin{aligned}
& F_{x}=-\int_{A} \sigma_{x} d A \\
& F_{z}=-\int_{A} \sigma_{z} d A
\end{aligned}
$$

where A represents the entire projectile surface. The translational equations of motion are

$$
\begin{aligned}
& \ddot{M X}=F_{x} \cos \theta+F_{z} \sin \theta \\
& \ddot{M Z}=-F_{x} \sin \theta+F_{z} \cos \theta
\end{aligned}
$$

where $M$ is the projectile mass and $\ddot{x}$ and $\ddot{z}$ are the components of acceleration in the $\mathrm{X}$ - and $\mathrm{Z}$-directions, respectively. The projectile is assumed rigid, and the rotational equation of motion is

$$
I_{C G} \ddot{\theta}=\int_{A} z d F_{x}-\int_{A} x d F_{z}
$$

where $I_{C G}$ is the mass moment of inertia about the $C G$, and $\ddot{\theta}$ is the angular acceleration. The right-hand side of Equation 2.19 is the total moment exerted on the projectile about its CG.

\subsection{WAKE SEPARATION AND REATTACHMENT}

It is likely that some parts of the projectile lose contact with the target during penetration. Part of the nose must remain in contact, but separation can occur anywhere, especially on the aftbody. While a precise analysis of the separation mechanism itself is unmanageable, it is still possible to assess the gross effect of a specified amount of separation upon the projectile. 
Consider a projectile with no rotational or lateral velocity $\left(\dot{\theta}=0, V_{x}=0\right)$. Separation is thought to occur near the base of the nose (Figure 2.3), with reattachment somewhere on the aftbody (if anywhere). The separation and reattachment points probably change with velocity, and the width of the separation gap may vary with position. This behavior is simplified and idealized (Figure 2.4) in the following assumptions:

1. The entire nose is in contact with the target.

2. The width of the separation gap $\delta$ between aftbody and target is directly proportional to the local aftbody radius $r$.

Assumption 1 is reasonable for long projectiles, for which the nose represents only a fraction of the total surface area. According to Assumption 2, a cavity exists in the target aft of the nose (Figure 2.4), such that $\delta / r$ remains constant. These assumptions have no effect whenever $v_{x}=0$ and $\dot{\theta}=0$. However, if $v_{x} \neq 0$ or $\dot{\theta} \neq 0$, then there is a distribution of local lateral velocity

$$
v_{x}=v_{x}+z \dot{\theta}
$$

and part of the aftbody surface may collide with the cavity wall (which is regarded as fixed). Reattachment is defined as any collision between the aftbody and the cavity wall.

The problem is still complicated because the cavity wall will not be straight if $\mathrm{V}_{\mathrm{x}} \neq 0$ or $\dot{\theta} \neq 0$. Instead, it will be a curved cylindrical surface, mapping out the trajectory of the nose base. Addi- tional simplification is necessary if the analysis is to be tractable.

Consider the two views of the idealized wake separation shown in Figure 2.4. Suppose that the cavity is, almost straight between points 1 and 2, but that point 1 (on the projectile) is moving toward the cavity wall. The simplified reattachment criterion is as follows: if point 1 can collide with the cavity wall before going past point 2 , then point 1 is assumed to be already in contact with the cavity wall. Thus, the condition required for contact is 


$$
-\frac{\delta}{v_{x}}<\frac{s}{v_{z}}
$$

where $s$ is the axial distance between the point in question and the base of the nose. At arbitrary points on the aftbody (such as point 3 ), one of the following conditions is required for contact:

$$
\begin{aligned}
& \frac{\sqrt{r^{2} \cos ^{2} \psi+2 r \delta+\delta^{2}}-r \cos \psi}{v_{x}}<\frac{s}{v_{z}}, \quad-\frac{\pi}{2}<\psi<\frac{\pi}{2} \\
& \frac{\sqrt{r^{2} \cos ^{2} \psi+2 r \delta+\delta^{2}}+r \cos \psi}{-v_{x}}<\frac{s}{v_{z}}, \quad \frac{\pi}{2}<\psi<\frac{3 \pi}{2}
\end{aligned}
$$

Wherever this condition is satisfied (on the aftbody), the stress is defined by Equations 2.11 and 2.12; otherwise, the stress is set equal to zero (no contact).

\subsection{INTERNAL FORCES AND MOMENTS IN A RIGID PROJECTILE}

The external forces and moments create internal forces and moments within the rigid projectile itself. According to D'Alambert's principle, the $x$ - and $z$-components of the internal force at any point $z$ on the axis of symmetry are, respectively,

$$
\begin{aligned}
& f_{x}(z)=\int_{\xi=z}^{\xi=z}\left[d F_{x}(\xi)-\dot{v}_{x} d M(\xi)\right] \\
& f_{z}(z)=\int_{\xi=z}^{\xi=z}\left[d F_{z}(\xi)-\dot{v}_{z} d M(\xi)\right]
\end{aligned}
$$

where $z_{n}$ is the z-coordinate of the nose tip, the differential function $\operatorname{dM}(z)$ represents the point distribution of mass along the 
projectile axis $(x=0)$, and $\xi$ is a variable of integration. The differential force-components, $\mathrm{dF}_{x}(z)$ and $\mathrm{dF}_{z}(z)$, are given by Equations 2.13 and 2.14. The local lateral and axial accelerations are given by

$$
\begin{gathered}
\dot{v}_{x}=\frac{d}{d t} v_{x}=\frac{d}{d t} v_{x}+z \ddot{\theta} \\
\dot{v}_{z}=\frac{d}{d t} v_{z}=\frac{d}{d t} v_{z}-z \dot{\theta}^{2}-\ddot{x}
\end{gathered}
$$

The internal (bending) moment at $z$ is

$$
\begin{aligned}
\Gamma(z)= & \int_{\xi=z_{n}}^{\xi=z}\left(z_{n}-\xi\right) d F_{x}(\xi)+\int_{x=-r}^{x=+r} x d F_{z}(x, z) \\
& -\int_{\xi=z_{n}}^{\xi=z} \int_{x=-r}^{x=+r}\left[\left(z_{n}-\xi\right) \dot{v}_{x}-x \dot{v}_{z}\right] d M(x, \xi)
\end{aligned}
$$

The differential functions $\mathrm{dM}(x, z)$ and $\mathrm{dF}_{z}(x, z)$ represent the distributions of mass and external axial force, respectively, throughout the projectile.

\subsection{MODIFIED AVCO COMPUTER CODE}

The equations for the $x$ - and $z$-components of stress (Equations 2.ll and 2.12) have been installed in a modified version of the AVCO DAFL code, replacing the AVCO definitions of the same quantities. Algorithms have also been added for calculating internal force (Equations 2.24 and 2.25) and bending moment (Equation 2.28) in a rigid projectile. Figure 2.5 shows a block diagram for calculations using the CET analysis and the modified DAFL code. 
2.9 RESTRICTION TO HARD TARGETS AND

SMALL ANGLES OF ATTACK

The theory in Sections 2.1 through 2.7 is intended only for hard targets such as rock and concrete. Furthermore, since the analysis uses purely axial motion as a point of departure from normal impact, calculations should be restricted to small angles of attack ( $\alpha \leq 10$ degrees), for which the projectile motion is predominantly axial. 


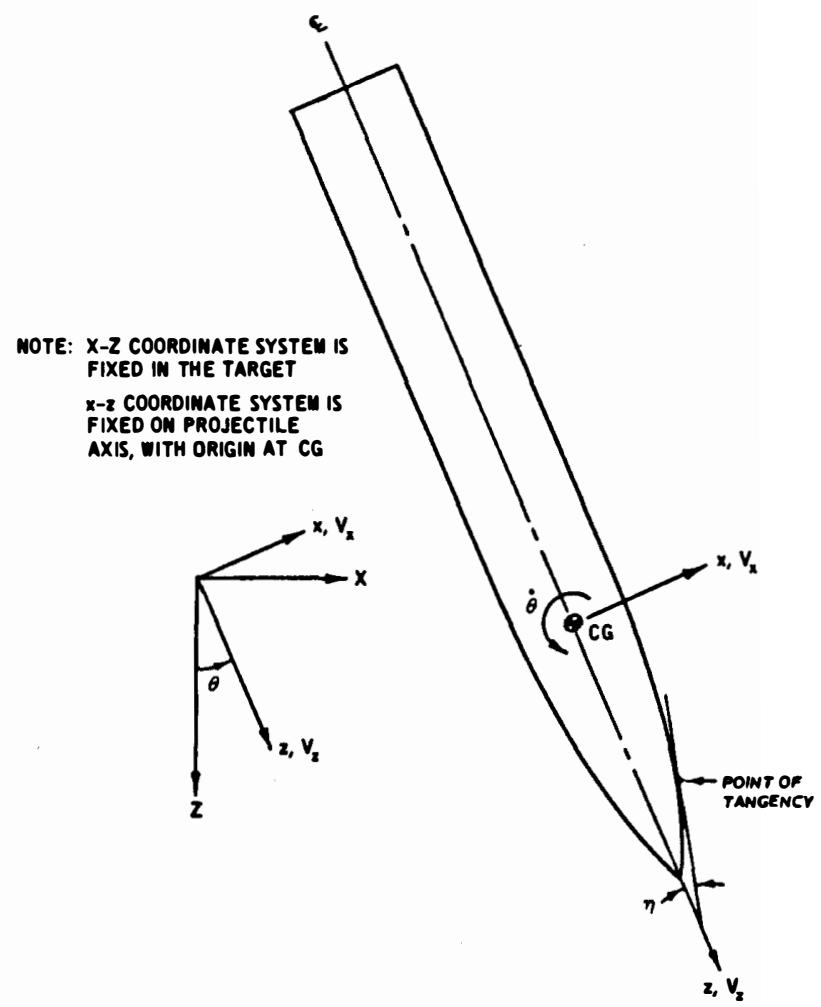

Figure 2.1 Projectile motion in two dimensions. 


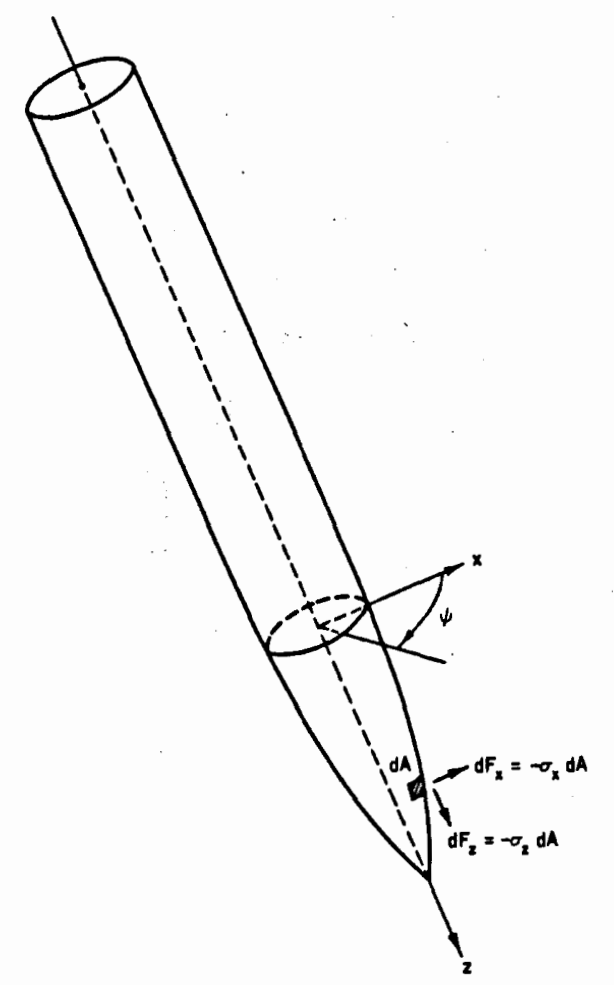

Figure 2.2 Three-dimensional view of projectile.

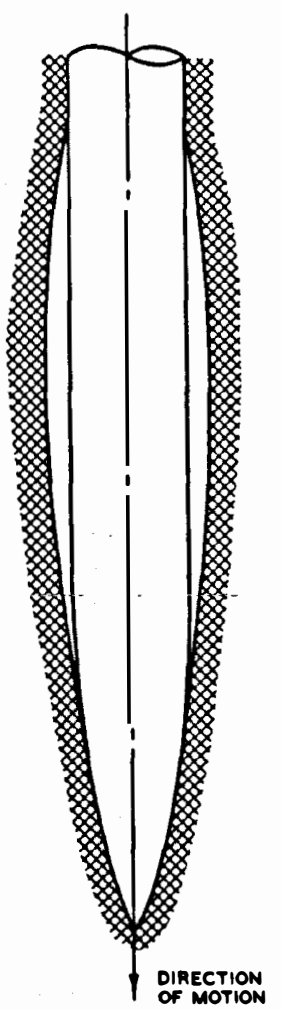

Figure 2.3 Wake separation and reattachment for purely axial motion. 


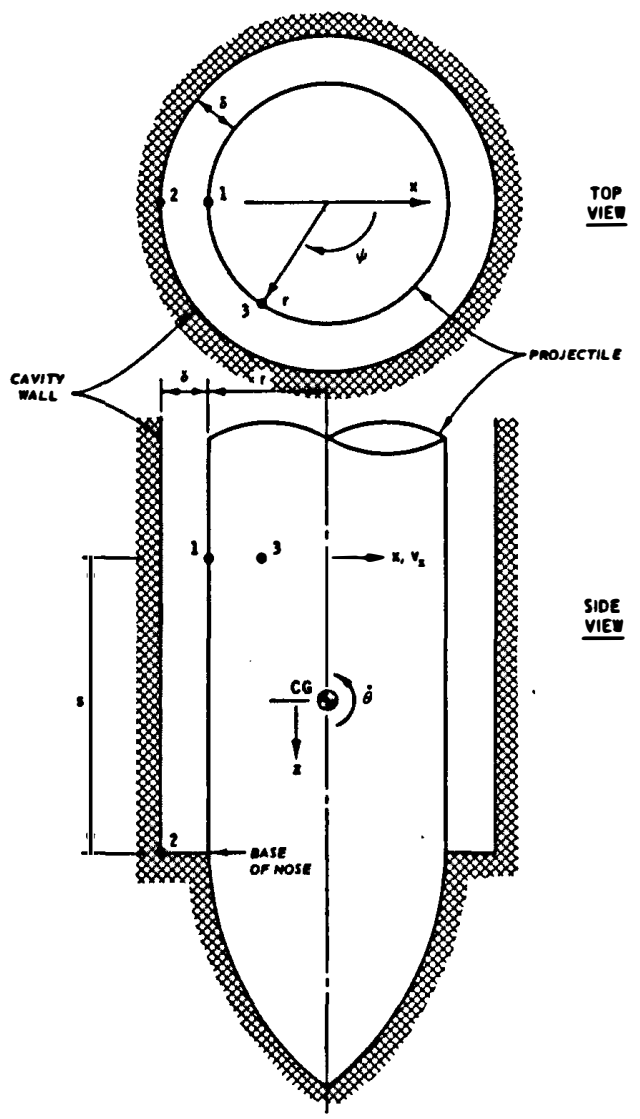

Figure 2.4 Idealized wake separation.

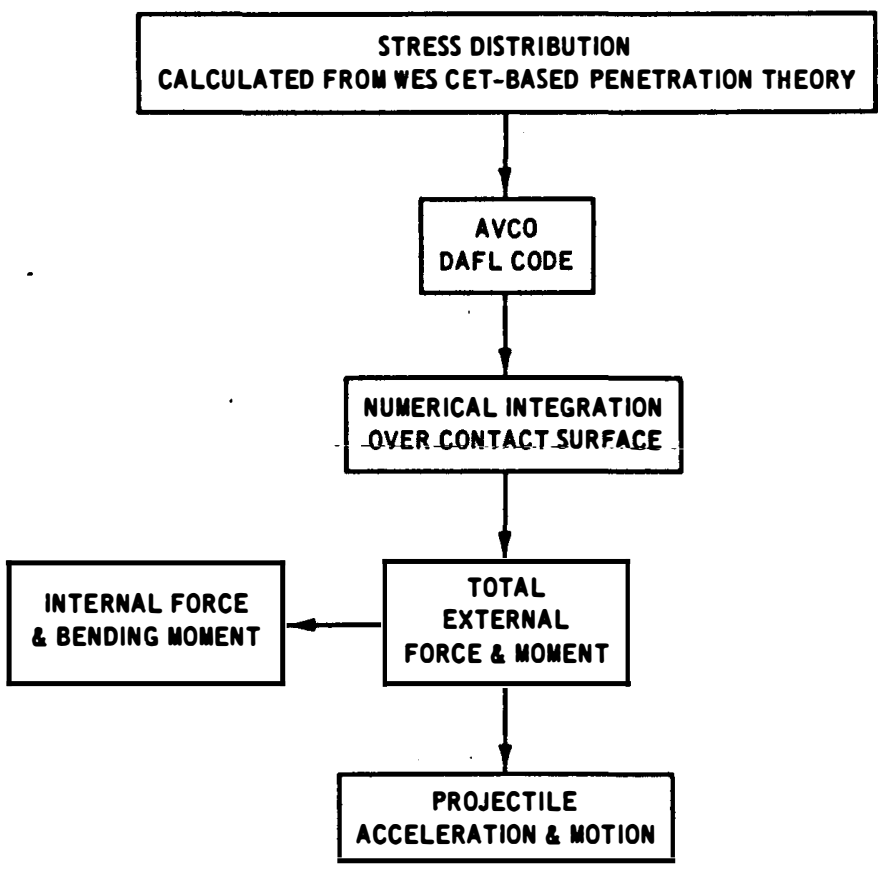

Figure 2.5 Block diagram for non-normal impact-and-penetration - calculations using CET analysis and AVCO DAFL code. 


\section{CALCULATIONS AND TEST DATA}

\subsection{AVAILABILITY OF NON-NORMAL TEST DATA}

Direct measurements of the lateral forces incurred by a projectile during non-normal impact and penetration are scarce. In fact, with the exception of tests recently conducted by Sandia Laboratories (References 3 and 4 ) and AVCO Corporation ${ }^{1}$ (References 5 and 6), lateral forcerelated data are virtually nonexistent. These tests seem to offer the only benchmarks for checking the theory formulated in Chapter 2 , but the available data are too few to establish the general credibility of the theory. More tests are needed under different impact conditions, and the test results that do exist are sufficient only for tentative verification.

\subsection{LIMITATIONS AND SIMPLIFICATIONS IN THE CET ANALYSIS}

The CET analysis is intended for calculations in which the initial angle of attack is less than 10 degrees. The primary assumption is that, for small attack angles, the lateral resisting force can be found by linear superposition of axial, lateral, and rotational effects.

It will be shown that aftbody wake separation has little effect in the calculations if the assumed separation gap width $\delta$ is small compared to the local aftbody radius $r$. For hard targets it is likely that the projectile-target separation is small; thus the comparison of calculations and test data will be made on the assumption that $\delta / r \approx-0$. The parametric effect of varying $\delta / r$ in the calculations will be shown separately.

The quantity $\sigma_{s}$, which appears in Chapter 2, is discussed in

1 Personal communication dated 10 May 1977 from P. J. Grady, AVCO Corporation, Wilmington, Mass., to MAJ D. Spangler, Defense Nuclear Agency, Washington, D. C. 
Appendix A. Defined in terms of the target shear strength, $\sigma_{s}$ links the CET to the penetration theory. For calculations in hard materials (Reference 2), it has been found acceptable to assume that the target obeys the von Mises failure condition. The strength parameters (Appen$\operatorname{dix}$ A) then become

$$
\begin{gathered}
\phi_{1}=\phi_{2}=0 \\
c_{1}=c_{2}=\frac{1}{2} Y
\end{gathered}
$$

where $Y$ is the unconfined compressive strength. The expression for $\sigma_{\mathrm{s}}$ reduces to

$$
\sigma_{S}=\frac{2}{3} Y\left(I+\ln I_{1}\right)
$$

where $I_{1}$ is the rigidity index, given by

$$
I_{1} \approx \frac{2 E}{3 Y}
$$

and $E$ is Young's modulus for the target.

\subsection{SANDIA REVERSE BALLISTIC TESTS}

\subsubsection{Test Description}

Sandia Laboratories has conducted a series of RBT's for both normal and non-normal impact. In each of the experiments, a sandstone target ${ }^{2}$ -was mounted on a rocket sled and accelerated to a velocity of about $1500 \mathrm{ft} / \mathrm{s}$ before striking a stationary 1.9-inch-diameter projectile. Two of the tests were conducted at attack angles of 3 degrees; the impact conditions, projectile parameters, and sandstone properties for these tests are shown in Figure 3.1.

The projectiles were instrumented with strain gages and with lateral

2 The targets were hexagonal prisms, 45 inches across and 30 inches deep
(in the direction of motion). 
and axial accelerometers (Figure 3.2), and data were recorded for the first body length of penetration. The outputs of the accelerometers (at stations $F$ and $R$ ) and the strain gage (at station $S)^{3}$ can be compared directly with the predictions of the CET analysis.

\subsubsection{Accelerometer Data}

Figures 3.3 and 3.4 show comparisons of the calculated and measured acceleration records for the forward accelerometer location (station F). The axial deceleration calculation (Figure 3.3) reproduces the experimental results about as accurately as can be expected for a rigid-body calculation. The lateral acceleration records for this station (Figure 3.4) are more difficult to appraise. The CET calculation reproduces the maximum acceleration levels, but not the instantaneous details.

Figures 3.5 and 3.6 show the calculated and measured acceleration records for the rear accelerometers (station $R$ ). Again, the axial deceleration calculation is in reasonable agreement with the experimental results (Figure 3.5). Figure 3.6, however, offers a more dramatic comparison of lateral acceleration records than does Figure 3.4. The experimental acceleration records show about the same magnitude and duration as the calculated results, but the peaks occur later than the calculated results. This delay is apparently caused by nonrigid projectile response to the rapidly varying applied loads (Appendix $B$ ).

\subsubsection{Strain Gage Data}

In the CET analysis it is assumed that the projectile is perfectly rigid, but actually strains are produced in the projectile by the internal force $f_{z}$ and bending moment $\Gamma$. In the plane of motion, the expression for the maximum axial strain $\varepsilon_{a}$ on either side of the projectile is

$$
\varepsilon_{a}=\frac{f_{z}}{E_{p} A_{s}} \pm \frac{r_{s} \Gamma}{E_{p} I_{s}}
$$

where

$$
E_{p}=\text { Young's modulus for projectile }
$$

3 There were strain gages at several locations, but the one nearest the CG has been chosen for discussion. 
$A_{S}=$ area of projectile cross section $S$

$r_{\mathrm{S}}=$ projectile radius at section $\mathrm{S}$

$I_{S}=$ area moment of inertia of projectile cross section $\mathrm{S}$

If $\varepsilon_{a}$ is small and $f_{z}$ and $\Gamma$ are slowly varying functions of time, then Equation 3.5 is an exact formula for the strain gage output.

Figure 3.7 shows a comparison of the calculated and measured axial strains for strain gage $S$ (Figure 3.1). The calculated and experimental strain levels are about the same, but the experimental results are delayed, as were the lateral acceleration data. Again, the delay seems to be caused by the rapidly varying applied loads (Appendix B).

\subsection{PARAMETER STUDY}

The real test of the CET analysis lies not in the prediction of individual test results, but in the prediction of the results (or trends) observed in many tests. The data required for such a verification are as yet unavailable, but it is still worthwhile to investigate the importance of different parameters in the calculations themselves. Accordingly, a brief study has been made in which the attack angle, the impact velocity, the target strength, and the wake separation were varied. The Sandia test conditions were used as a baseline, and the projectile parameters (Figure 3.1) were held fixed.

3.4.I Calculated Effect of Attack Angle

Figure 3.8 shows the lateral acceleration of the projectile CG for different initial values of the attack angle. Beyond the point of nose - embedment (0.2 ms)-3 there is a marked difference in acceleration level for attack angles of 1,3 , and 5 degrees. The same is true of the bending moment (Figure 3.9).

An increase in the initial attack angle clearly raises the magnitudes of the lateral acceleration and the bending moment. This rise is a direct consequence of Equations $2.5,2.7$, and 2.9 in Chapter $2 .{ }^{4}$ The ${ }^{4}$ Appendix C presents a comparison of lateral accelerations obtained
with the WES and the AVCO formulations of the force distribution. 
rate of rise, however, awaits experimental data for verification. If future tests generally show a stronger-than-predicted increase in acceleration and bending moment with increasing attack angle, then the velocity terms in the lateral stress equations will need to be enlarged, with the $\sigma_{s}$ terms reduced.

3.4.2 Calculated Effect of Impact Velocity

Aside from decreasing the lateral acceleration and the bending moment, a reduction of the impact velocity lengthens the time required for penetration, and vice versa (Figures 3.10 and 3.11). From the calculations, it also appears that a given change in the impact velocity has a stronger effect than the same relative change in the angle of attack. In this case a factor of 2 increase in the impact velocity produces about the same increase in the lateral load as a factor of 5 change in the attack angle.

\subsubsection{Calculated Effect of Target Strength}

Inspection of Equations 2.5, 2.7, 2.9, and 3.3 reveals that the loads on the projectile must exhibit a target-strength dependence that falls somewhere between linear and square root. For an impact velocity of $1500 \mathrm{ft} / \mathrm{s}$ and an attack angle of 3 degrees, the lateral acceleration and the bending moment are roughly proportional to the square root of the strength, as can be seen from Figures 3.12 and 3.13. At much lower velocities, the dependence will be more nearly linear.

\subsubsection{Calculated Effect of Wake \\ Separation}

The analysis of wake separation in Chapter 2 is insufficient for predicting separation. It is, however, adequate for assessing the consequences of a specified amount of separation. Thus, by varying the ratio $\delta / r$, it is possible to find out the degree to which separation (and reattachment) may influence the loads on the projectile.

The value $\delta / r=0$ represents no initial wake separation, but parts of the projectile may rotate away from the target, thereby losing contact. The value $\delta / r=1$ represents an unreasonably large amount of 
separation (see Figure 2.4). For rock and concrete, ratios on the order of $\delta / r \approx 0.1$ seem reasonable.

Figures 3.14 and 3.15 show the results of calculations made with different values of $\delta / \mathrm{r}$. The variation of $\delta / \mathrm{r}$ has little influence on the maximum lateral acceleration, affecting only the pulse duration. The bending moment is more strongly affected, especially by the larger values of $\delta / r$. Nevertheless, the bending moment and the lateral acceleration are essentially unchanged when $\delta / r$ is increased from 0.0 to 0.1 . According to the calculations, a great deal of separation $(\delta / r \geq 0.5)$ is required to produce a significant change in the bending moment.

\subsection{AVCO REVERSE BALLISTIC TESTS}

The Sandia RBT's offer perhaps the best non-normal penetration data on record, since the projectiles were fully instrumented and the targets were large enough to delay edge effects for a whole body length of penetration. However, the only nonzero angle of attack used was 3 degrees. At least one more value is needed to establish or verify a relation between the projectile loads and the attack angle for a specified target. AVCO Corporation has conducted RBT's in concrete for angles of 2 , 5, and 10 degrees.

\subsubsection{Test Description}

The projectile parameters, target properties, and impact conditions for the AVCO tests are given in Figures 3.16 and 3.17. A 5-degree angle was tested at $1050 \mathrm{ft} / \mathrm{s}$, and all angles were tested at $1500 \mathrm{ft} / \mathrm{s}$. All the projectiles were instrumented with strain gages, ${ }^{5}$ but only the 1050-ft/s projectile was instrumented with accelerometers.

In each of the tests a concrete cylinder 15 inches across and 9 inches deep was fired from a oun, striking a stationary 3-inch-diameter projectile. Due to the size of the target and the sonic speed $(\approx 8000$ $\mathrm{ft} / \mathrm{s}$ ) in the concrete, the tests were free of edge effects for no more than $0.2 \mathrm{~ms}^{6}$

5 Only the strain gage $S$, shown in Figures 3.18 and 3.19 , has been 6 chosen for discussion.

In the Sandia tests, edge effects were absent for about $1 \mathrm{~ms}$, or 18 inches of penetration. 


\subsubsection{Accelerometer Data for 1050-ft/s Test}

Figure 3.20 shows a comparison of the axial deceleration data with the CET results for the 1050-ft/s test. Except for the peaks in the test record, the calculation overshoots the data by at least a factor of 2 after the first $0.4 \mathrm{~ms}$. Thus, the penetration resistance of the concrete is either (1) less than indicated by the strength or (2) affected by the target dimensions.

It is likely that the low penetration resistance is the result of a low ratio of target diameter to projectile diameter ( 5 in this case). In the Sandia tests, this ratio was 30 , and the calculated deceleration matched the test data. The larger the ratio, the better the target simulates a half-space. (An infinite ratio is assumed in the calculations.)

Figure 3.21 shows a comparison of the calculated and measured lateral accelerations for the forward accelerometer. ${ }^{7}$ The sharp spikes in the calculated results are due to the integration scheme used in the code, $\overline{8}$ and there is so much oscillation in the test data that the comparison is difficult to appraise.

\subsubsection{Strain Gage Data for 1050-ft/s Test}

The measured strains for the 1050-ft/s test (Figure 3.22) are much lower than the calculated strains for the same reason that the accelerometer data (Figure 3.21) were low. Furthermore, the onset of strain is delayed, as in the Sandia tests. After the delay, the initial rise in the measured strain is comparable with the calculated strain, but the rise rate drops after about $0.2 \mathrm{~ms}$, probably due to edge effects.

\subsubsection{Strain Gage Data for}

1500-ft/s Tests

Measured and calculated strains for the 1500-ft/s tests are shown in Figures 3.23 through 3.25. Again, the onset of the measured strain

7 The rear lateral accelerometer failed to operate. The same is true for all calculated results shown hereafter. 
is delayed, and the observed strain levels are much lower than calculated. The discrepancy between the data and the CET analysis decreases with increasing attack angle, but this decrease does not necessarily mean that the predictions are more accurate for higher attack angles in general. Figure 3.26 indicates that the calculated maximum strain is a linear function of the attack angle, while the measured maximum strain is nonlinear. ${ }^{9}$ The nonlinearity may be due to edge effects, in which case the comparison made in Figure 3.26 is inappropriate. Overprediction of the strain is to be expected for small targets; but if future tests for large targets exhibit the same type of nonlinearity, then the CET analysis will require some modification.

9 Individual rapid oscillations are ignored in determining the maximum strain levels from Figures 3.23 through 3.25 . 
PROJECTILE

\subsection{4-SCALE EARTH PENETRATOR}

WEIGHT $=9.48$ LB

MAXIMUM DIAMETER $=1.9 \mathrm{IN}$

MOMENT OF INERTIA $=221.9$ LB $-I N^{2}$ (ABOUT CG)

NOSE SHAPE: 6.00 CRH OGIVE (BEVELED TIP)

$$
\begin{aligned}
& E_{p}=2.8 \times 10^{7} \mathrm{PSI} \\
& \mathrm{I}_{s}=0.34 \mathrm{IN}^{4} \\
& A_{s}=1.32 \mathrm{IN}^{2} \\
& r_{s}=0.85 \mathrm{IN}
\end{aligned}
$$

NOTE: CRH IS THE OGIVE CALIBER RADIUS

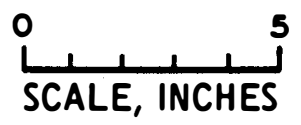

LATERAL DIRECTION
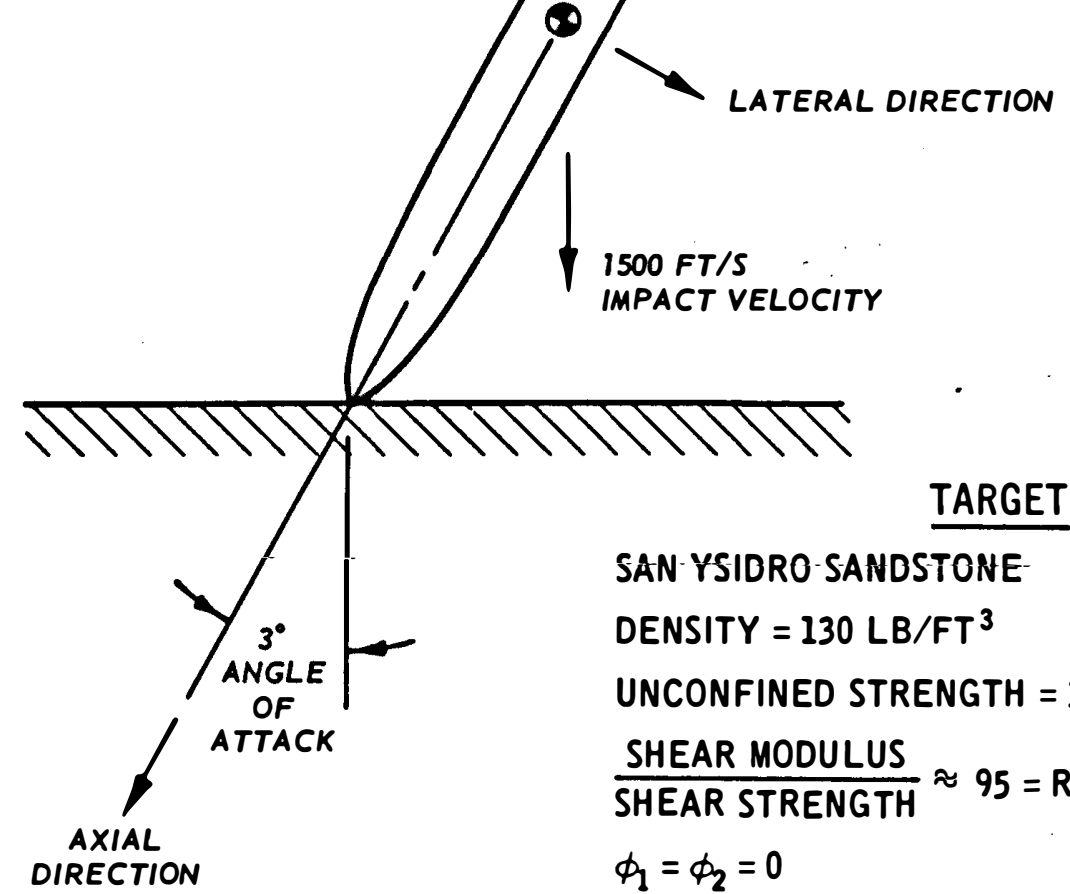

$$
\begin{aligned}
& \frac{\text { TARGET }}{\text { SAN } Y \text { SIDRO SANDSTONE }} \\
& \text { DENSITY }=130 \text { LB }^{-} \text {FT }^{3} \\
& \text { UNCONFINED STRENGTH = } 3400 \text { PSI } \\
& \frac{\text { SHEAR MODULUS }}{\text { SHEAR STRENGTH }} \approx 95=\text { RIGIDITY INDEX, } I_{1} \\
& \phi_{1}=\phi_{2}=0 \\
& c_{1}=c_{2}=1700 \text { PSI }
\end{aligned}
$$

Figure 3.1 Projectile parameters, target properties, and impact conditions for Sandia RBT's. 


\begin{tabular}{|c|c|c|}
\hline STATION & $\begin{array}{l}\text { LOCATION } \\
\text { INCHES }\end{array}$ & SIGNIFICANCE \\
\hline B & +4.91 & NOSE BASE \\
\hline CG & 0.00 & CENTER OF GRAVITY \\
\hline $\mathbf{F}$ & +0.75 & FORWARD ACCELEROMETER \\
\hline $\mathbf{R}$ & -8.38 & REAR ACCELEROMETER \\
\hline S & -0.89 & STRAIN GAGE \\
\hline
\end{tabular}

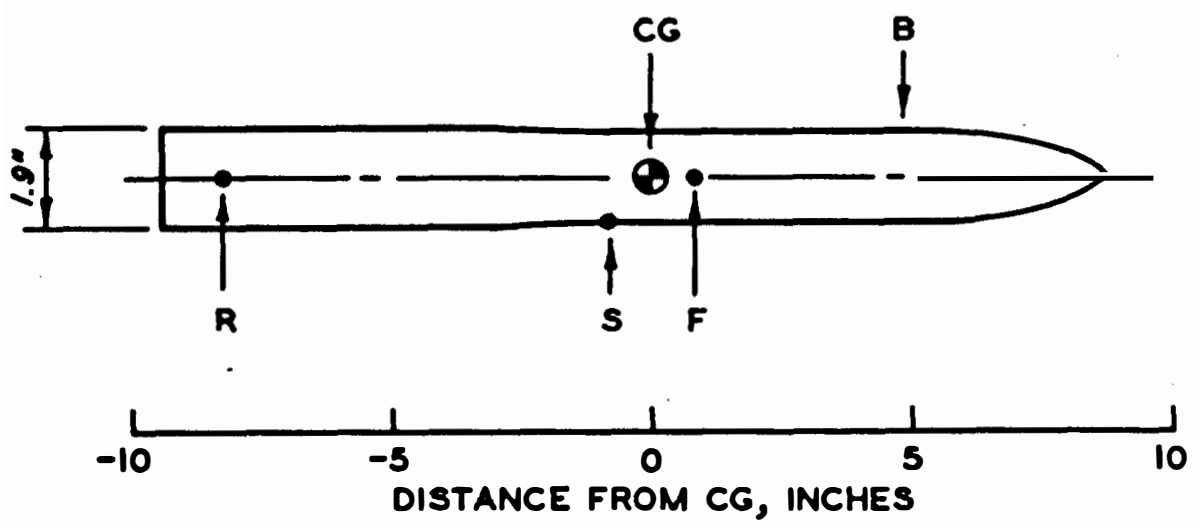

Figure 3.2 Axial location of strain gage and accelerometers for projectile used in Sandia RBT. 


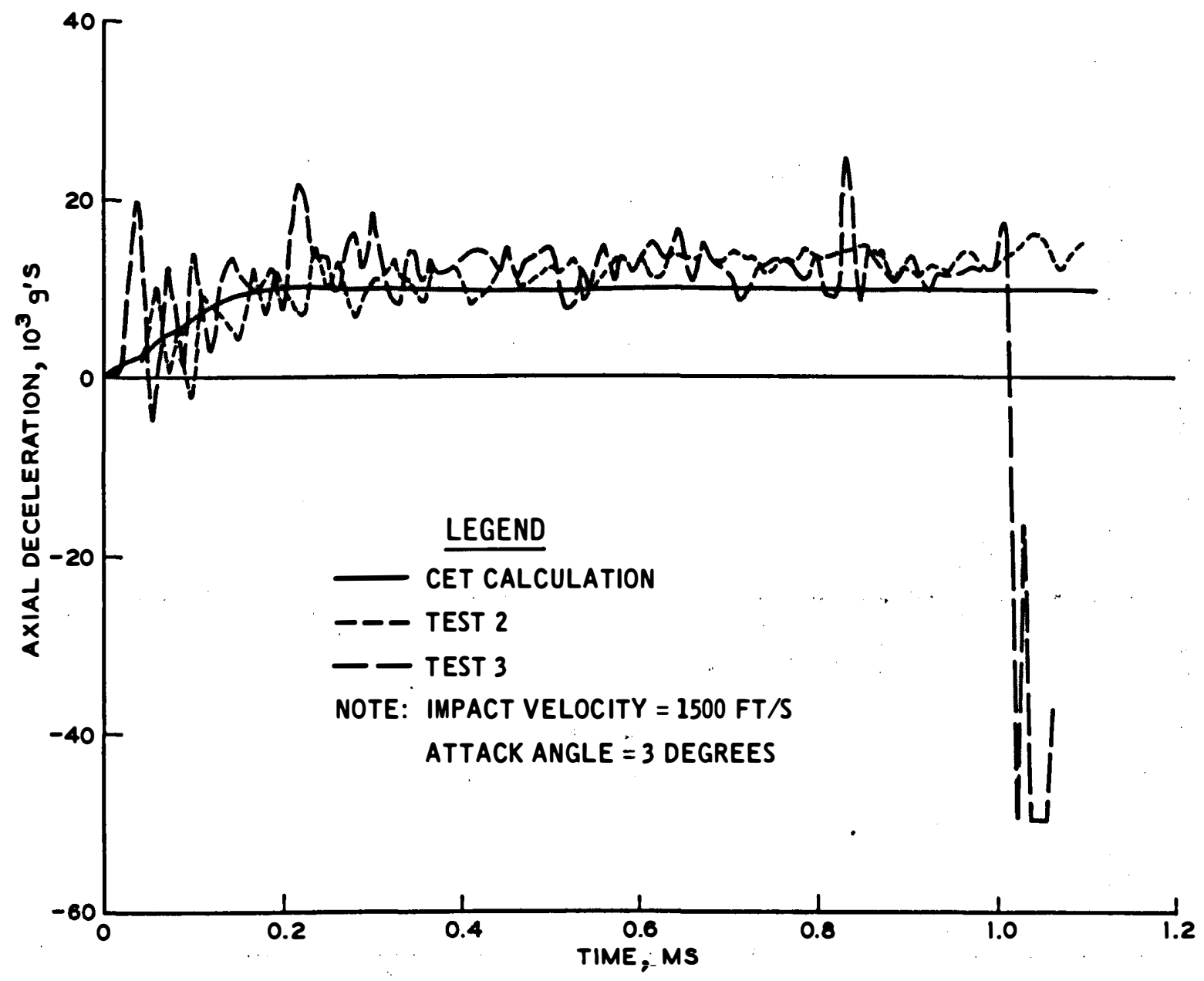

Figure 3.3 Comparison of calculated and measured axial decelerations for Sandia RBT (forward accelerometer). 


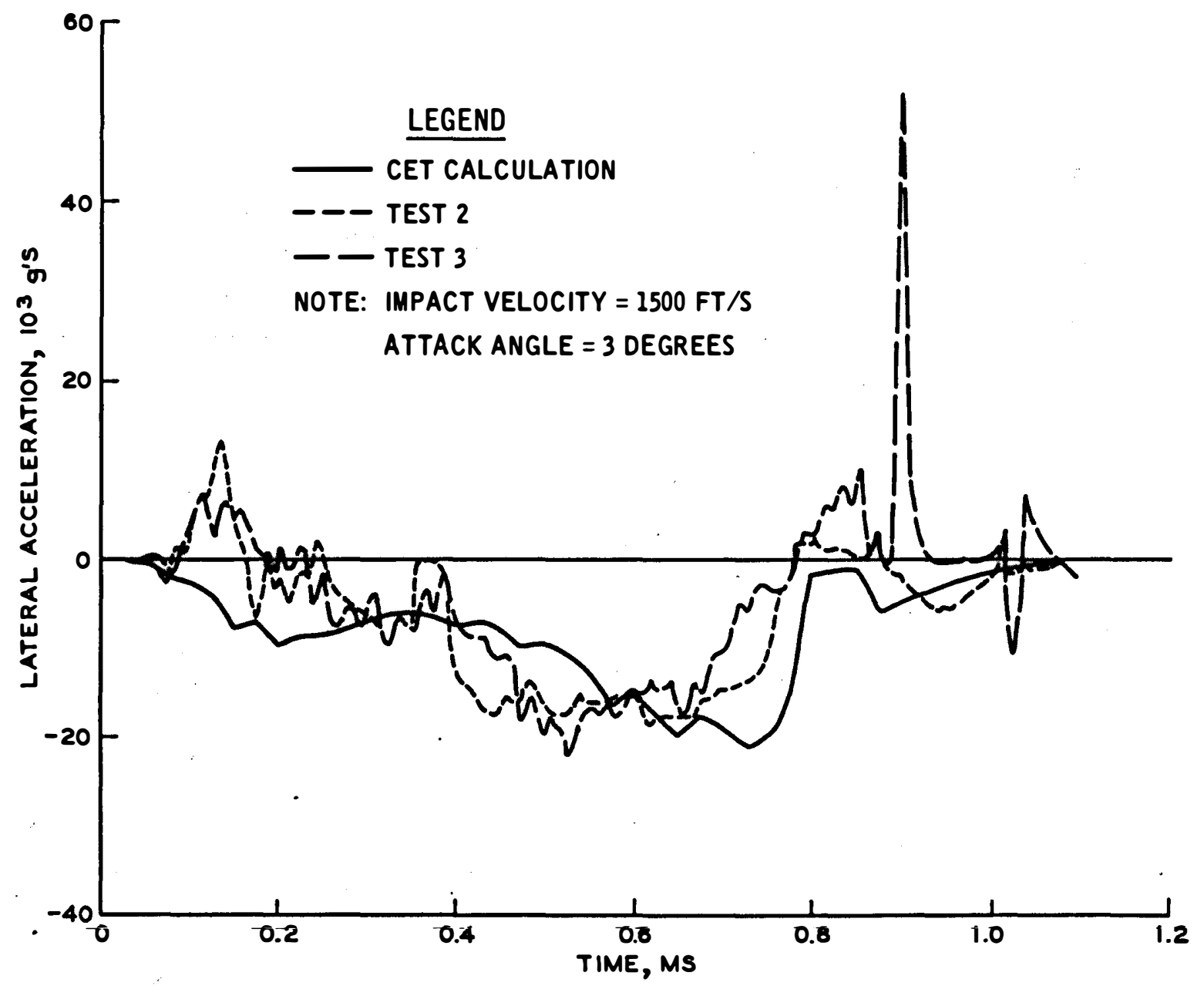

Figure 3.4 Comparison of calculated and measured lateral accelerations for Sandia RBT (forward accelerometer). 


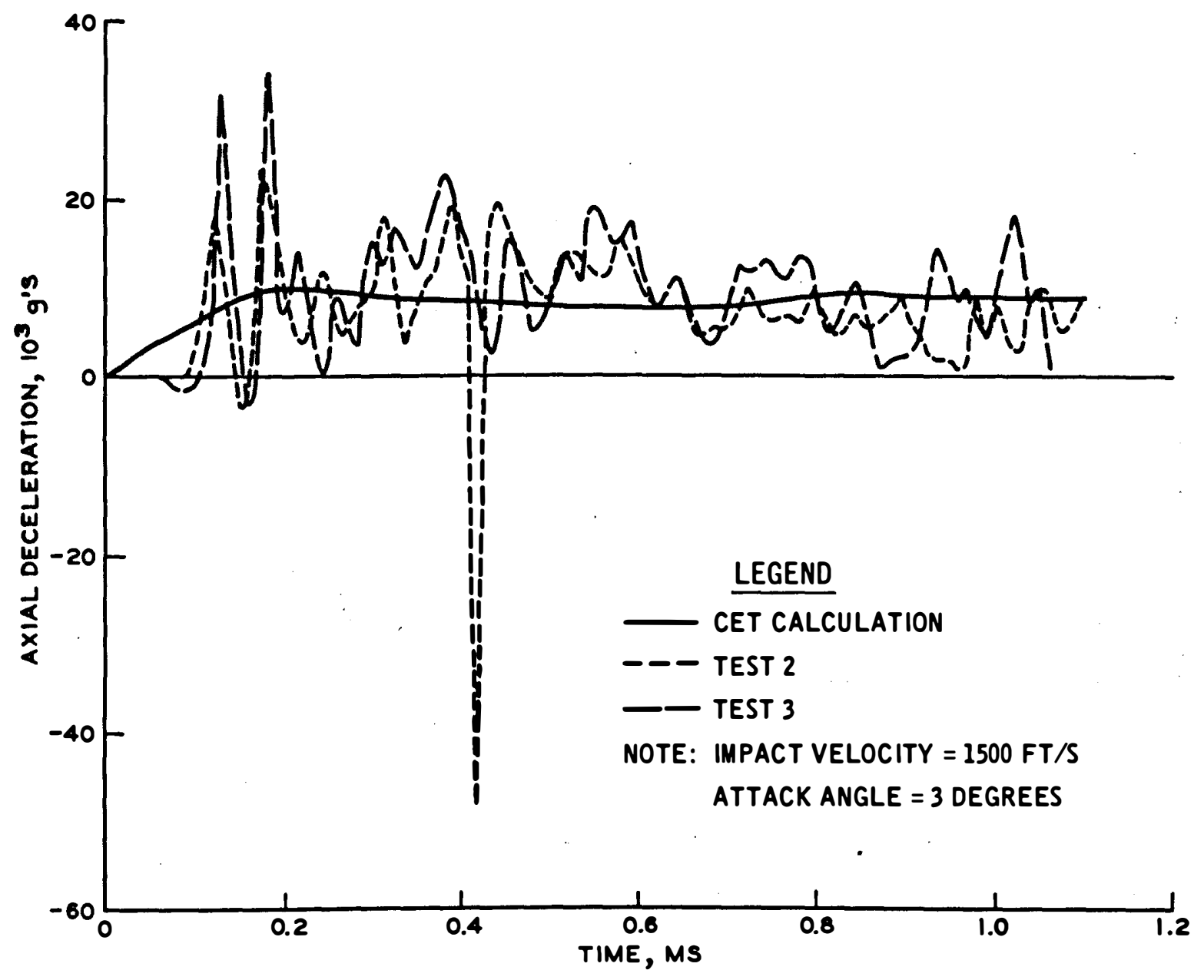

Figure 3.5 Comparison of calculated and measured axial decelerations for Sandia RBT (rear accelerometer). 


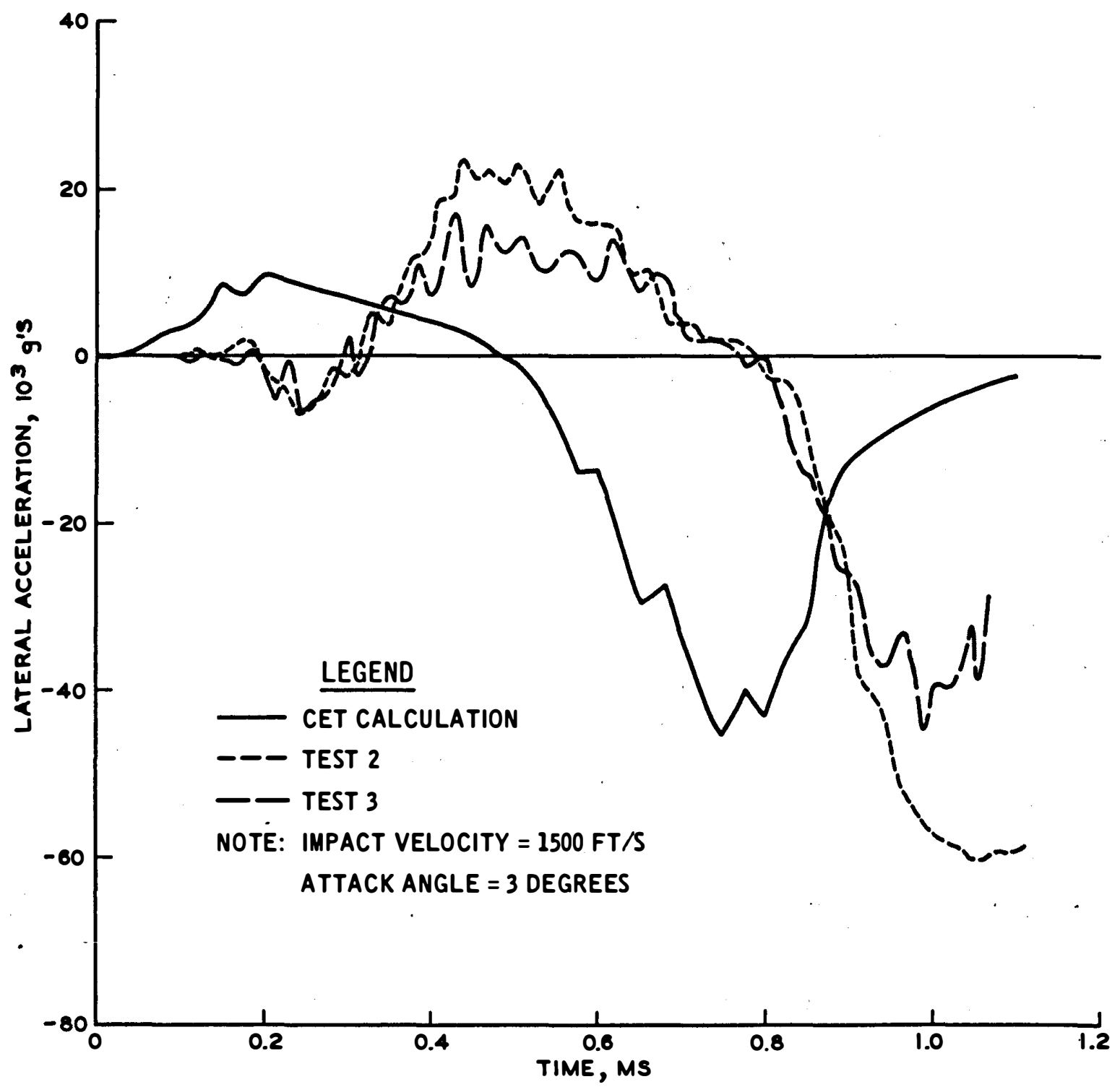

Figure 3.6 Comparison of calculated and measured lateral accelerations for Sandia RBT (rear accelerometer). 


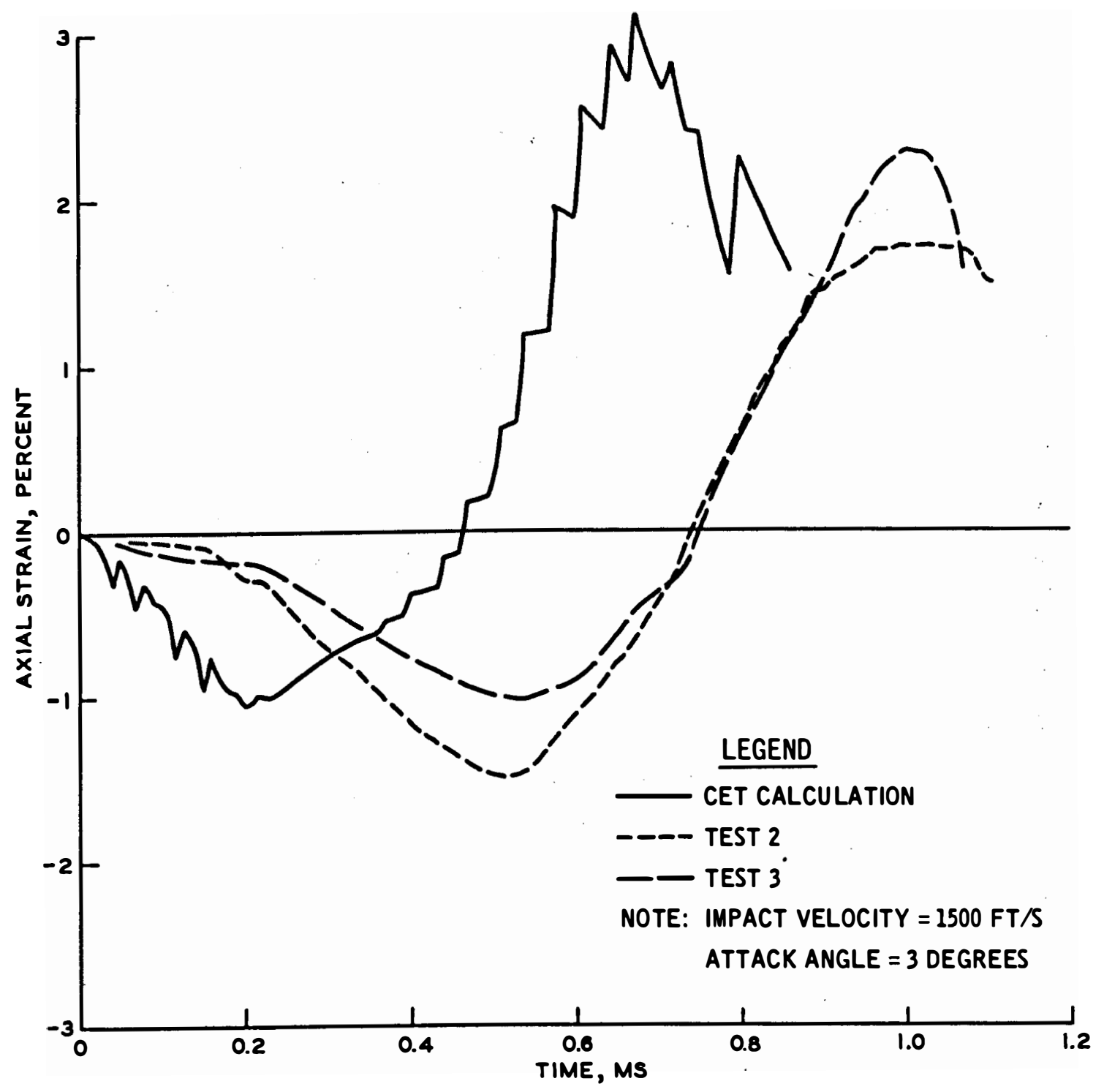

Figure 3.7 Comparison of calculated and measured axial strains for Sandia RBT, strain gage $\mathrm{S}$. 


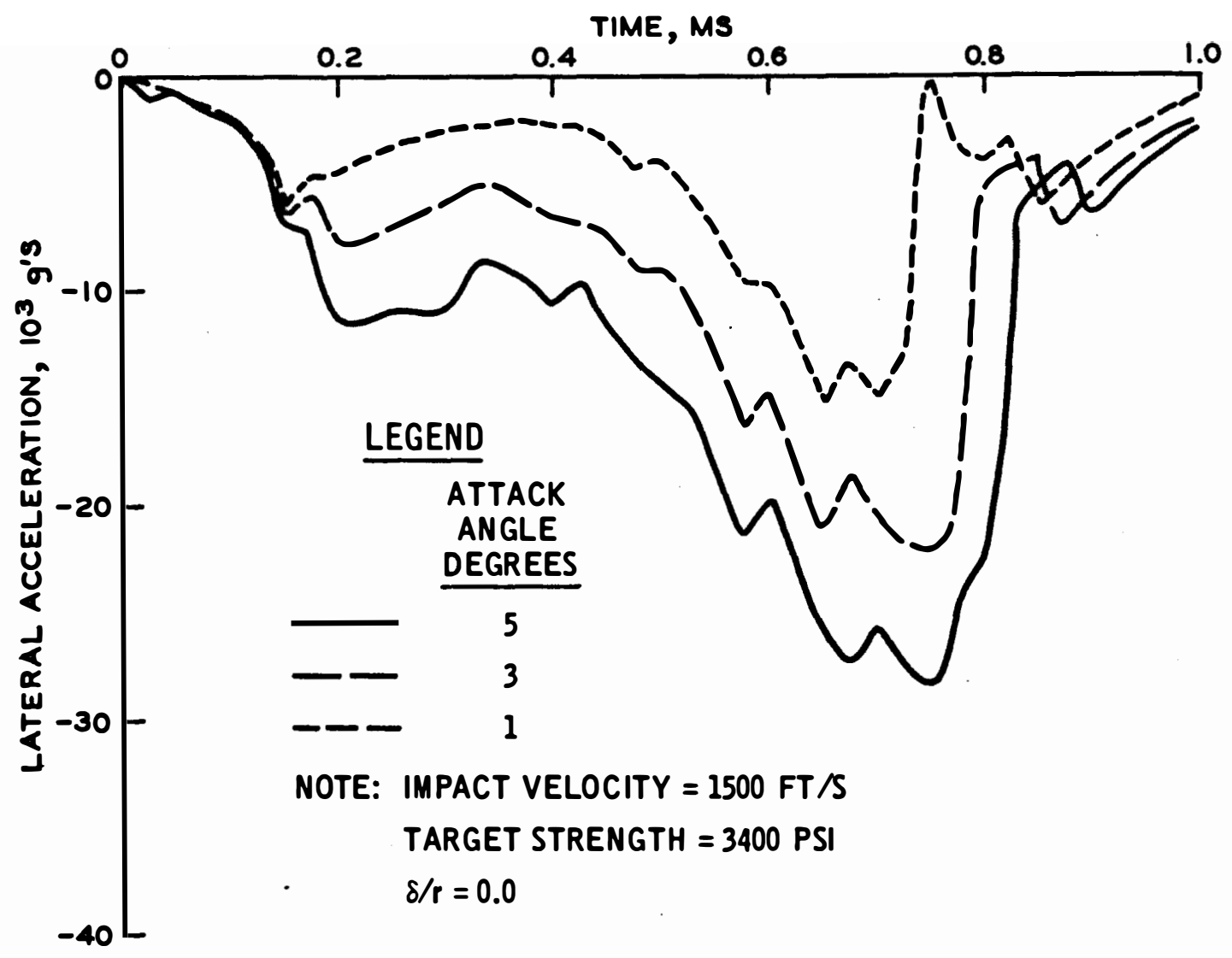

Figure 3.8 Calculated CG lateral acceleration for different angles of attack, Sandia RBT. 


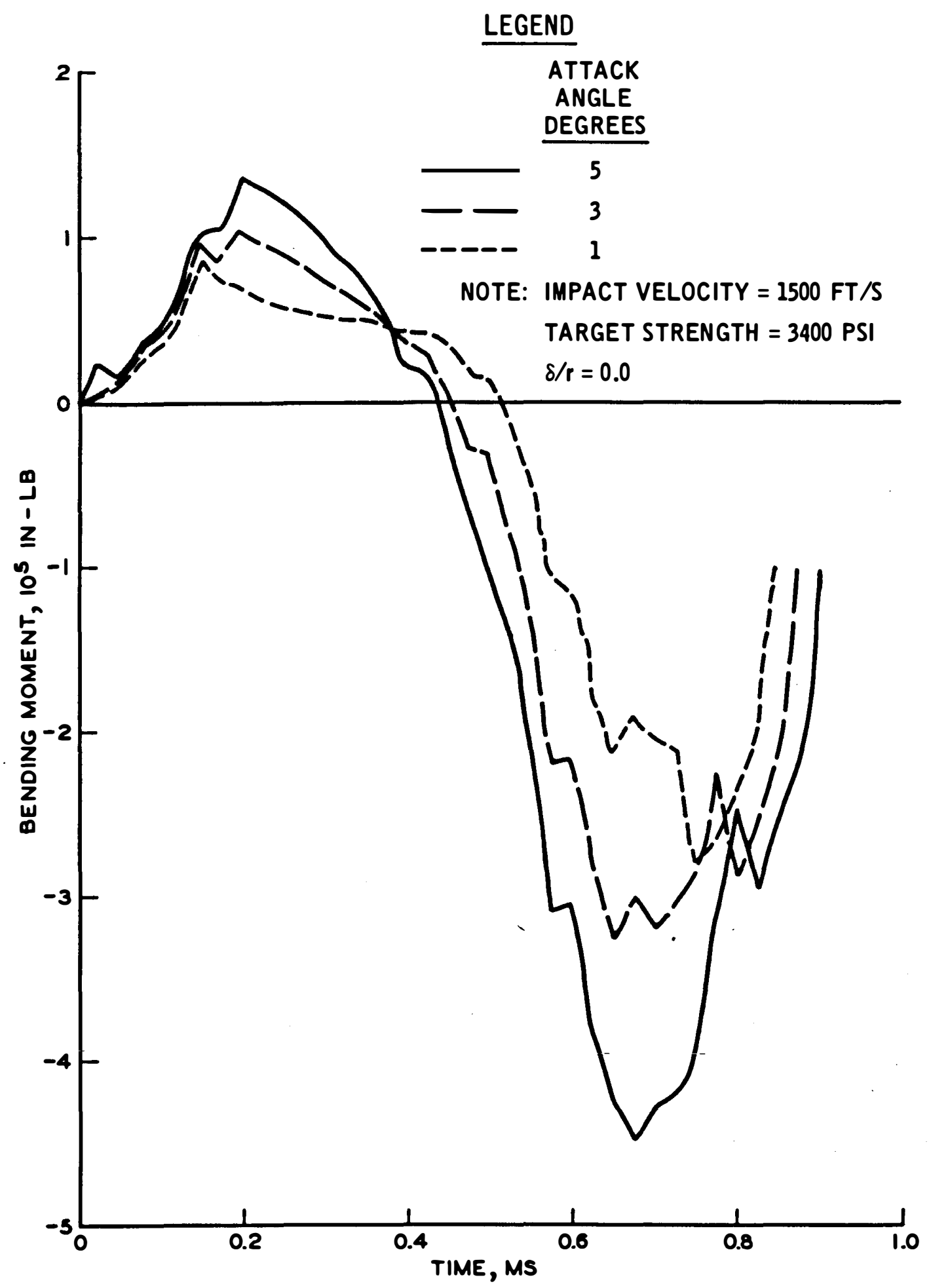

Figure 3.9 Calculated bending moment for different angles of attack, Sandia RBT, section $\mathrm{S}$. 


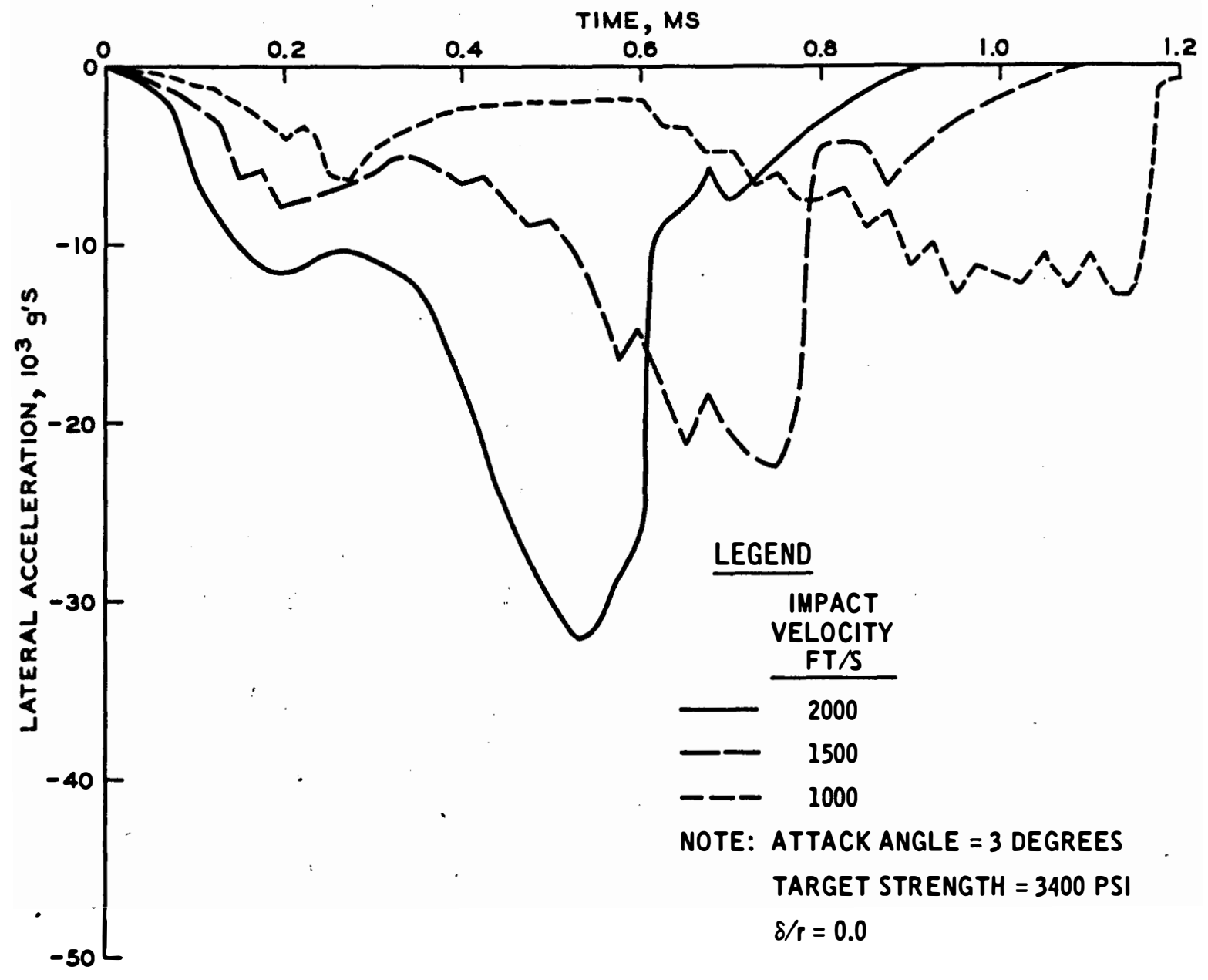

Figure 3.10 Calculated CG lateral acceleration for different impact velocities, Sandia RBT. 


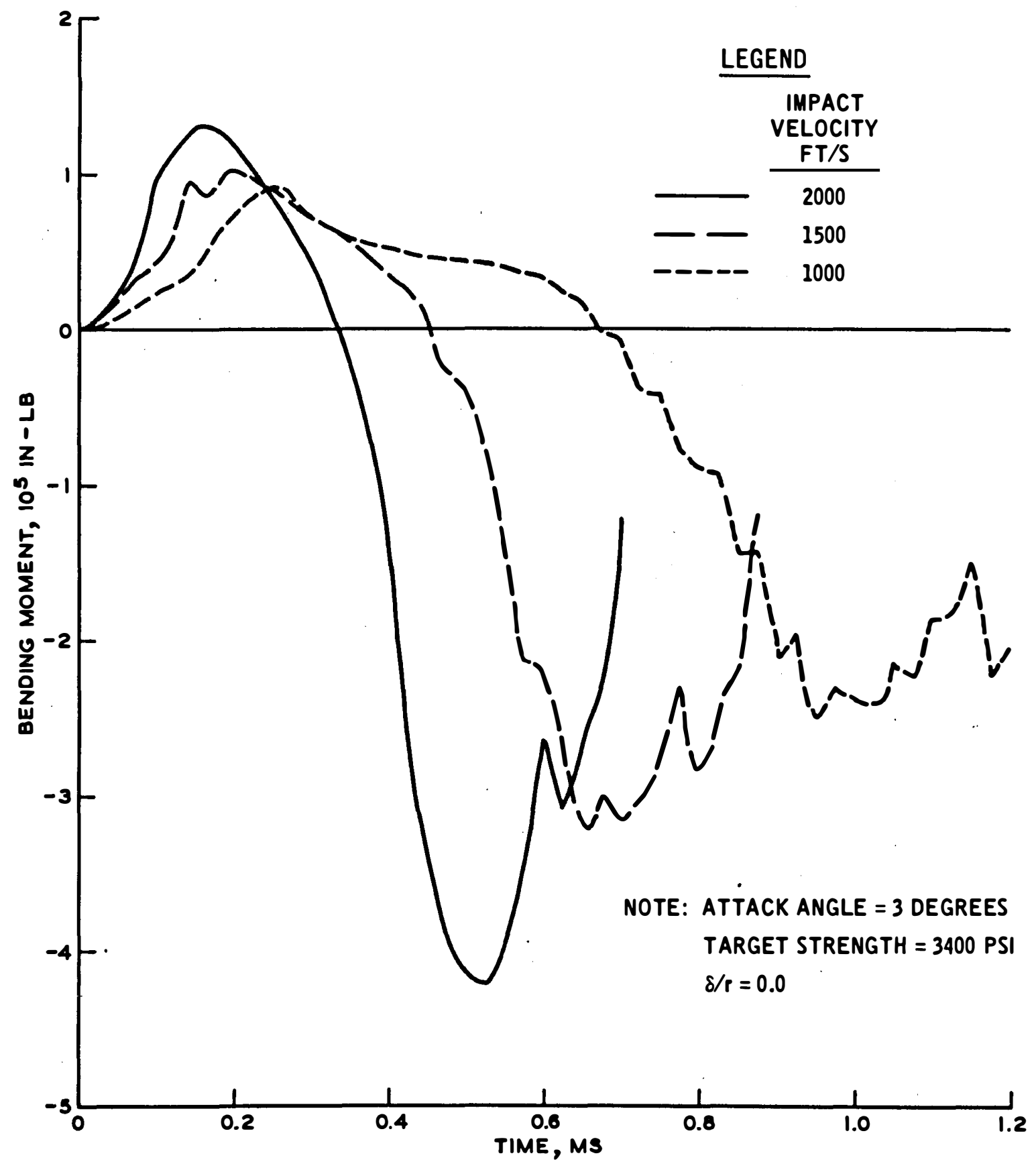

Figure 3.11 Calculated bending moment for different impact velocities, Sandia RBT, section $\mathrm{S}$. 


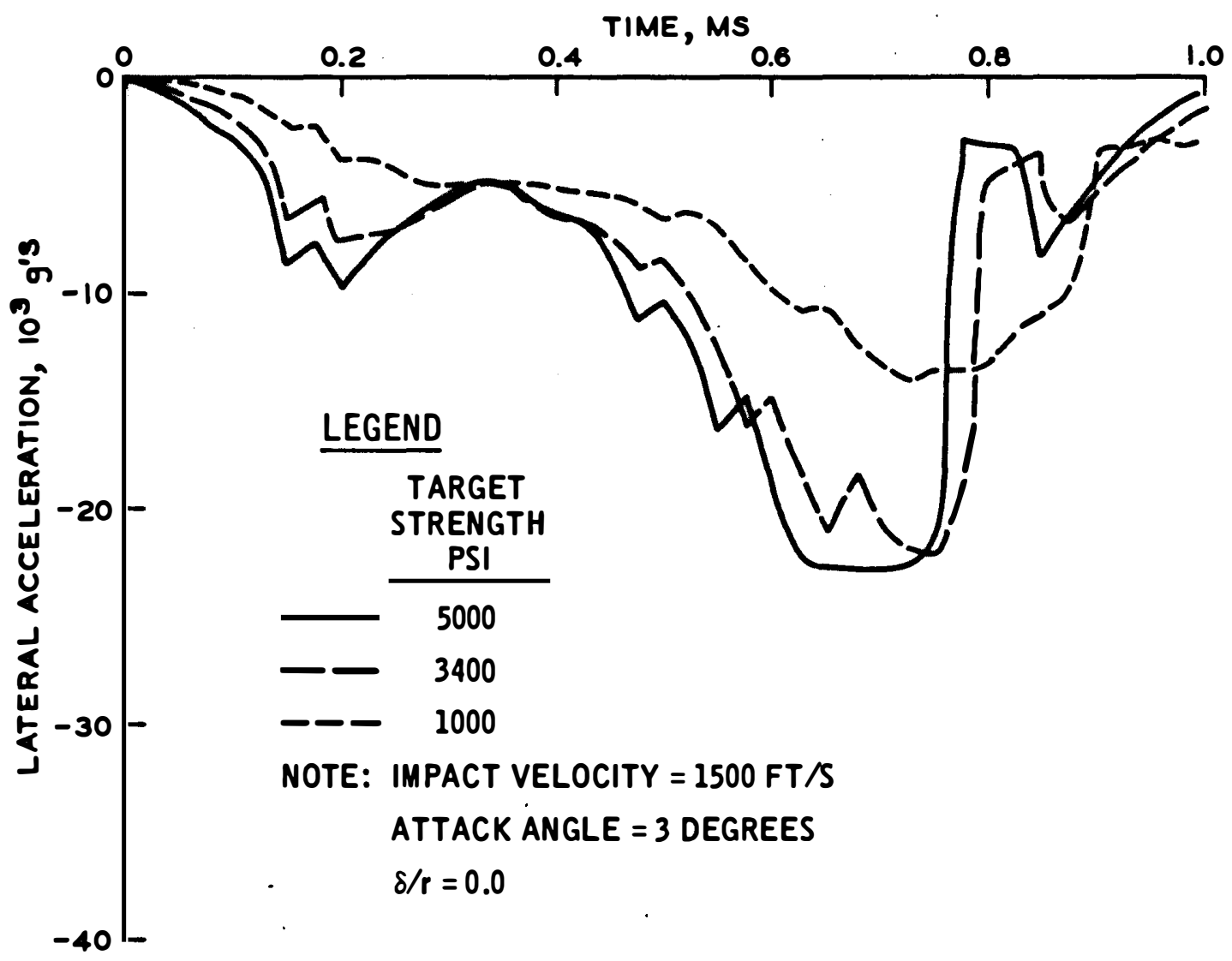

Figure 3.12 Calculated CG lateral acceleration for different values of target strength, Sandia RBT. 


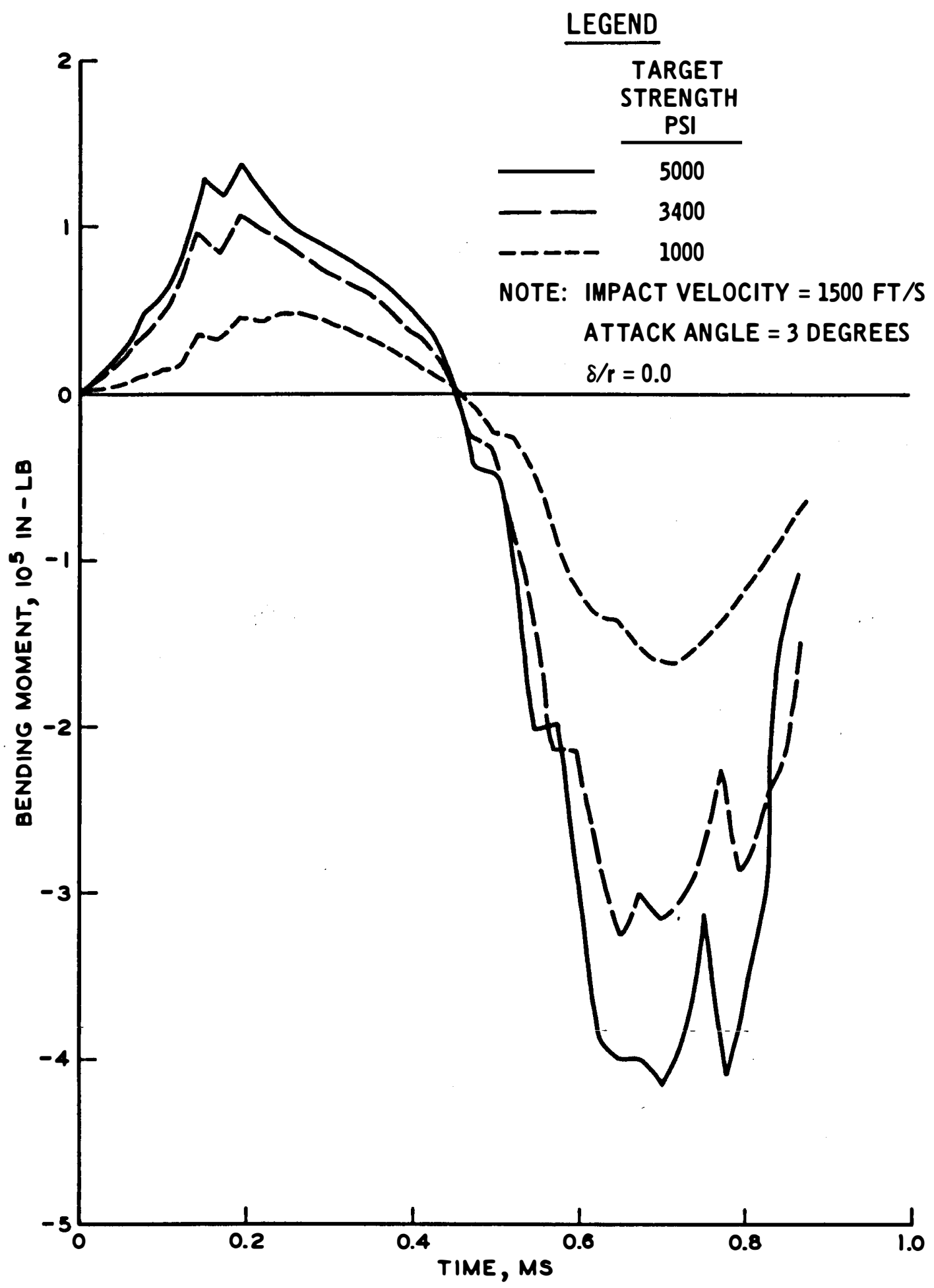

Figure 3.13 Calculated bending moment for different values of target strength, Sandia RBT, section $\mathrm{S}$. 


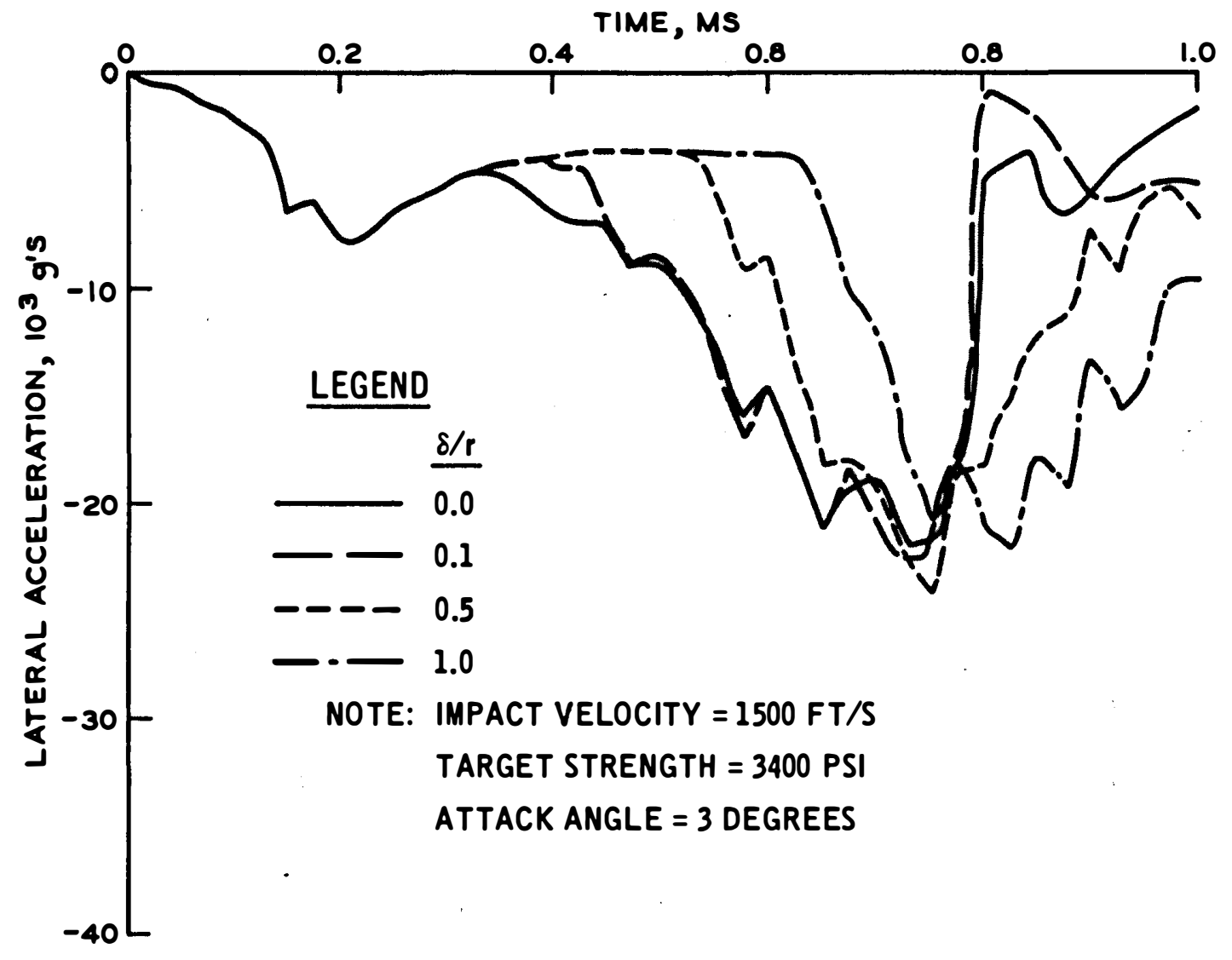

Figure 3.14 Calculated CG lateral acceleration for different amounts of wake separation, Sandia RBT. 


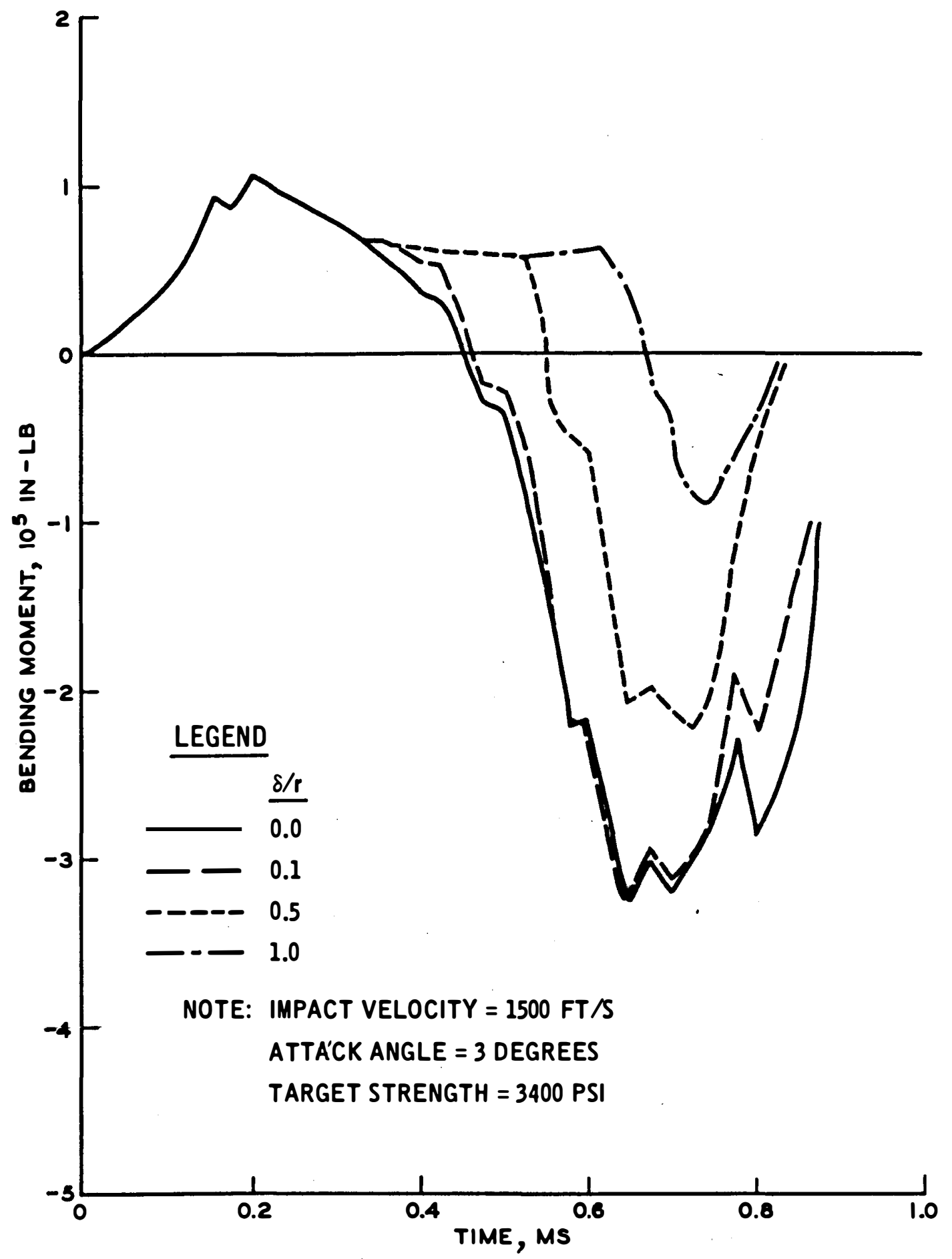

Figure 3.15 Calculated bending moment for different amounts of wake separation, Sandia RBT, section $\mathrm{S}$. 


\section{PROJECTILE}

\subsection{7-SCALE EARTH PENETRATOR}

WEIGHT $=38.2 \mathrm{LB}$

MAXIMUM DIAMETER = 3 IN

MOMENT OF INERTIA = 2160 LB-IN² (ABOUT CG)

NOSE SHAPE: 9.25 CRH OGIVE (BEVELED TIP)

$$
\begin{aligned}
& E_{p}=2.8 \times 10^{7} \mathrm{PSI} \\
& I_{s}=3.98 \mathrm{IN}^{4} \\
& A_{s}=7.07 \mathrm{IN}^{2} \\
& r_{s}=1.5 \mathrm{IN}
\end{aligned}
$$
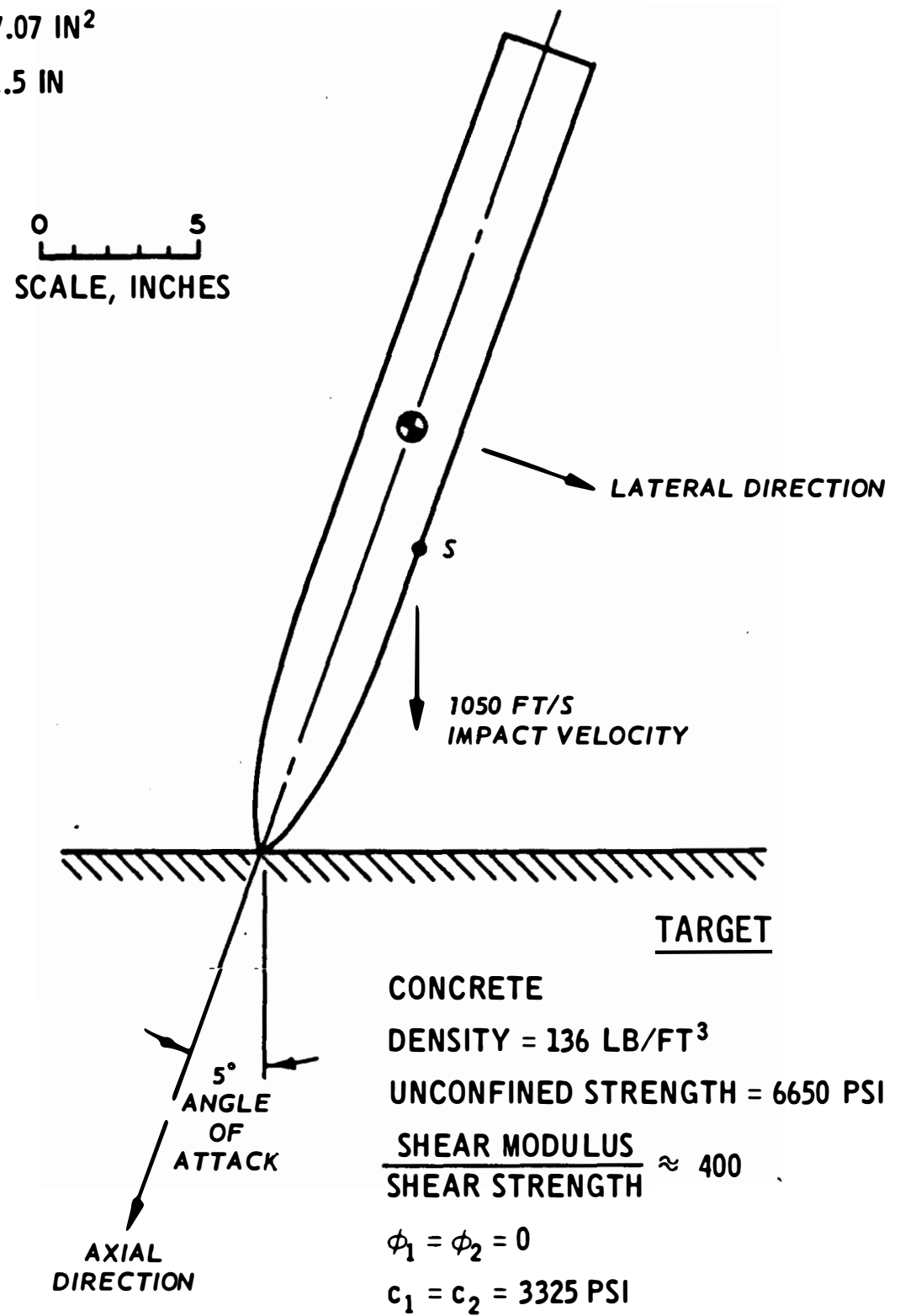

Figure 3.16 Projectile parameters, target properties, and impact conditions for AVCO 1050-ft/s RBT. 


\section{PROJECTILE}

\subsection{7-SCALE EARTH PENETRATOR}

WEIGHT $=36.6$ LB

MAXIMUM DIAMETER $=3 \mathrm{IN}$

MOMENT OF INERTIA = 1937 LB-IN $^{2}$ (ABOUT CG)

NOSE SHAPE: 9.25 CRH OGIVE (BEVELED TIP)

$E_{p}=2.8 \times 10^{7} \mathrm{PSI}$

$\mathrm{I}_{\mathrm{s}}=3.98 \mathrm{IN}^{4}$

$A_{s}=7.07 \mathrm{IN}^{2}$

$r_{s}=1.5 \mathrm{IN}$

$a=2,5,10$ DEGREES

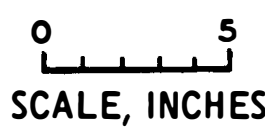

LATERAL DIRECTION

IMPACT VELOCITY
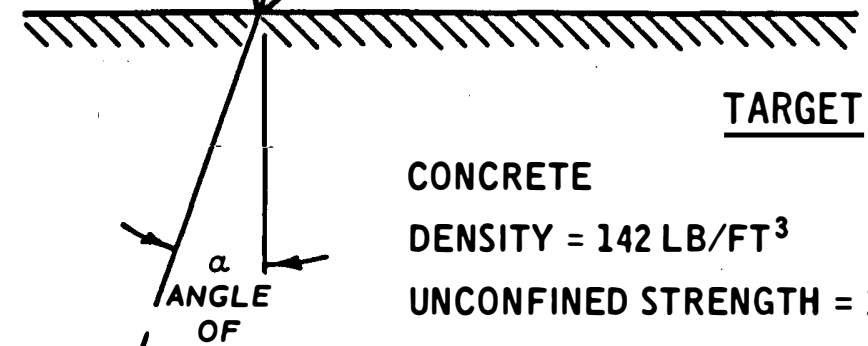

CONCRETE

DENSITY $=142 \mathrm{LB} / \mathrm{FT}^{3}$

UNCONFINED STRENGTH $=3870$ PSI

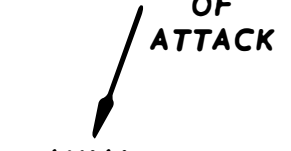

AXIAL

DIRECTION

$$
\begin{aligned}
& \frac{\text { SHEAR MODULUS }}{\text { SHEAR STRENGTH }} \approx 400 \\
& \phi_{1}=\phi_{2}=0 \\
& c_{1}=c_{2}=1935 \text { PSI }
\end{aligned}
$$

Figure 3.17 Projectile parameters, target properties, and impact conditions for AVCO 1500-ft/s RBT. 


\begin{tabular}{crrll} 
STATION & & $\begin{array}{c}\text { LOCATION } \\
\text { INCHES }\end{array}$ & & \multicolumn{1}{c}{ SIGNIFICANCE } \\
\cline { 1 - 1 } CG & & +5.78 & & NOSE BASE \\
$F$ & & 0.00 & & CENTER OF GRAVITY \\
$R$ & & +2.48 & & FORWARD ACCELEROMETER \\
$S$ & & -12.52 & & REAR ACCELEROMETER \\
$S$ & +3.70 & & STRAIN GAGE
\end{tabular}

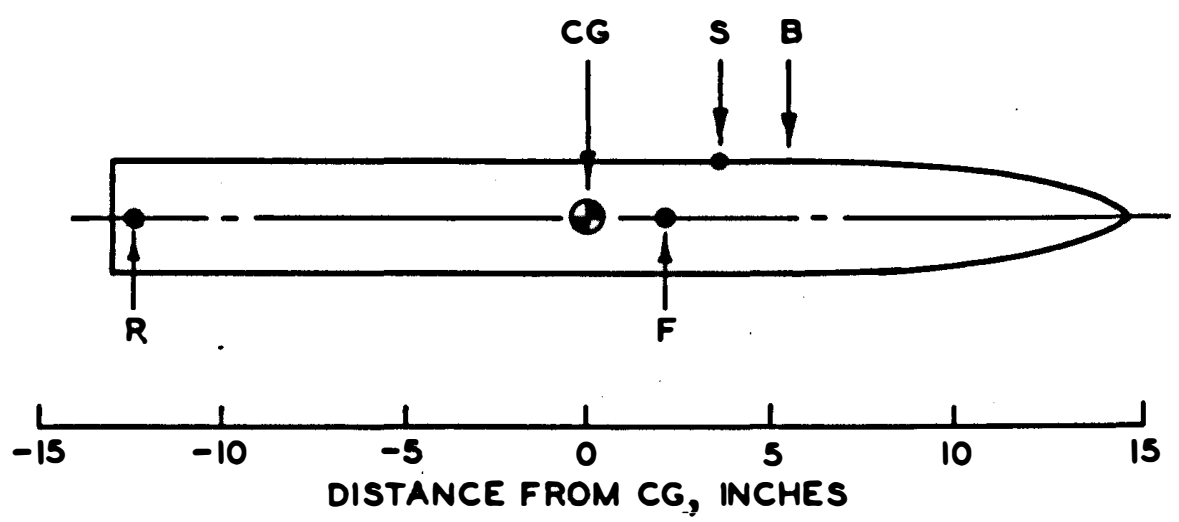

Figure 3.18 Axial location of strain gage and accelerometers for projectile used in AVCO 1050-ft/s RBT. 


\begin{tabular}{|c|c|c|}
\hline STATION & $\begin{array}{l}\text { LOCATION } \\
\text { INCHES } \\
\end{array}$ & SIGNIFICANCE \\
\hline B & 5.36 & NOSE BASE \\
\hline CG & 0.00 & CENTER OF GRAVITY \\
\hline $\mathbf{S}$ & 3.28 & STRAIN GAGE \\
\hline
\end{tabular}
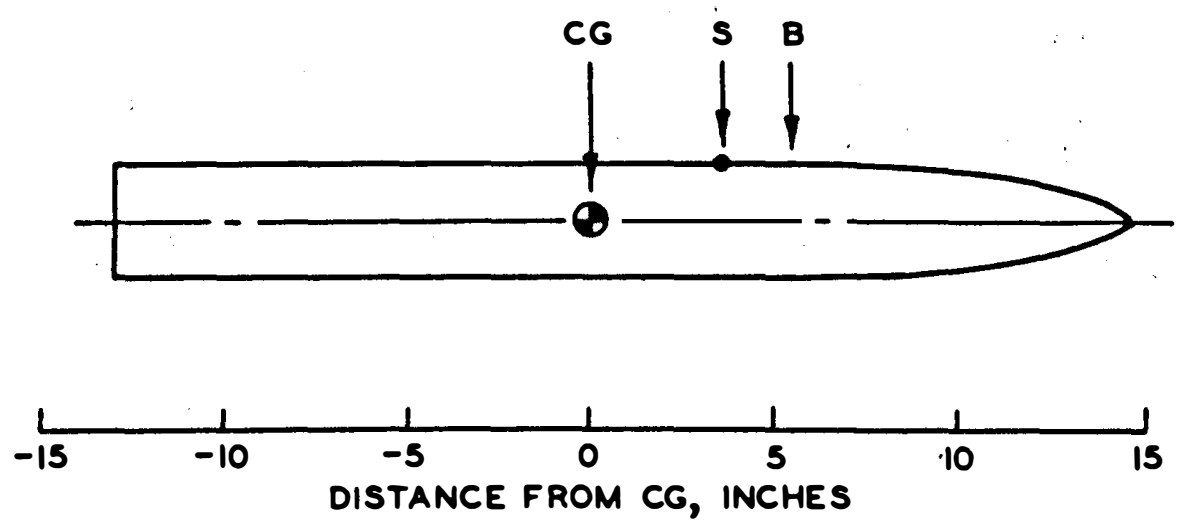

Figure 3.19 Axial location of strain gage for projectile used in AVCO 1.500-ft/s RBT. 


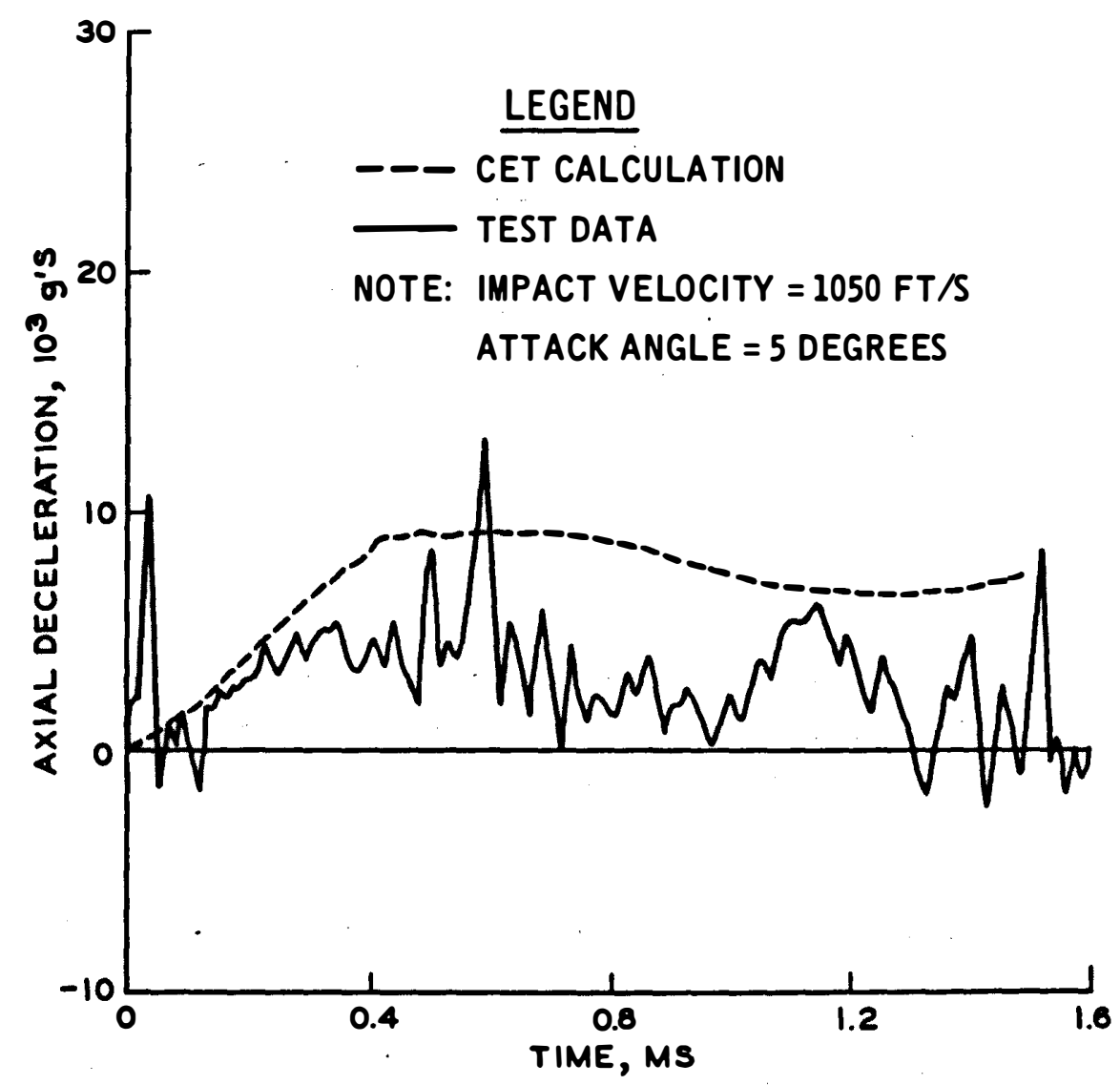

Figure 3.20 Comparison of calculated and measured axial decelerations for AVCO 1050-ft/s RBT, rear accelerometer. 


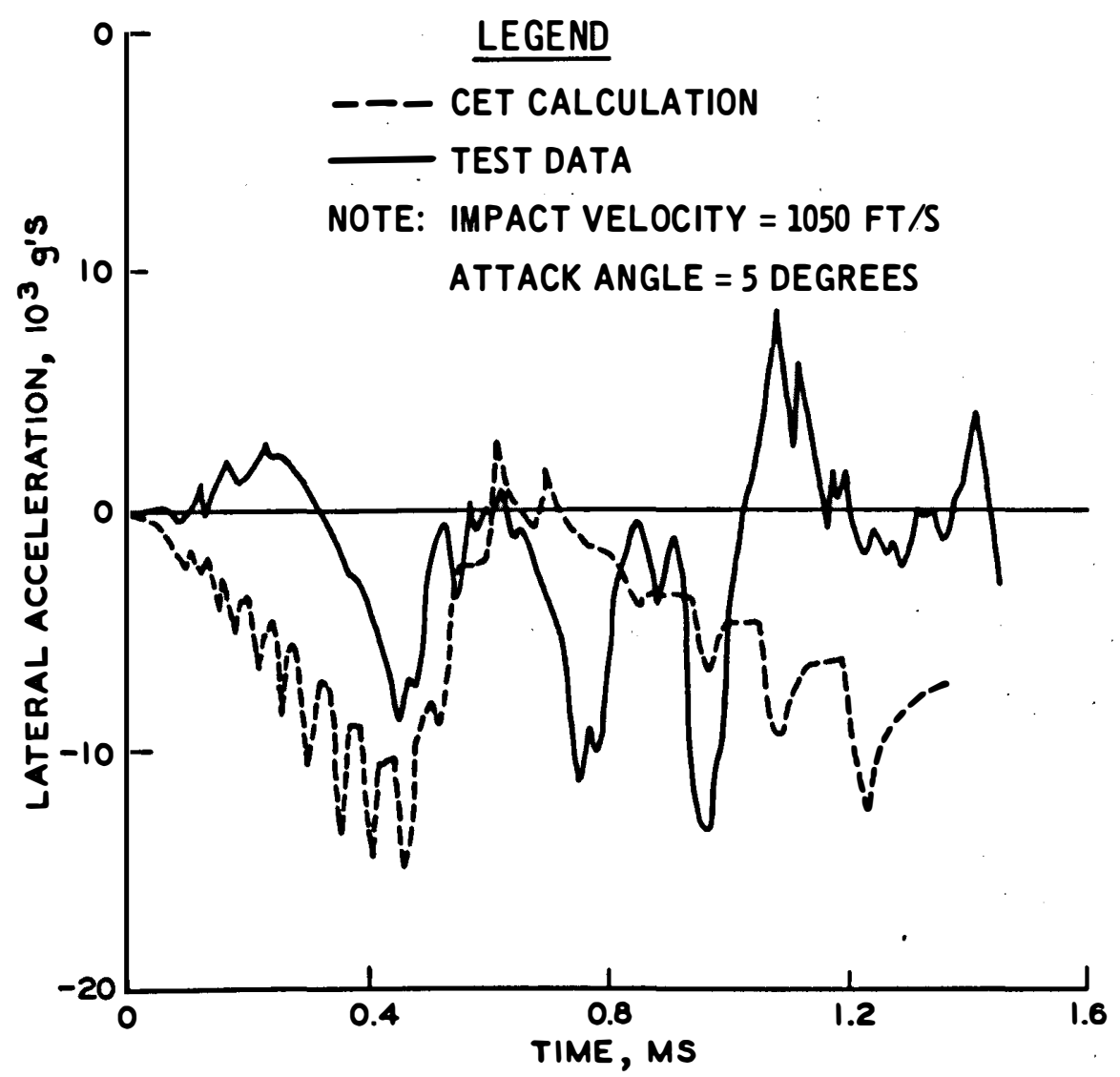

Figure 3.21 Comparison of calculated and measured lateral accelerations for AVCO 1050-ft/s RBT, forward accelerometer. 


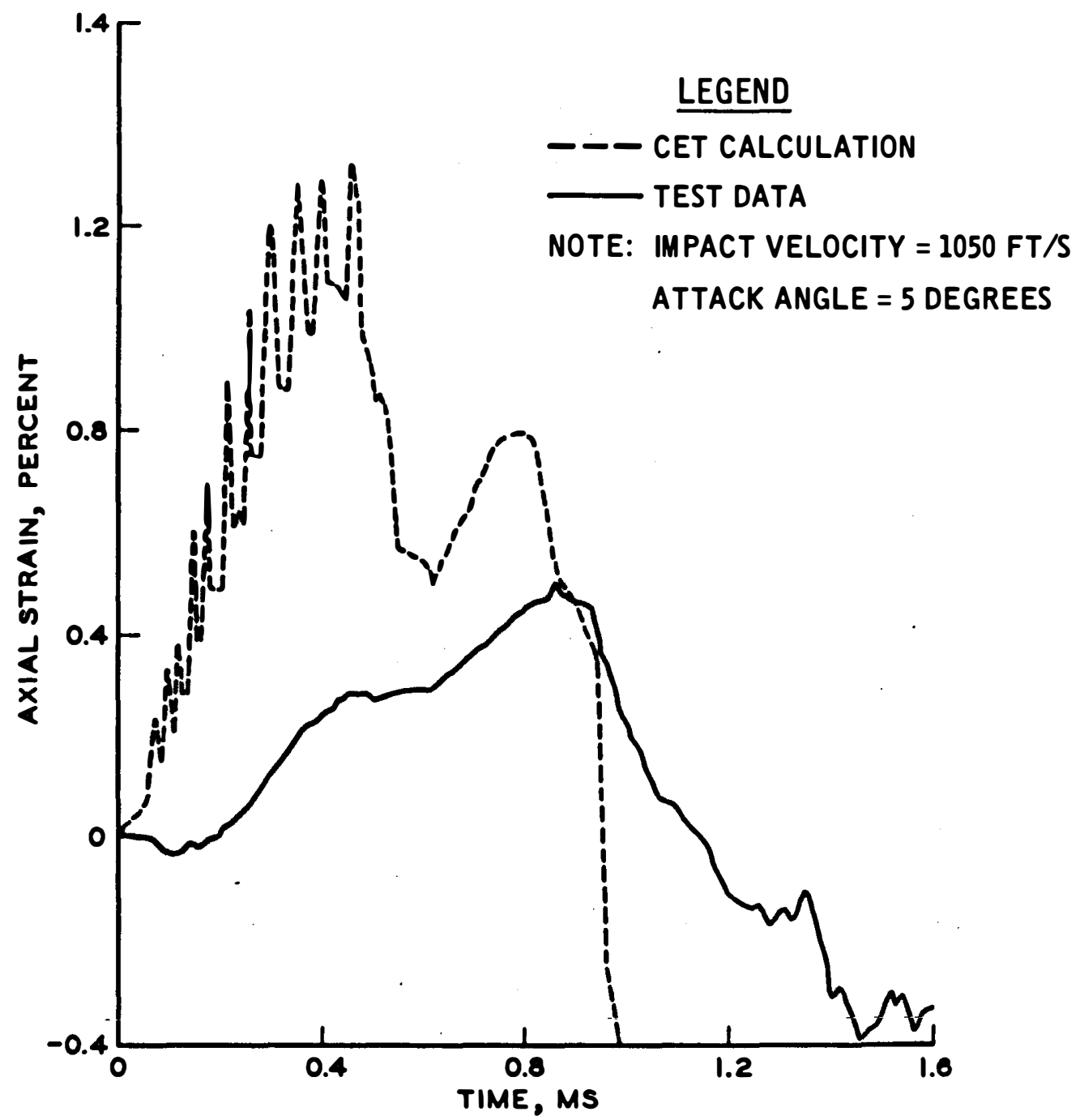

Figure 3.22 Comparison of calculated and measured strains for AVCO 1050-ft/s RBT, strain gage $S$. 


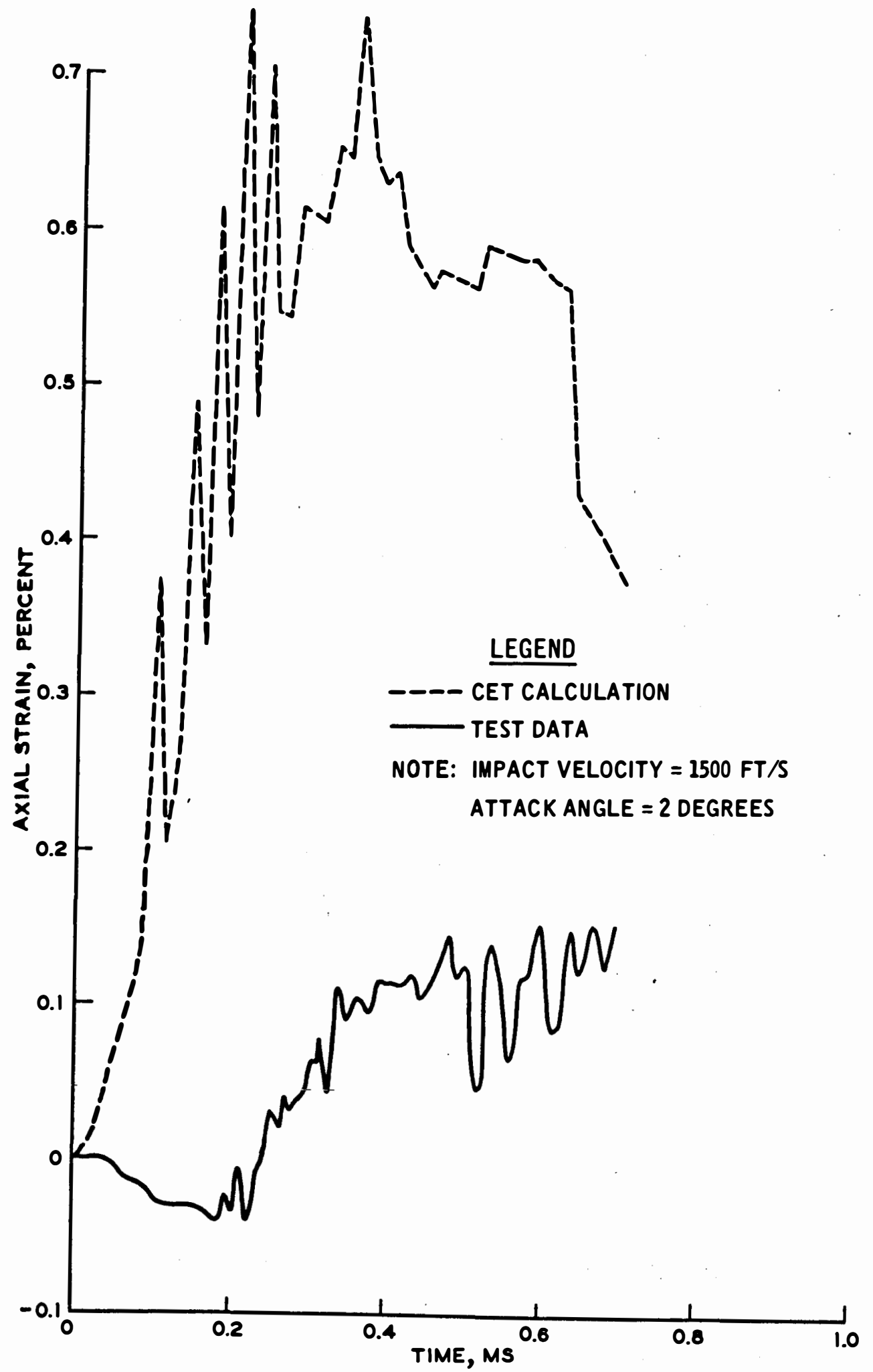

Figure 3.23 Comparison of calculated and measured strains for AVCO 2-degree RBT, strain gage $\mathrm{S}$. 


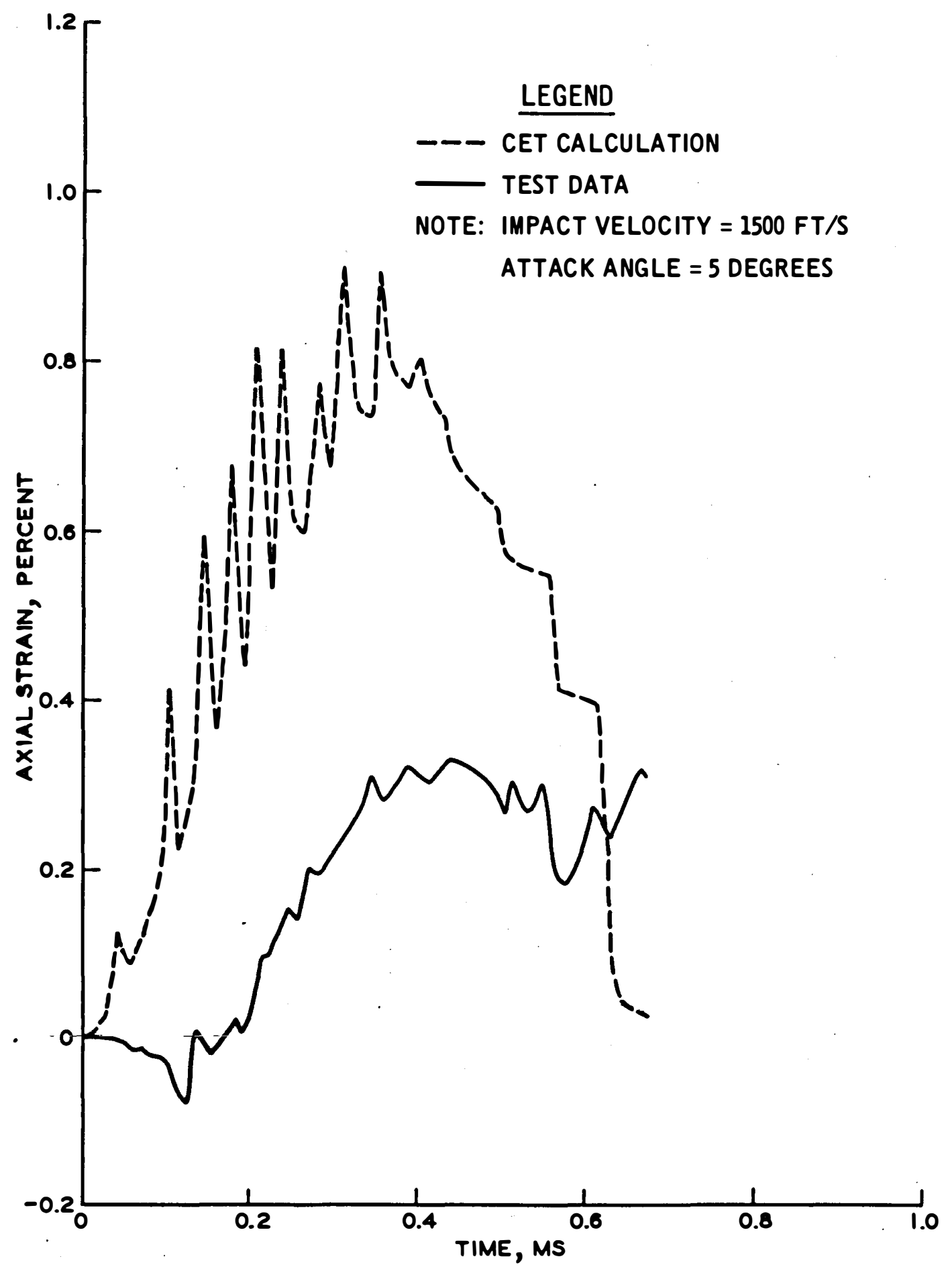

Figure 3.24 Comparison of calculated and measured strains for AVCO 5-degree RBT, strain gage $\mathrm{S}$. 


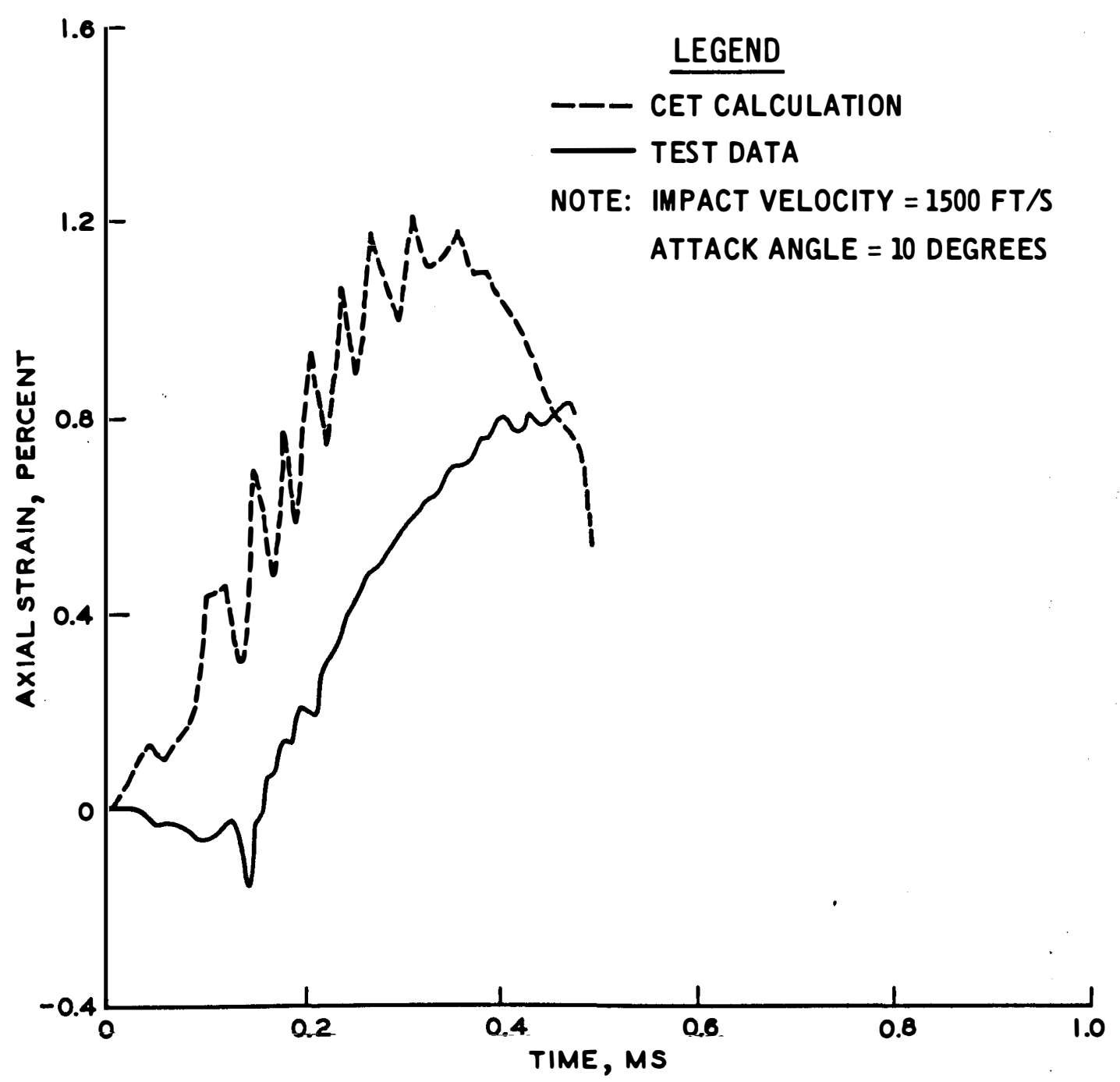

Figure 3.25 Comparison of calculated and measured strains for AVCO 10-degree RBT, strain gage $\mathrm{S}$. 


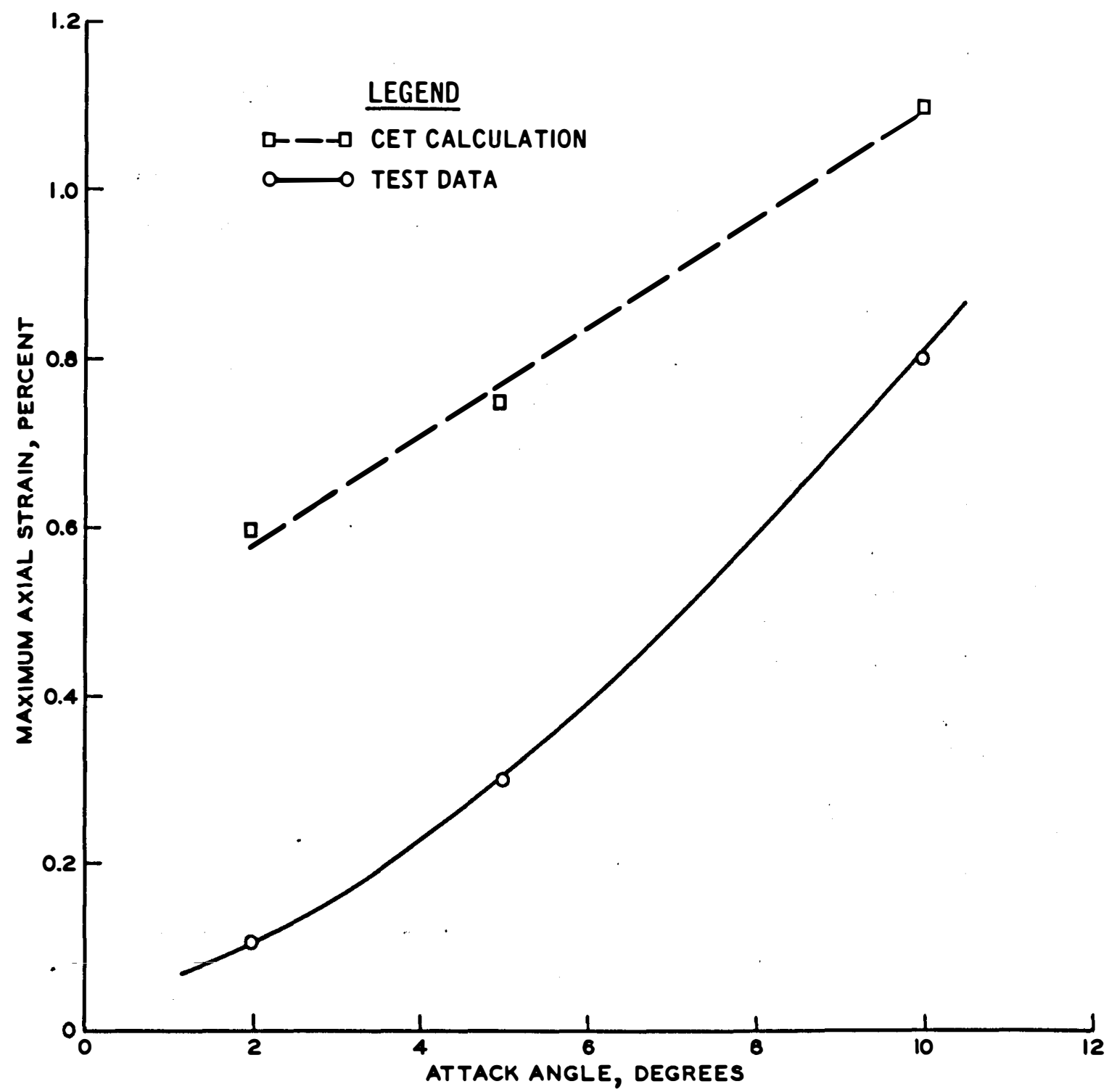

Figure 3.26 Comparison of calculated and measured strain levels for AVCO 1500-ft/s RBT, strain gage $S$. 


\section{CONCLUSIONS AND RECOMMENDATIONS}

The CET analysis for normal impact and penetration has been extended to include non-normal impact for small angles of attack (less than 10 degrees) and hard targets (such as rock and concrete). The extension was accomplished without introducing any new target parameters (empirical or otherwise), the primary assumption being that the lateral and axial force distributions can be specified separately.

The non-normal CET analysis was installed in a modified version of the AVCO DAFL code, replacing AVCO's definition of the force distribution on the projectile. The modified code was then used to make calculations for comparison with non-normal RBT data obtained by Sandia Laboratories and by AVCO Corporation.

The calculated results reproduced the Sandia data fairly well, except for a time delay. ${ }^{1}$ The calculations, however, overpredicted the AVCO strain and acceleration data by a factor of 2 to 6 , depending on the angle of attack. The AVCO targets were apparently too small to simulate the resistance of a half-space for depths greater than 40 percent of the nose length or times greater than $0.2 \mathrm{~ms}$. In the AVCO tests, the ratio of target diameter to projectile diameter was 5; in the Sandia tests, this ratio was 30 .

The agreement between the calculations and the Sandia data is encouraging, but more tests are needed to check the theory at angles of attack other than 3 degrees. If the trends observed in the AVCO tests are borne out in future tests with larger targets, then the CET analysis may require some modification. Nevertheless, the theory as it stands seems to be accurate enough for projectile design calculations in the meantime.

I The time delay is apparently caused by nonrigid projectile response to the rapidly varying applied loads. Appendix B presents the results of a dynamic structural analysis, revealing a similar internal-response time delay. 
1. F. R. Lascher, et al.; "Determination of Penetration Forcing Function Data for Impact Fuzes" (Interim Final Report, Phase I); Report No. AVSD-0074-75-RR, 15 June 1974; AVCO Corporation, Wilmington, Mass.

2. R. S. Bernard and D. C. Creighton; "Projectile Penetration in Earth Materials: Theory and Computer Analysis;" Technical Report S-76-13, February 1976; U. S. Army Engineer Waterways Experiment Station, CE, Vicksburg, Miss.

3. W. R. Kampfe; "DNA $1 / 3$ Scale Pershing Penetrator Tests;" Letter report to Defense Nuclear Agency, dated October 1977; Sandia Laboratories, Albuquerque, N. Mex.

4. D. C. Creighton; "Correlation of Reverse Ballistic Test Data;" Letter report to Defense Nuclear Agency, dated December 1977; U. S. Army Engineer Waterways Experiment Station, CE, Vicksburg, Miss.

5. "Impact and Penetration Technology: Progress Report No. 2;" Prepared for Defense Nuclear Agency, June 1975; AVCO Corporation, Wilmington, Mass.

6. "Impact and Penetration Technology: Progress Report No. 3;" Prepared for Defense Nuclear Agency, August 1975, AVCO Corporation, Wilmington, Mass.

7. D. Henderson, "Impact and Penetration Technology Program Parameter Study," Report No. DNA3921F, May 1976, AVCO Systems Division, Wilmington, Mass. 
Reference 2 documents an analysis of quasi-static spherical cavity expansion in an elastic-plastic material. ${ }^{1}$ This analysis, known as the Cavity Expansion Theory (CET), is the basis of the normal-impact penetration theory (Reference 2). For non-normal impact and penetration in hard targets, the effects of overburden and compressibility are negligible, and the basic assumptions and results of the CET are those given below.

Consider an infinite medium surrounding a spherical cavity that slowly expands from zero initial radius to instantaneous radius $a>0$. Denoting the radial and circumferential stresses ${ }^{2}$ by $\sigma_{r}$ and $\sigma_{\theta}$, respectively, the equations that describe the bilinear failure envelope $H B A$ (Figure A.I) on segments $H B$ and $B A$ are

$$
\begin{array}{ll}
\text { Segment HB: } & \sigma_{r}-\sigma_{\theta}=\left(\sigma_{r}+\sigma_{\theta}\right) \sin \phi_{1}+2 c_{1} \cos \phi_{1} \\
\text { Segment BA: } & \sigma_{r}-\sigma_{\theta}=\left(\sigma_{r}+\sigma_{\theta}\right) \sin \phi_{2}+2 c_{2} \cos \phi_{2}
\end{array}
$$

The quantities $c_{1}$ and $\phi_{1}$ are, respectively, the values of the cohesion and the internal friction angle for segment $\mathrm{HB} ; c_{2}$ and $\phi_{2}$ are the corresponding values for segment $B A$.

The material surrounding the cavity is divided into separate elastic and plastic regions, as shown in Figure A.2. Denoting the radial position by the symbol $r$, the relation between $\sigma_{r}$ and $\sigma_{\theta}$. in the region $b \leq r \leq h$ is given by Equation A.l, and the corresponding relation in the region $a \leq r \leq b$ is given by Equation A.2. The geometry is spherically symmetric, and the material equation of equilibrium is

1 Reference numbers refer to similarly numbered items in the References 2 at the end of the main text. Compressive stresses and strains are considered positive. 


$$
\frac{d \sigma_{r}}{d r}+\frac{2}{r}\left(\sigma_{r}-\sigma_{\theta}\right)=0
$$

Upon integrating Equation A.3 from $r=a$ to $r=\infty$, it is found that the radial stress $\sigma_{s}$ at the cavity wall is

$$
\begin{aligned}
\sigma_{s}= & \left(c_{2} \cot \phi_{2}-c_{1} \cot \phi_{1}\right)\left(I_{12}^{B / 3}-1\right) \\
& +\frac{c_{2} \cos \phi_{2}\left(1+\sin \phi_{1}\right)-c_{1} \cos \phi_{1}\left(1+\sin \phi_{2}\right)}{\sin \phi_{1}-\sin \phi_{2}}
\end{aligned}
$$

where

$$
\begin{gathered}
I_{12}=\frac{I_{1}}{I_{2}^{3 / \gamma}} \\
\gamma=\frac{4 \sin \phi_{1}}{1+\sin \phi_{1}} \\
B=\frac{4 \sin \phi_{2}}{1+\sin \phi_{2}} \\
I_{1}=\left(\frac{3}{2} \varepsilon_{*}\right)^{-1} \\
I_{2}=\frac{\left(3-\sin \phi_{1}\right)\left[c_{2} \cos \phi_{2}-c_{1}\left(1+\cot \phi_{1}\right) \sin \phi_{2}\right]}{3\left(\sin \phi_{1}-\sin \phi_{2}\right) c_{1} \cot \phi_{1}}
\end{gathered}
$$

The quantity $I_{1}$ is the material rigidity index, and $\varepsilon_{*}$ is the radial strain at the onset of plastic behavior (which is the same as the axial strain to failure in a triaxial compression test).

The von Mises condition $\left(c_{1}=c_{2} \equiv c, \phi_{1}=\phi_{2}=0\right)$ is the simplest failure condition for which Equation A.4 is applicable. In this case, 
the expression for $\sigma_{s}$ reduces to

$$
\sigma_{s}=\frac{4}{3} c\left(I+\ln I_{1}\right)
$$

If the material is governed by the linear Mohr-Coulomb condition $\left(c_{1}=c_{2} \equiv c, \phi_{1}=\phi_{2} \equiv \phi>0\right)$, then Equation A. 4 becomes

$$
\sigma_{s}=\frac{3(1+\sin \phi)\left(I_{1}^{\gamma / 3}-1\right)}{3-\sin \phi} c \cot \phi
$$

The failure criterion for some materials may be best approximated using a bilinear condition in which $\phi_{1}>0$ and $\phi_{2}=0$ (von Mises limit). When this situation arises, the expression for $\sigma_{s}$ simplifies to

$$
\sigma_{s}=\frac{c_{2}\left(1+\sin \phi_{1}\right)-c_{1} \cos \phi_{1}}{\sin \phi_{1}}+\frac{4}{3} c_{2} \ln I_{12}
$$

If $I_{12} \leq 1$ (when $0<c_{1}<c_{2}, 0<\phi_{2}<\phi_{1}$ ), then the entire plastic region is governed by segment $\mathrm{HB}$ of the failure envelope. In this case, $c$ is set equal to $c_{1}, \phi$ is set equal to $\phi_{1}$, and $\sigma_{s}$ is given by Equation A.1l. 


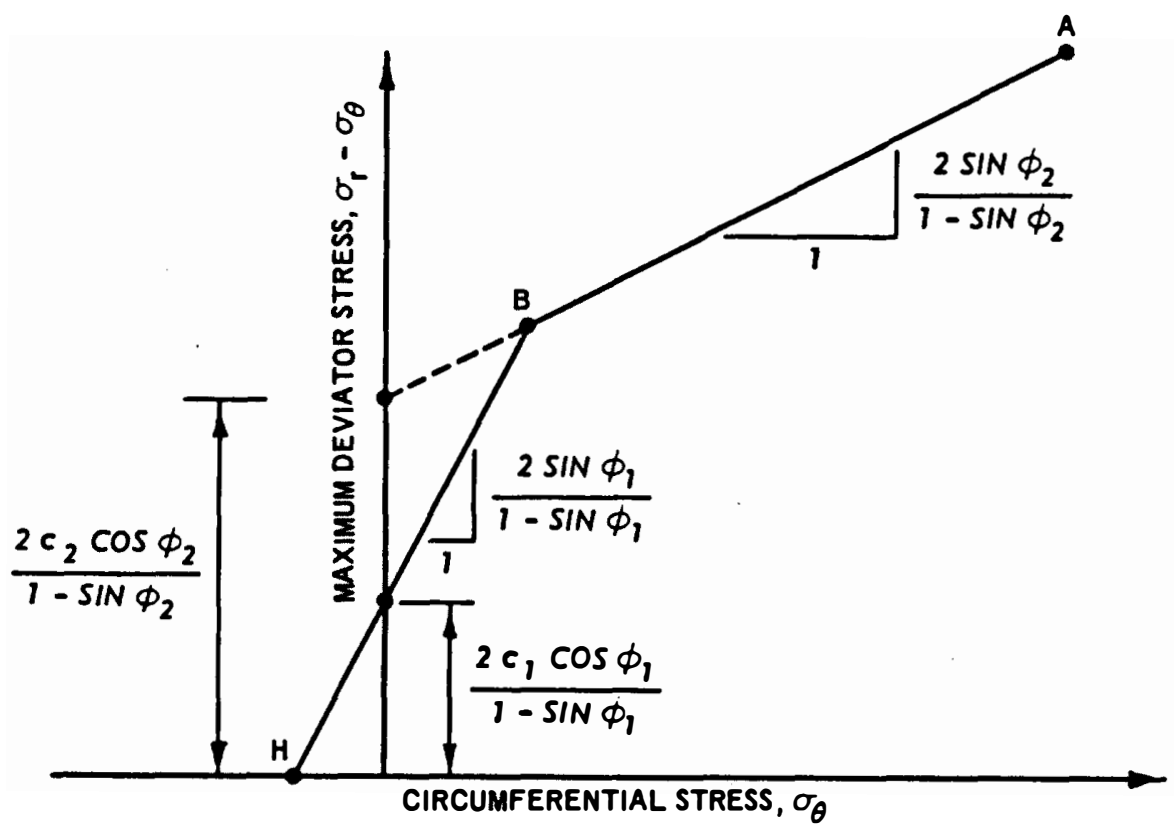

Figure A.l Bilinear failure envelope.

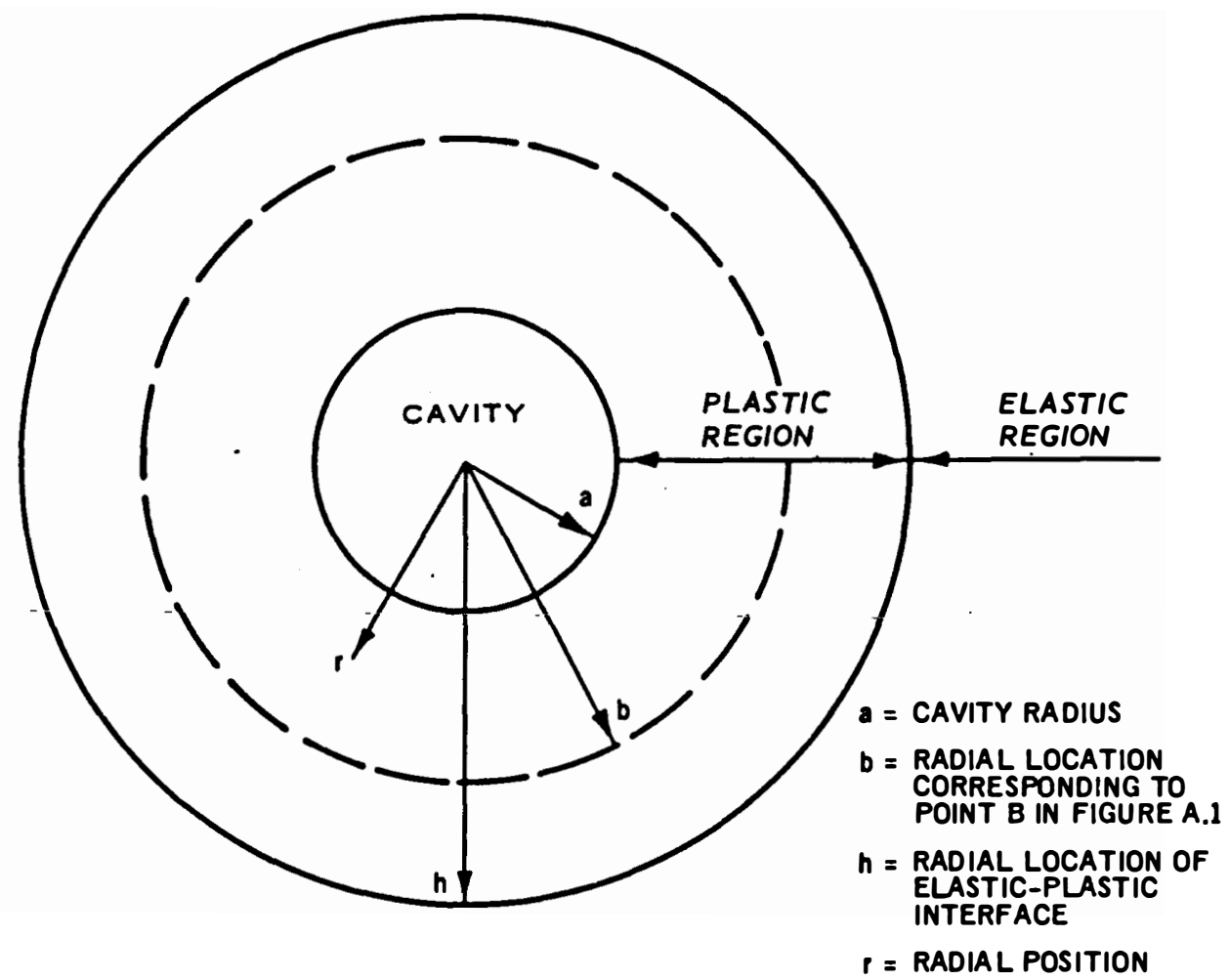

Figure A.2 Slowly expanding spherical cavity in an infinite elastic-plastic medium. 


\section{APPENDIX B}

\section{NONRIGID PROJECTILE RESPONSE}

Chapter 3 discusses briefly projectile deformation under static load, ignoring the complications introduced by a rapidly changing (dynamic) load. Although dynamic structural-response analysis is beyond the scope of Chapters 2 and 3, it seems to explain in part the time delay in the RBT data.

T. Belytschko ${ }^{1}$ has used the CET-calculated external loads in a lumped-parameter computer code, calculating dynamic projectile response for the 3-degree Sandia RBT's. Figures B.I and B.2 show Belytschko's lateral-acceleration results compared with the original rigid-body calculations (Chapter 3). A time delay is clearly evident in the nonrigid response for the rear accelerometer.

A comparison of the nonrigid calculations with the test data (Figures B.3 through B.5) shows that the predicted initial response is indeed closer to the measured initial response than are the rigid-body calculations. The late-time accelerations, however, are still out of phase with the data. The best agreement occurs for the axial strain data (Figure B.5).

These nonrigid response calculations do not fully reconcile the CET predictions with the RBT data. Nevertheless, the appearance of a time delay (due solely to nonrigidity) in the calculations is evidence that the delays observed in Chapter 3 probably arise from the same source.

1 Personal communication dated June 1978 from T. Belytschko, Inc., Chicago, Ill., to R. Bernard, Soil Dynamics Division, Soils and Pavements Laboratory. 


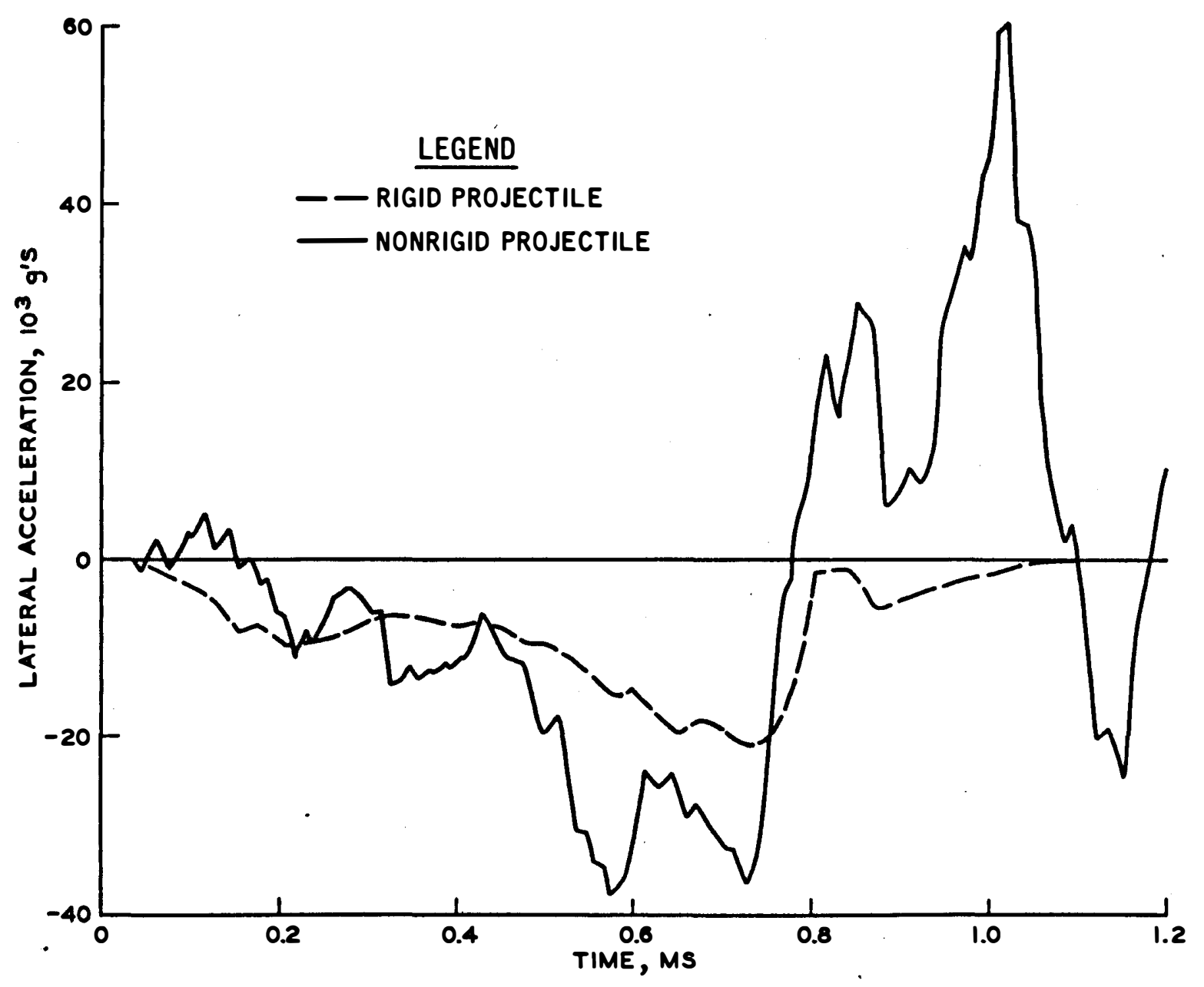

Figure B.I Comparison of rigid and nonrigid projectile-response calculations for forward accelerometers, Sandia RBT. 


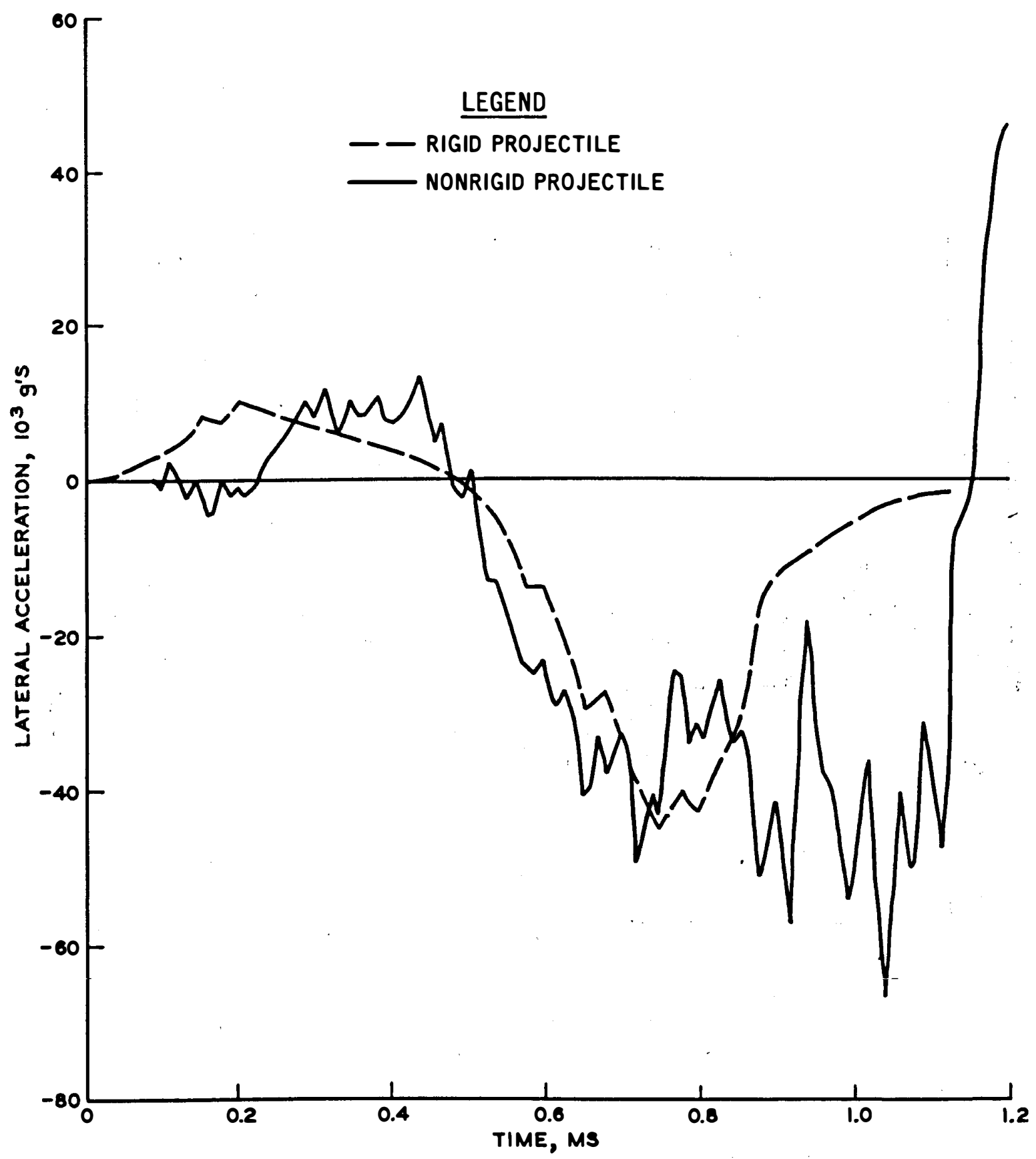

Figure B.2 Comparison of rigid and nonrigid projectile-response calculations for rear accelerometer, Sandia RBT. 


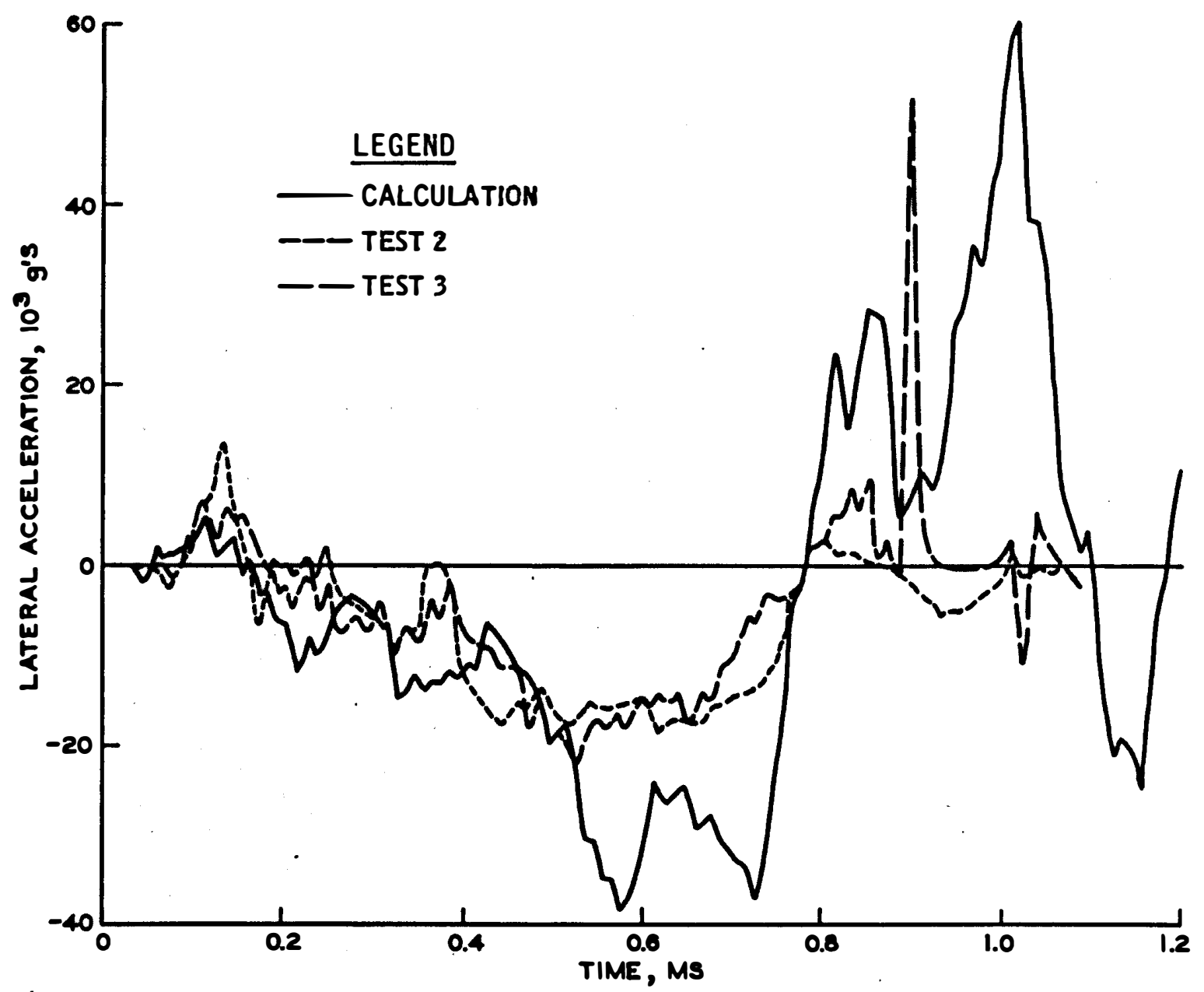

Figure B.3 Comparison of measured lateral accelerations with dynamic structural-response calculation for forward accelerometer, Sandia RBT. 


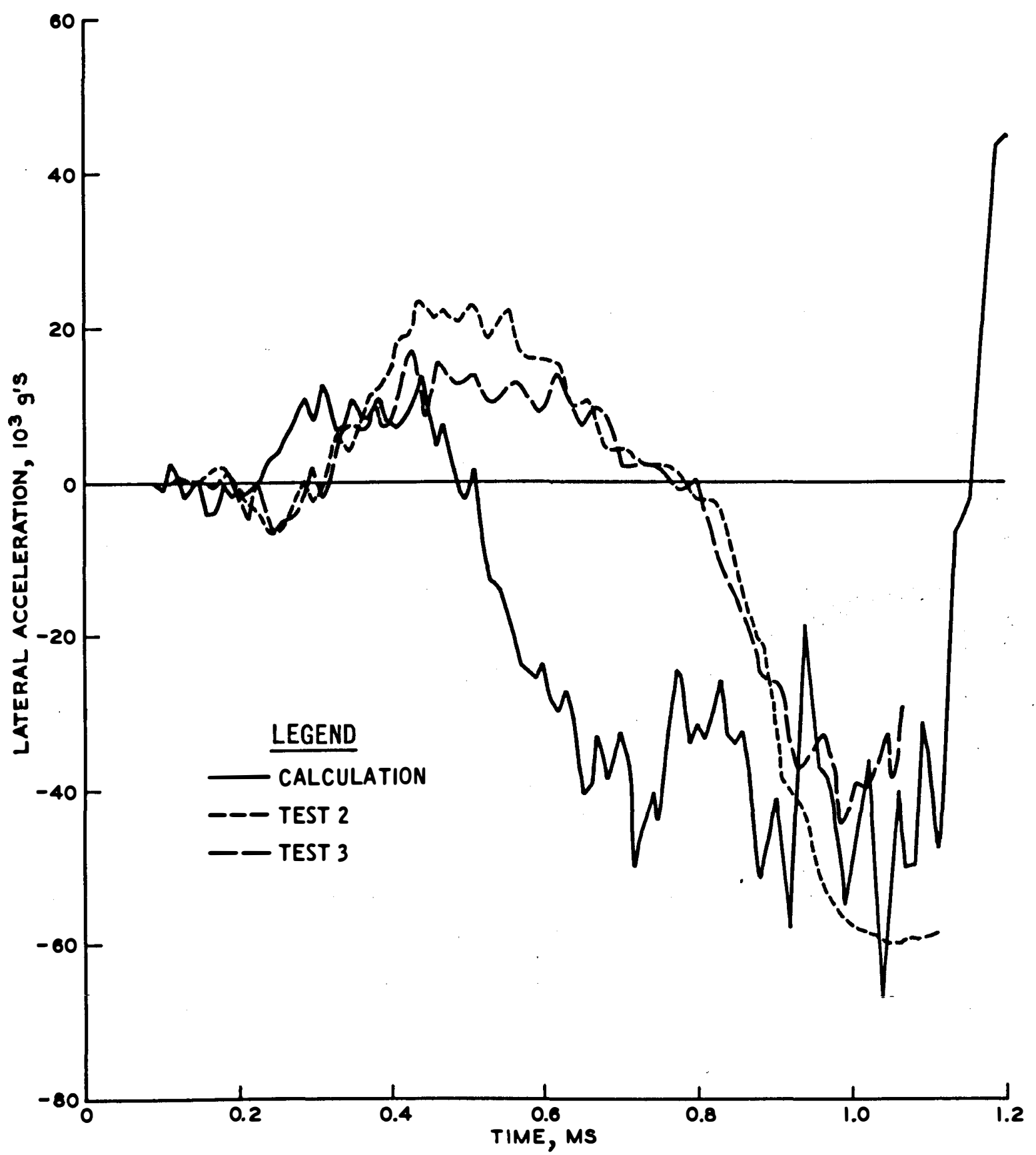

Figure B.4 Comparison of measured lateral accelerations with dynamic structural-response calculation for rear accelerometer, Sandia RBT. 


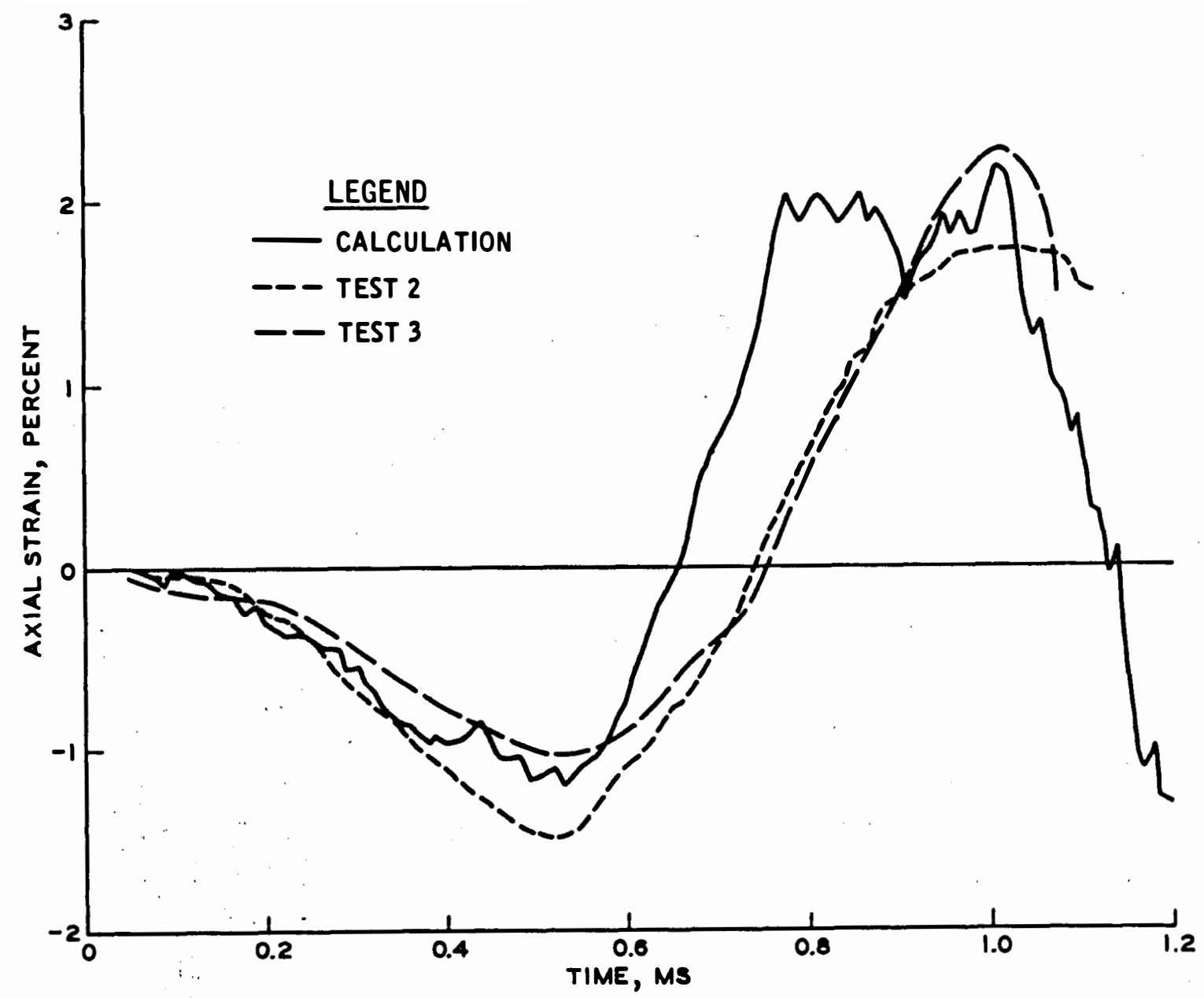

Figure B.5 Comparison of measured axial strains with dynamic structural-response calculation for strain gage S, Sandia RBT. 


\section{APPENDIX C \\ COMPARISON OF CET AND AVCO CALCULATIONS}

At present, the AVCO DAFL seems to be the only viable alternative to the CET analysis for calculating non-normal projectile loads. Although the DAFL formulation is quite different from the CET analysis, it is worthwhile to compare the predictions of the two for the same projectile, target, and impact conditions.

D. Henderson of AVCO has conducted an extensive parameter study (Reference 7) with the DAFL. The baseline projectile and concrete target from this study have been chosen for comparison of DAFL and CET predictions. The projectile parameters are shown in Figure C.l. The nominal properties of the concrete are as follows: $Y=5000 \mathrm{psi}, \rho=$ $4.66 \mathrm{slug} / \mathrm{ft}^{3}$, and $E=3 \times 10^{6} \mathrm{psi}$.

Figure C.2 compares the results for maximum lateral CG acceleration versus angle of attack. In these calculations, the CET analysis consistently overshoots the AVCO results by about 50 percent. The discrepancy, however, is in the absolute magnitude of the acceleration; the slope of the curves is about the same for the same impact velocity.

Since mechanical properties are usually more readily obtainable than are AVCO's empirical target parameters, the CET analysis is the easier method to use for before-the-fact calculations in untried targets. Nevertheless, when used by an experienced analyst such as Henderson, the DAFL has generally proved to be capable of accurate predictions. Both methods should be used whenever possible. 


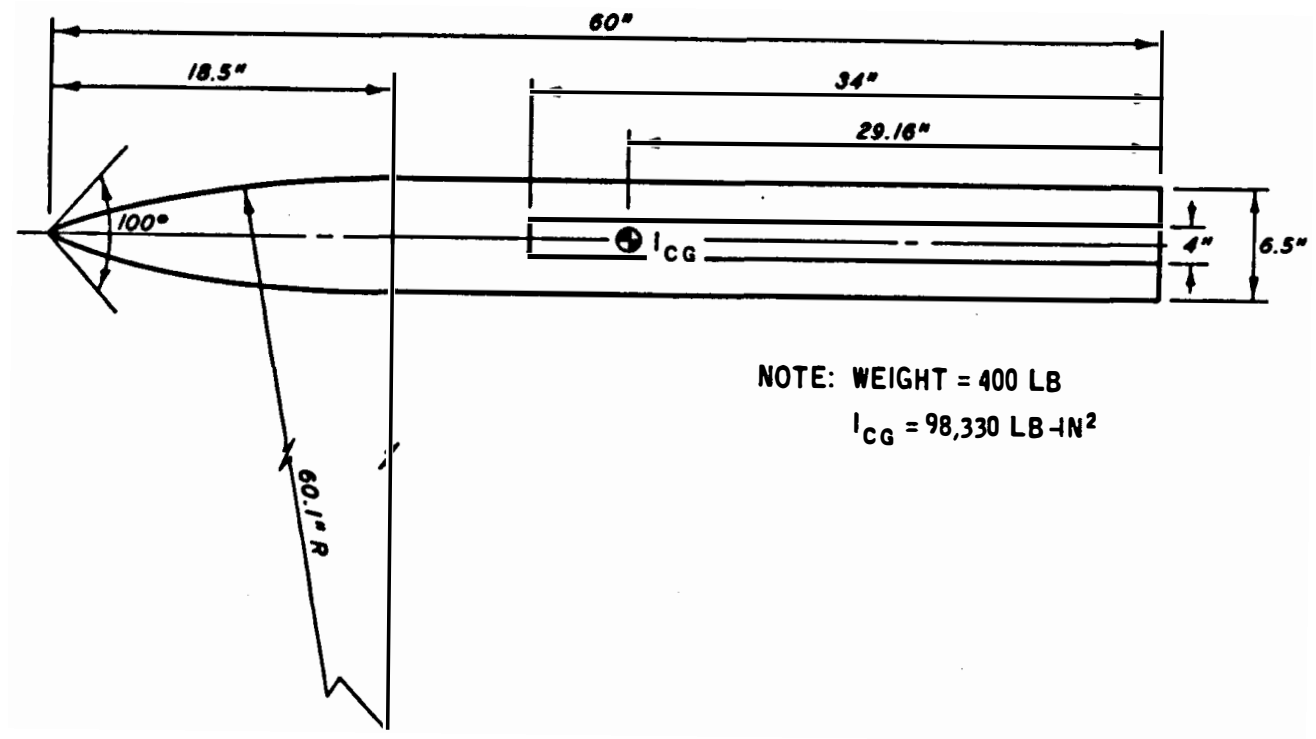

Figure C.I Baseline AVCO projectile parameters. 


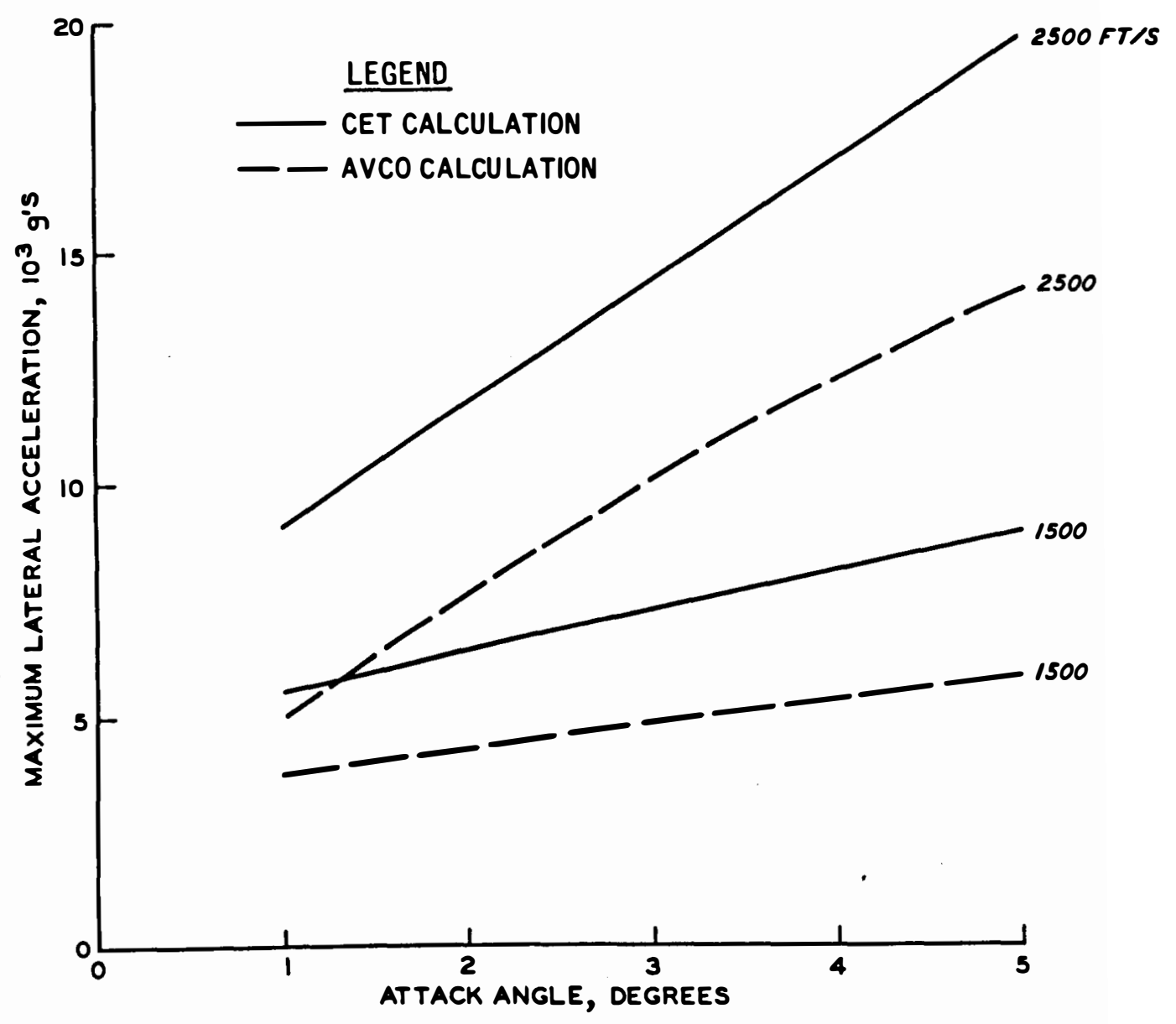

Figure C.2 Comparison of AVCO and CET calculations of lateral acceleration. 
a Spherical cavity radius

A Surface area

$A_{S} \quad$ Cross-sectional area of projectile at section $S$

b Radial position corresponding to break point on bilinear failure envelope

c Material cohesion

$c_{1}, c_{2}$ Value of cohesion describing bilinear failure envelope

CG Center of gravity

dA Differential surface area

$\mathrm{dM}(\mathrm{z})$ Point distribution of mass along the projectile axis

E Young's modulus for target

$E_{p} \quad$ Young's modulus for projectile

$f_{x} \quad$ Lateral component of internal force

$f_{z}$ Axial component of internal force

$\mathrm{F}_{\mathrm{x}} \quad$ Lateral component of external force

$\mathrm{F}_{\mathrm{z}}$ Axial component of external force.

$\mathrm{h}$ Radial location of elastic-plastic interface

$I_{C G}$ Mass moment of inertia about CG

$I_{S} \quad$ Area moment of inertia of projectile cross section $S$

$I_{1}$ Material rigidity index ( $=2 \mathrm{E} / 3 \mathrm{Y}$ for incompressible von

L Projectile length

M Projectile mass

$r$ Local aftbody radius; radial position in the CET 
$r_{\mathrm{S}} \quad$ Projectile radius at section $\mathrm{S}$

s Axial distance from any point on aftbody to base of nose

$\mathrm{v}_{\mathrm{x}} \quad$ Local lateral velocity

$v_{z} \quad$ Local axial velocity

$\mathrm{V}_{\mathrm{x}} \quad$ Lateral component of $\mathrm{CG}$ velocity

$\mathrm{V}_{\mathrm{z}}$ Axial component of CG velocity

$\mathbf{x}$ Lateral distance from $\mathbf{C G}$

$\mathrm{X}$ Horizontal distance from origin fixed in target

$\ddot{\mathrm{X}}, \ddot{\mathrm{Z}} \quad$ Components of acceleration in the $\mathrm{X}$ - and $\mathrm{Z}$-directions, respectively

Y Unconfined compressive strength

z Axial distance (forward) from CG

$z_{n} \quad z$-coordinate of the nose tip

$\mathbf{z} \dot{\theta} \quad$ Lateral velocity due to pure rotation

Z Vertical distance from origin fixed in target

$\alpha \quad$ Angle of attack

$\Gamma \quad$ Bending moment

$\delta \quad$ Wake-separation gap width

$\varepsilon_{\text {a }} \quad$ Axial strain

$\varepsilon_{*}$ Compressive radial strain at failure

$\eta \quad$ Angle between projectile surface and projectile axis

$\theta$ Angle of rotation

$\dot{\theta}$ Angular velocity

$\ddot{\theta}$ Angular acceleration

$\xi \quad$ Variable of integration

p Target mass density 


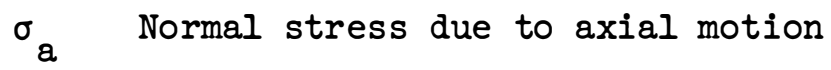

$$
\begin{aligned}
& \sigma_{\mathrm{r}} \quad \text { Radial stress } \\
& \sigma_{\mathrm{s}} \quad \text { Radial compressive stress at surface of slowly expanding } \\
& \text { spherical cavity } \\
& \sigma_{\mathrm{x}} \quad \text { Lateral component of stress } \\
& \sigma_{x}^{\prime}, \sigma_{x}^{\prime \prime}, \sigma_{x}^{\prime \prime \prime} \quad \text { Contributions to lateral stress due to axial, lateral, } \\
& \text { and rotational motion, respectively } \\
& \sigma_{z} \quad \text { Axial component of stress } \\
& \sigma_{\mathbf{Z}}^{\prime}, \sigma_{\mathbf{Z}}^{\prime \prime}, \sigma_{\mathbf{Z}}^{\prime \prime} \text { Contributions to axial stress due to axial, lateral, } \\
& \text { and rotational motion, respectively } \\
& \sigma_{\theta} \quad \text { Circumferential stress } \\
& \phi \quad \text { Internal friction angle } \\
& \phi_{1}, \phi_{2} \quad \begin{array}{l}
\text { Internal friction angle describing bilinear failure } \\
\text { envelope }
\end{array} \\
& \Psi \quad \text { Azimuthal angle, measured around projectile }
\end{aligned}
$$


DEPARTMENT OF DEFENSE

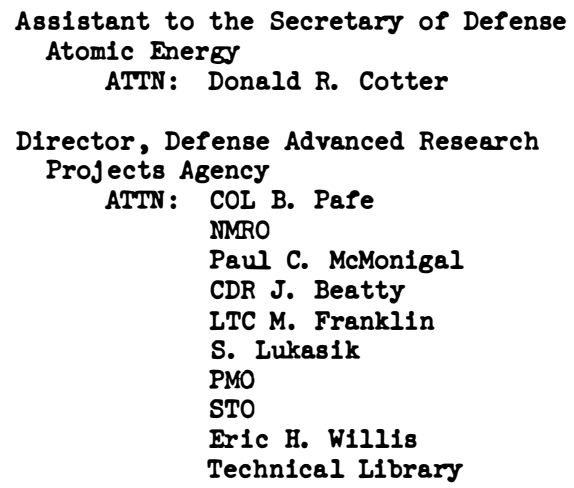

Director, Defense Civil Preperedness Agency ATTN : RE(ADM)

Defense Documentation Center, Cameron Station

12 cy ATTN: TC/Nyer B. Kahn

Director, Defense Intelligence Agency ATTN : DI-TE

DT-2, Weapons \& Systems Division

DI-TD, Phys. Vul. Div., Edward O'Farrell

Technical Library

Defense Mapping Agency

ATTN: H. Lindsey

Director, Defense Nuclear Agency

ATTN : STSI (Archives)

2 cy STTL (Technical Library)

$15 \mathrm{cy} \quad$ SPSS

DDST

Director of Defense Research and Ingineering

ATTN: Assistant Director, Strategic Weapons

Deputy Director, Strategic Systems

M. J. Minneman

George Barse

Cratis W. Hartzell.

R. Thorkildsen

Deputy Director, Tactical

Warfare

Commander, Field Command, Defense Nuclear Agency

ATTN : FCPR

Interservice Nuclear Weapons School ATTN : Technical Library

Director, Joint Strategic Target Planning Starf, JCS

ATIN : Science and Technology Info Library

Director, Weapons Systems Evaluation Group ATTN: Technical Library
DEPARTMENT OF THE ARMY

Assistant Chief of Staff for Force Development ATTN: Director of Chem \& Nuc Ops Technical Library

Director, U. S. Army Ballistic Missile Defense Advanced Technolosy Center ATTN: BMDATC-X CRDABH-S

Ballistic Missile Defense Program Manager ATTN: DACS-BMT/Dr. John Shea

Headquarters, Central Army Group ATTN: CENEN LTC J. L. Spruill

Office, Chief of Engineers

2 cy ATTN: DAEN-ASI-L

2 cy DAEN-MCE-D DAEN-RDL

Office, Chief of Research, Development, and Acquisition

ATTN: DAMA-CSM/LTC Edward V. DeBoesser, Jr. Technical Library

Commander, Frankford Arsenal ATTN: L. Baldini

Commander, Harry Diamond Laboratories ATTN: A. Holmes

Commander, Harry Diamond Laboratories ATTN : AMDOO-NP AMODO-RBH/J. Gwaltney

Project Manager, Remotely Monitored Battlefield Sensor System ATTN: Chuck Higgins

Commanding Officer, Plcatinny Arsenal ATTN: Paul Harris

P. Angellot1

Technical Library

SMUPA-ND-S/E. Zimpo

William Meyer

Ray Goldstein

Ray Moessner

Merty Mergolin

Jerry-Fental

SUMPA-AD-D-A-7

SUMPA-AD-D-A

SUMPA-AD-D-M

Director, U. S. Army Ballistic Research Laboratories

ATTN : AMDBR-X/J. J. Meszaros J. H. Keefer AMXBR-TB/J. T. Frasier W. J. Taylor Norris J. Huffington, Jr.

D. Dunn

G. Grabarek

B. Reiter

G. Roecker

2 cy Technical Library/Edward Baicy

J. W. Apgar 
DEPARTMENT OF THE ARMY (Continued)

Commander/Director, U. S. Army Cold Regions Research and Engineering Laboratory ATTN : G. Swinzow

Division Engineer, U. S. Army Engineer Division, Huntsville ATTN: HNDED-CS/Michael M. Dembo

District Engineer, U. S. Army Engineer District, St. Paul ATTN: Librery

Division Engineer, U. S. Army Engineer Division, Ohio River ATTN: ORDAS-L/Technical Library

Director, U. S. Armu Engineer Waterways Experiment Station

ATIN : Mr. L. F. Ingram

Mr. L. K. Davis

Mr. William J. Flathau

$3 \mathrm{cy}$

Mr. John Strange

Ifibrery

Dr. Paul Hadala

Dr. Guy Jackson

Dr. Behzad Rohan1

Mr. Allen D. Rooke

Commander, U. S. Army Materials and Mechanics Research Center

ATTN: John Mescall

Technical Library

Richard Sheo.

Director, U. S. Army Material Systems Analysis Agency

ATTN : J. Sperazze

M. Reches

Commander, U. S. Army Mobility Equipment

R\&D Center

ATTN : STSFB-MW

STSFB-XS

Technical Library

Commandant, U. S. Army Englneer School ATTN: ATSEN-SY-I

Commander, U. S. Army Materiel Development and Readiness Command, (DARCOM)

ATTN: Technical Library

Commander, U. S. Army Materiel Development and Readiness Command, (DARCOM)

ATTN : Research and Concepts Branch

Commander, U. S. Armu Nuclear Agency

ATIN: Document Control

Technical Library

COL Quinn

MAJ F. P. Weichel

Commander, U. S. Army Missile Command

ATTN: Technical Library

F.'Fleming

AMCPM-PE-X (William K. Jann)
DEPARTMENT OF THE ARMY (Continued)

Commander, U. S. Army Armament Command ATTN: Technical Library

Division Engineer, U. S. Army Engineer Division, Missouri River ATTN: Librery

DEPARTMENT OF THE NAVY

Chief of Naval Research, Department of the Navy ATTN: Technical Library

Officer in Charge, Civil Engineering Laboratory, Naval Construction Battalion Center ATTN: R. J. Odello Technical Library

Commander, Naval Electronics Systems Command ATTN: PME-117-21A

Commander, Naval Facilities Engineering Command ATTN: Technical Library, Code 0911C

Superintendent, U. S. Naval Postgraduate School ATTN: Library, Code 2124

Director, Naval Research Laboratory ATTN: Code 2027/Tech Library

Commander, Naval Surface Weapons Center ATTN: Mr. Kasdorf

Technical Library, Code 730

Code 1224 Navy Nuc Proms Off

Jules Enis

Mery P. King

L. Roslund

Robert D. Heidenreich

G. Briggs

Commander, Naval Surface Weapons Center

Dahlgren Laboratory

ATTN: Technical Library

William Wisherd

Ted Williems

M. Welland

Commander, Naval Weapons Center

ATTN: Code 603, Dr. Carl Austin

Mr. P. Cordle

Code 533, Technical Library

Commander, Naval Weapons Evaluation Facility, Kirtland Air Force Base

ATTN: Technical Library

Director, Strategic Systems Project office ATTN: NSP-43, Technical Library

DEPARTMENT OF THE AIR FORCE

A1r Force Armament and Testing Laboratory, AFSC ATTN: Technical Library

MAJ Thomes Tomesett1

Mr. John Collins

Mr. Leonard Wilson

Mr. Masey Valentine

Mr. William Cramer

Dr. Kulp 
DEPARTMENT OF THE AIR FORCE (Continued)

A1r Force Institute of Technology ATTN: Technical Library

Commander, A1r Force Weapons Laboratory ATTN : SUL, Technical Iibrary DEV-S/Dr. M. A. Plamondon

Headquarters, Air Force Systems Command ATTN: Technical Library

Project Manager, Gator Mine Program ATTN : E. J. Lindsey

Oklahoma State University

Field Office for Weapons Effectiveness ATTN : Ed Jackett

Air Force Office of Sclentific Research ATTN: LTC L. P. Mosteller, Jr.

Commander, Rome Air Development Center ATIN: ENTID, Documents Library

Commander, Armament Development and Test Center ATTN: ADTC/DLODL/Technical Library

Commander, Foreign Technology Division ATTN : TD-BTA Library

HQ USAF/IN ATTN : INATA

HQ USAF/RD ATTN: RDPM, COI J. E. McCormick

Space and Missile Systems Organization ATTN : DEB

ENERGY RESEARCH \& DEVELOPMENT ADMINISTRATION

U. S. Energy Research and Development Administration, Division of Military Application ATTN : Doc Control for Test office

U. S. Energy Research and Development Administration, Albuquerque Operations Office ATTN: Doc Control for Technical Library

U. S. Energy Research and Development Administration, Division of Headquarters Services ATTN: Doc Control for Class Tech Lib

U. S. Fnergy Research and Development Administration, Nevada Operations Office ATTN: Doc Control for Technical Library

Los Alamos Scientific Laboratory

ATTN : Doc Control for Reports Library Doc Control for Tom Dowler Doc Control for C. Cremer Doc Control for G. Dials

Sandia Laboratories, Livermore Laboratory ATTN: Doc Control for T. Gold Doc Control for Technical Library
ENERGY RESEARCH \& DEVELOPMENT

ADMINISTRATION (Continued)

Sandia Laboratories

ATTN: Doc Control for Dr. Walter Herrmann

Doc Control for John Colp

Doc Control for John Kelzur Org. No. 1312

Doc Control for William Patterson

Doc Control for Al Chabal

Doc Control for 3141 Sandia Rpt Coll

Doc Control for Ray Reynolds

Director, Lawrence Livermore Laboratory

ATTN: Technical Information Division, Technical Ifibrary

Larry Woodruff, L-125

Doc Control for W. Scanlin

Frank Walker

Merk Wilkins

\section{OTHER GOVERMMENT AGENCIES}

Electric Power Research Institute ATTN : Dr. George Sliter

Office of Nuclear Reactor Regulation, Nuclear Regulatory Cominission

ATTN : Mr. Lawrence Shao, Chief, Struc Engrg Br

Bureau of Mines, Twln Cities Research Center ATTN: R. E. Thill

DEPARTMENT OF DEFENSE CONTRACTORS

Aerospace Corporation

ATTN: Technical Information Services

R. Strickler

George Young

Agbabian Associates

ATTN: Dr. M. S. Agbabian

Applied Theory Incorporated

2 cy ATTN : Dr. John G. Trul10

AVCO, Government Products Group

ATTN: David Henderson

Frank Lasher

Research Library A830, Room 7201

John Atanasorf

Battelle Columbus Laboratories

ATTN: Technical Library

Bell Telephone Laboratorles, Inc.

ATTN: Technical Report Center

Boeing Company

ATTN: Aerospace Library

Reynold Atles

Callfornia Research and Technology, Inc. ATTN : Dr. K. N. Kreyenhagen Technical Library

Civil/Nuclear Systems Corporation ATTN: Robert Crawford 
DEPARTMENT OF DEFENSE CONTRACTORS (Continued)

EC\&G, Inc., Albuquerque Division

ATTN: Technical Library

General Dynamics Corporation, Pomona Operation ATTN : Kelth Anderson

General Electric Company, TEMPO-Center

for Advanced Studies ATTN: DASIAC

IIT Research Institute ATTN: Technical Library

Institute for Defense Analyses ATTN: IDA Librarian Ruth S. Smith

Consulting and Special Engineering Services ATTN : Dr. J. L. Merritt Technical Library

Kaman Avidyne, Division of Kaman Sciences Corp. ATTN: Technical Library

E. S. Crisicone

N. P. Hobbs

Kaman Sclences Corporation ATTN: Technical Library

Lockheed Missiles and Space Company ATIN: Tech Info Center D/Coll

Lockheed Missiles and Space Company ATTN: Technical Library

Martin Marietta Aerospace, Orlando Division ATTN: M. Anthony Gerbert E. McQua18 (MP-81)

University of Illinols ATTN : Dr. Nathan M. Nevmark

University of New Mexico, Dept of Campus Security and Pollce ATTN : H. D. Southward

G. E. Triandafolidis

Physics International Company ATTN: Doc Control for Mr. Fred M. Sauer Doc Control for Dr. Robert Swift Doc Control for Technical Library Doc Control for Mr. Dennis L. Orphel Doc Control for Mr. Larry Behrman

R\&D Associates

ATTN : Dr. Harold L. Brode

Dr. H. F. Cuoper, Jr.

Mr. R. J. Port

Technical Library

Mr. William B. Wright

Dr. C. P. Knowles

Mr. J. G. Lewis

Science Applications, Inc.

ATTN: Mr. David Bernstein

Dr. D. E. Merwell

Dr. Cecil Ivan Hudson, Jr.

Dr. W. M. Iayson
DEPARTMENT OF DEFENSE CONTRACTORS (Continued)

Stanford Research Institute

ATTN: Dr. Carl Peterson

Dr. G. Abrahamson

Mr. Lyann Seamans

SRI Library Room G02I

Systems, Science and Sortware

ATTN: Dr. Donald R. Grine

Dr. E. W. Gaffney

Technical Library

Terra Tek, Inc.

ATTN : Mr. S. J. Green

Dr. A. H. Jones

Technical Library

Texas A\&M University

ATTN : Harry Coyle

Texas A\&M University

ATIN : Prof. I. J. Thompson

Braddock, Dunn, \& McDoneld, Inc. ATHN: Technical Library

TRW Defense and Space Systems Group ATIN: Tech Info Center/S-1930

Weidlinger Associates, Consulting Engineers ATIN: Dr. Melvin L. Baron Mr. J. W. Wright

Weidlinger Associates, Consulting Engineers ATTN : Dr. J. Isenbers

Lowell Technical Institute, Department of Civil Engineering ATTN: L. W. Thispen

Georgia Institute of Technology,

Department of Aerospace Fingineering ATIN : S. V. Hanagud

L. N. Rehfield

Engineering Socleties Library ATTN: Miss Anne Mott, Acquisitions Librarian

Pacifica Technology, Inc. ATIN: G. I. Kent

R. I. BJork

\section{FOREIGN EXCHANGES}

Reglerungsrat, Bundesanstalt fur Strassenwesen

Department of Physical Geography, Uppsala University

Prof. Leopold Muller, Abtellung Felsmechanik, Institut fur Bodenmechanik und Felsmechanik, Universitat Karlsruhe

DOMESTIC EXCHANGE

Tennessee Volley Authority

ATTN: Ronald G. Domer, Chief, Civil Engineering Branch 
DISTRIBUTION IIST

DEPARTMEAT OF DEFEASE

Assistant to the Secretary of Defense Atomic Ener

ATIM: Donald R. Cotter

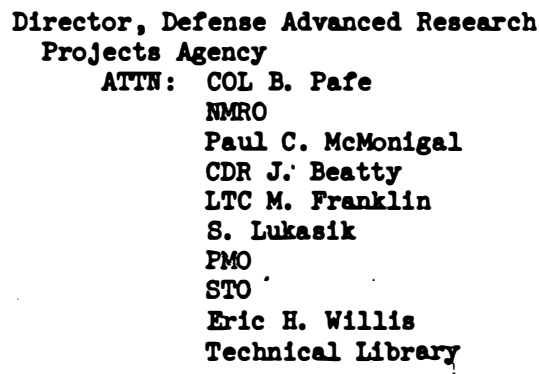

D1rector, Defense C1v1l Preparedness Agency ATHN : RE(ADM)

Defense Documentation Center,

Cameron Station

12 cy ATTI: TC/Nyer B. Kahn

D1rector, Defense Intelligence Agency ATHT: DI-7E

DT-2, Weapons \& Systems Division

DI-TD, Phys. Vul. DIV., Edward O'Farrell

Technical Iflbrary

Defense Mapping Agency

ATTI : H. LIndsey

D1rector, Defense Nuclear Agency

ATTIN : STSI (Archives)

2 cy STIL (Technicel Library)

$\begin{array}{ll}15 \mathrm{cy} & \text { SPSS } \\ & \text { DDST }\end{array}$

Director of Defense Research and Englneering

ATHIN : Assistant Director, strategle Weapons

Deputy Director, Strateg1c Systems

M. J. Minneman

Ge्णrie Barse

Cralg W. Bartsell

R. Thork1ldsen

Deputy Director, Tactical

Warfare

Commander, Field Command, Defense Nuclear Agency ATHT: FCPR

Interservice Nuclear Weapons School ATTI: Technical Library

Director, Jolnt Strateg1c Target Planning Staff, JCS

ATHI: Sclence and Technology Info Ilbrary

D1rector, Weapons Systens Bvaluation Group ATIII : Technical Itbrary
DEPARTMEYTS OF THE ARMY

Assistant Chlef of Staff for Force Development ATIN: Director of Chem Ine Ops Technical Library

Director, U. 8. Army Ballist1c M1ssile Defense Advanced Technology Center ATHN: BMDATC-X CRDABH-S

Bell1st1c Missile Defense Program Manager ATTH: DACS-BMT/Dr. John Shea

Headquarters, Centrel Army Group ATTI: CENET ITC J. L. Spruill

Office, Chief of Engineers

2 cy ATHI: DAET-ASI-I

2 cy DADN-MCE-D

. DAETS-RDL

Offlce, Chlef of Research, Development, and Acquisition

1HWS: DAKA-CSM/LTC EAward v. DeBoesser, Jr. Techofcal Library

Commander, Frankford Arsenel ATIN: I. Baldins

Commander, Harry Dlamond Laboratorles ATTH: A. Holmes

Commander, Harry Dlamond Laboratorles ATTIN : AMDOO-NP AYODO-RBE/J. Graltney

Project Manager, Remotely Monitored Battlef1eld Sensor System ATHI: Chuck H1ggins

Commanding Offlcer, Plcatinny Arsenal ATH: : Paul Harr18

P. Angellot1

Technical Ifbrary

SMUPA-ND-S/E. Z1mpo

W11l1am Meyer

Ray Goldstein

Ray Moessner

Marty- Margalla.

Jerry Pental

SUMPA-AD-D-A-T

SUNPA-AD-D-A

SUMPA-AD-D-M

Director, U. 8. Army Bellist1c Research Inbaretorles

AMzu: AMOBR-X/J. J. Meszaros

J. H. Keefer AMOBR-TB/J: T. Frasier

W. J. Taylor

Norr18 J. Huefington, Jr.

D. Dunn

G. Grabarek

B. Relter

G. Roecker

2 cy Technicel Llbrary/Edvard Balcy 